\title{
Ionic liquid pre-treatment of microalgae and extraction of biomolecules
}

Rupali K. Desai 


\section{Thesis committee}

\section{Promotors}

Prof. Dr M.H.M. Eppink

Special Professor Biorefinery with Focus on Mild Separation Technologies of Complex Biomolecules

Wageningen University

Prof. Dr R.H. Wijffels

Professor of Bioprocess Engineering

Wageningen University

\section{Other members}

Prof. Dr A.B. de Haan, Delft University of Technology

Prof. Dr W.J.H. van Berkel, Wageningen University

Dr M.G. Freire, University of Aveiro, Portugal

Dr K. Goiris, KU Leuven, Belgium

This research was conducted under the auspices of the Graduate School VLAG (Advanced studies in Food Technology, Agrobiotechnology, Nutrition and Health Sciences) 


\title{
Ionic liquid pre-treatment of microalgae and extraction of biomolecules
}

\author{
Rupali K. Desai
}

Thesis

submitted in fulfilment of the requirements for the degree of doctor at Wageningen University

by the authority of the Rector Magnificus

Prof. Dr A.P.J. Mol, in the presence of the

Thesis Committee appointed by the Academic Board

to be defended in public

on Friday $9^{\text {th }}$ of December 2016

at 11 a.m. in the Aula. 
Rupali K. Desai

Ionic liquid pre-treatment of microalgae and extraction of biomolecules 126 pages

PhD thesis, Wageningen University, Wageningen, NL (2016)

With references, with summary in English

ISBN: 978-94-6257-980-4

DOI: $10.18174 / 393439$ 
Dedicated to my family 



\section{Contents}

Chapter 1 General introduction and thesis outline 9

Section 1: Extraction and separation using IL based two phase system

$\begin{array}{lll}\text { Chapter } 2 & \text { Extraction of proteins with ABS } & 19\end{array}$

Chapter 3 Extraction and stability of selected proteins in ionic liquid based aqueous 35 two phase systems

Chapter 4 Mild separation concept for functional biomolecules using IL based emulsions

Section 2: Pre-treatment using lonic liquid

Chapter $5 \quad$ Novel astaxanthin extraction from Haematococcus pluvialis using cell $\quad 73$ permeabilising ionic liquids

Chapter 6 Novel selective fractionation technology for fragile biomolecules from Neochloris oleoabundans using ionic liquids

$\begin{array}{lll}\text { Chapter } 7 & \text { General Discussion } & 105\end{array}$

$\begin{array}{ll}\text { Summary } & 115\end{array}$

$\begin{array}{ll}\text { Acknowledgement } & 119\end{array}$

$\begin{array}{ll}\text { About the Author } & 121\end{array}$

$\begin{array}{ll}\text { List of publications } & 123\end{array}$

$\begin{array}{ll}\text { Overview of completed training activities } & 125\end{array}$ 



\section{Chapter 1}

General introduction and thesis outline 


\section{Introduction}

In the bioprocess and chemical industry, many separation technologies are already highly developed and more than one technology option is available for most processes. However, these separation technologies could be improved in terms of energy efficiency, raw materials used, or cost effectiveness. In addition, changing technologies and changing customer demands continually create new needs for the chemical and biochemical industry. Liquid-liquid extractions (LLE) is an interesting purification alternative and is widely used in the chemical industry due to its simplicity, and ease of scale up [1]. Liquid-liquid extraction is the transfer of certain components from one phase to another when immiscible or partially soluble liquid phases are brought into contact with each other. The conventional process employed in this field consist of water-organic solvent two-phase systems and, therefore, are generally not suitable for separation of biomolecules (e.g. proteins, carbohydrates) due to problems such as protein denaturation [2]. Moreover, with increasing safety concerns for personnel and consumers, extraction by organic solvents is a challenge due to volatility, flammability and toxicity of the solvents [3]. In this respect, complex fluids have been studied for liquid-liquid extraction of biomolecules by means of aqueous two-phase systems (ATPS) that provide a bio-compatible environment. ATPS are formed by mixing polymers (e.g. Polyethylene Glycol (PEG), Polypropylene Glycol (PPG)) with inorganic salt (e.g. phosphate, citrate) or another polymer beyond a certain critical concentration (see Figure 1.1). These systems are used for separation, concentration and fractionation of fragile biomolecules [4]. Polymer-polymer based systems usually display two hydrophobic phases and the difference in polarities depends essentially on the amount of water in each phase. On the other hand, polymer-salt Aqueous Biphasic System (ABS) has a hydrophobic phase constituted by the polymer and a hydrophilic (and more ionic) phase, typically formed by high charge-density salts. The restricted difference in polarities between the two phases prevents vast use of polymer-based ABS for extraction purposes. By virtue of their tunability, ionic liquids (IL) (see below) can ideally cover the whole hydrophilicity-hydrophobicity range [5]. This necessitates the need to develop separation processes with alternative solvents such as IL, supercritical fluids. Microemulsions, such as reverse micelles which are also a two phase system have also been studied for separation. This system suffers from poor back extraction efficiency and denaturation of protein [6]. Therefore the goal of this thesis is to evaluate the feasibility of using IL based system for extraction of value added components, both hydrophilic and hydrophobic components from complex biomass such as microalgae. 


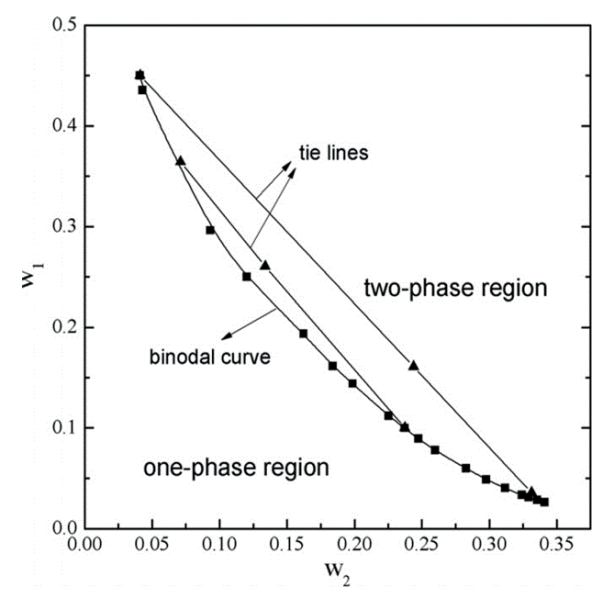

Figure 1.1 Schematic picture of a typical aqueous two phase diagram Re-printed from [7] with permission from Elsevier

\section{Ionic liquids}

Ionic liquids are molten salts at a temperature below $100^{\circ} \mathrm{C}$. They consist of a large organic cation and a small organic or inorganic anion. The large dimension of its ions does not allow the organization to a crystalline structure and hence are liquids at lower temperature in comparison to conventional salts. The interest in ILs as separation media can be attributed to its interesting chemical and physical properties such as low vapor pressure, high thermal and chemical stability, non-flammability and good solvation properties [8-10]. These are also referred to as designer solvents [11], as their properties such as polarity, viscosity and hydrophobicity can be tuned by combination of cations and anions. These properties make them a desirable class of solvents for liquid-liquid extraction. Most commonly used anions and cations are depicted in Figure 1.2. In the past years ILs have been used for extraction of value added components from biomass [10, 12] and in synthesis [13], in material chemistry as electrolytes for the electrochemical industry and liquid crystals. Moreover, ILs also demonstrated a good performance in biocatalysis [14], while providing a non-denaturing environment for biomolecules and maintaining the protein structure and enzymatic activity [15]. These liquids are promising alternatives for separation and they need to be investigated with respect recycling so as to decrease cost and enhance sustainability of the process. 


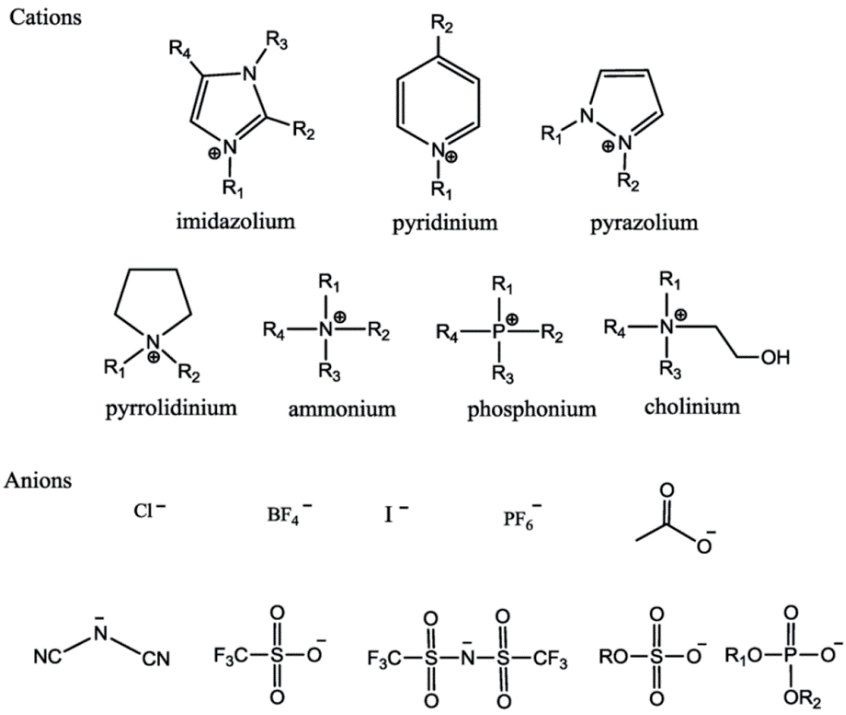

Figure 1.2 Commonly used cations and anions in lonic liquids [16]. Re-printed with permission from International Journal of Molecular Science.

\section{Microalgae}

Microalgae are photosynthetic unicellular microorganisms capable of accumulating lipids and other value added components in its biomass (e.g. proteins, pigments). They are considered as promising feedstock for biofuel production as they do not compete for arable land and do not place additional stress on food production [17]. Microalgae have a rigid cell wall [18] and are composed of a nonhydrolysable biopolymer; algenan. The complexity and filamentous structure of algal cell walls makes them stronger and more difficult to disrupt than cells from other organisms. Furthermore, effective solvent extraction requires that the solvent can firstly penetrate the solid matrix enclosing the lipid, secondly physically contact the lipid and thirdly solvate the lipid [19]. Since most microalgae are protected by a cell wall that limits the solvents access to the lipid, mechanical disruption techniques such as bead milling, homogenisation, etc., are required to break open the cells and release the intracellular components (e.g. proteins, carbohydrates, lipids, pigments). Conventional harvesting and extraction processes are energy intensive [20] and thus are the main barriers in the economical production of algae biofuels on a commercial scale [21]. These processes are thus in need of innovation. Traditionally, lipids are extracted from biomass using a combination of organic solvents such as chloroform, methanol and water i.e. Bligh and Dyer's method [22]. Although the lipid extraction efficiency is higher, such a process would generate a significant amount of solvent waste on large scale which is costly to recycle. However, to develop a process with biodiesel as the only end product is not sustainable and economically feasible. Additionally, use of solvent denatures the proteins and makes the biomass unsuitable for isolation of valuable products (e.g. proteins). Therefore, biorefining of microalgae must be done so as to fractionate it into valuable components such as proteins and 
carbohydrates in addition to lipids [23]. Biorefinery is an integrated facility that combines processes and equipment to produce biofuel, high-value biochemicals and energy from the same biomass. Thus, the primary requirement to develop a microalgal biorefinery is to be able to separate the different fractions such that the components retain their functionality. This necessitates the development of separation technologies that are mild and inexpensive [24]. Although, currently there is no established biorefinery process for microalgae, a typical biorefinery would involve multiple unit operations as shown in Figure 1.3. While each of the unit operations is being studied so as to develop alternatives to the current processes [24], this thesis focuses on alternative extraction processes based on ionic liquids.

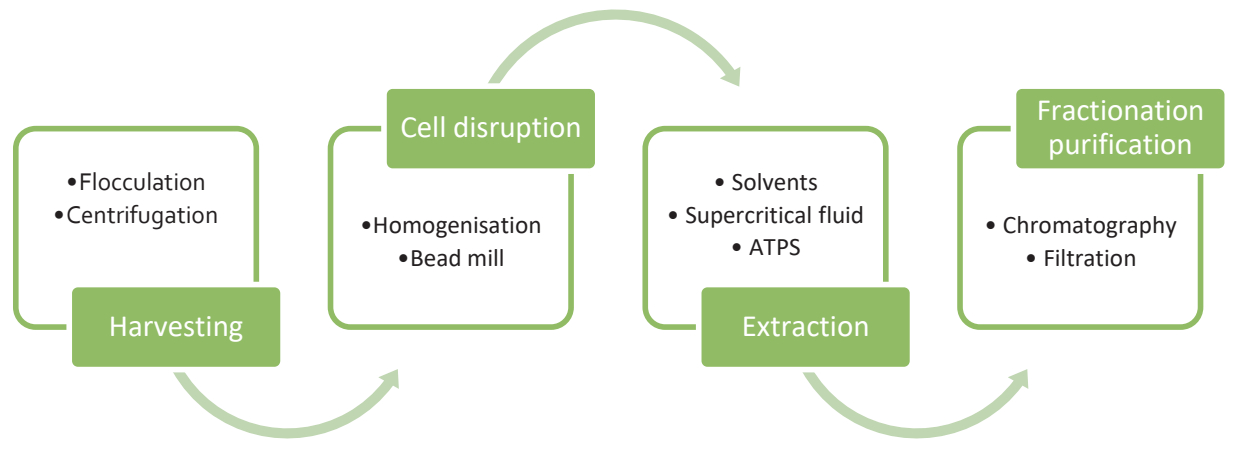

Figure 1.3 Schematic diagram of unit operations involved in biorefinery of microalgae

\section{Outline of thesis}

In this thesis the possibility of using IL and IL based systems for fractionation of components into hydrophilic and hydrophobic components using IL based systems is investigated. Both known and novel systems for extraction of fragile biomolecules from complex biomass such as microalgae are investigated. The effect of ILs on microalgal biomass pre-treatment and subsequent extraction of biomolecules therein was also explored.

\section{Section 1: Extraction and separation using IL based two phase system}

In chapter $\mathbf{2}$ we provide a literature review on extraction of proteins using aqueous two phase systems and also discuss about the stability of proteins in ILs. This chapter describes a general approach to protein purification using IL based ABS and factors that influence the partitioning of the proteins in the system. It also discusses the challenges in developing a successful ABS for extraction of proteins. Stability of proteins in ILs is a prerequisite for its use in extraction of these fragile molecules. In chapter 3, the stability of Rubisco together with two other model proteins $B S A$ and $\lg _{1}$ in aqueous solution of ILs was studied. Furthermore, studies were done to systematically understand the relationship between IL concentration and protein stability with the ATPS system. The influence of different process parameters on extraction was studied and compared with the conventional two phase system (PEG/potassium citrate ATPS). In chapter 4, we studied the feasibility of using a novel system, IL based 
emulsion stabilised by microgel, for separation of hydrophilic and hydrophobic components from microalgae biomass while keeping the proteins in their native form. Continuous separation of biomolecules using such a system was also investigated.

\section{Section 2: Pre-treatment using lonic liquid}

In chapter 5, the effect of IL pre-treatment on microalgal cells was investigated under mild conditions of temperature. The extraction efficiency of pigment after pre-treatment was determined and a hypothesis for the extraction of pigment without cell disruption is also presented. In chapter 6 , we went a step ahead and studied the fractionation of microalgal biomass after pre-treatment with ILs. Extraction of lipids after pre-treatment with ILs and subsequent cell disruption to yield proteins and carbohydrates were studied. Moreover the stability of extracted protein was also studied.

Finally chapter 7 discusses the major findings in this thesis and bottlenecks and challenges in using ILS and IL based systems for extraction of biomolecules from complex matrices. More studies would be needed to have better understanding of these system and therefore opportunities for future work is also presented. 


\section{References}

1. Mazzola, P.G., et al., Liquid-liquid extraction of biomolecules: an overview and update of the main techniques. Journal of Chemical Technology \& Biotechnology, 2008. 83(2): p. 143-157.

2. Klibanov, A.M., Why are enzymes less active in organic solvents than in water? Trends in Biotechnology, 1997. 15(3): p. 97-101.

3. Ge, L., et al., Solubility of luteolin in several imidazole-based ionic liquids and extraction from peanut shells using selected ionic liquid as solvent. Separation and Purification Technology, 2014. 135: p. 223-228.

4. Albertsson, P.-A., Partition of Proteins in Liquid Polymer-Polymer Two-Phase Systems. Nature, 1958. 182(4637): p. 709-711.

5. Freire, M.G., et al., Aqueous biphasic systems: a boost brought about by using ionic liquids. Chem Soc Rev, 2012. 41(14): p. 4966-4995.

6. Melo, E.P., M.R. Aires-Barros, and J.M.S. Cabral, Reverse micelles and protein biotechnology, in Biotechnology Annual Review2001, Elsevier. p. 87-129.

7. $\quad \mathrm{Li}, \mathrm{Z}$., et al., Ionic liquid-based aqueous two-phase systems and their applications in green separation processes. TrAC Trends in Analytical Chemistry, 2010. 29(11): p. 1336-1346.

8. Hallett, J.P. and T. Welton, Room-Temperature lonic Liquids: Solvents for Synthesis and Catalysis. 2. Chem Rev, 2011. 111(5): p. 3508-3576.

9. Cassity, C.G., et al., Ionic liquids of superior thermal stability. Chemical Communications, 2013. 49(69): p. 7590-7592.

10. Passos, H., M.G. Freire, and J.A.P. Coutinho, lonic liquid solutions as extractive solvents for valueadded compounds from biomass. Green Chemistry, 2014. 16(12): p. 4786-4815.

11. Freemantle, M., Designer Solvents. Chemical \& Engineering News Archive, 1998. 76(13): p. 3237.

12. Louros, C.L., et al., Extraction of biomolecules using phosphonium-based ionic liquids $+K(3) P O(4)$ aqueous biphasic systems. Int J Mol Sci, 2010. 11(4): p. 1777-91.

13. Wasserscheid, P.W., Thomas lonic liquid in synthesis2003.

14. Sheldon, R.A., et al., Biocatalysis in ionic liquids. Green Chemistry, 2002. 4(2): p. 147-151.

15. Ventura, S.P.M., et al., lonic liquids microemulsions: the key to Candida antarctica lipase $B$ superactivity. Green Chemistry, 2012. 14(6): p. 1620-1625.

16. Fan, L.-L., H.-J. Li, and Q.-H. Chen, Applications and Mechanisms of Ionic Liquids in Whole-Cell Biotransformation. Int J Mol Sci, 2014. 15(7): p. 12196.

17. Wijffels, R.H. and M.J. Barbosa, An outlook on microalgal biofuels. Science, 2010. 329(5993): p. 796-9.

18. Takeda, H. and T. Hirokawa, Studies on the cell wall of Chlorella I. Quantitative changes in cell wall polysaccharides during the cell cycle of Chlorella ellipsoidea. Plant and Cell Physiology, 1978. 19(4): p. 591-598.

19. Cooney, M., G. Young, and N. Nagle, Extraction of Bio-oils from Microalgae. Separation \& Purification Reviews, 2009. 38(4): p. 291-325.

20. de Boer, K., et al., Extraction and conversion pathways for microalgae to biodiesel: a review focused on energy consumption. Journal of Applied Phycology, 2012. 24(6): p. 1681-1698.

21. Coons, J.E., et al., Getting to low-cost algal biofuels: A monograph on conventional and cuttingedge harvesting and extraction technologies. Algal Research, 2014. 6, Part B: p. 250-270.

22. Bligh, E.G. and W.J. Dyer, A RAPID METHOD OF TOTAL LIPID EXTRACTION AND PURIFICATION. Canadian Journal of Biochemistry and Physiology, 1959. 37(8): p. 911-917.

23. Wijffels, R.H., M.J. Barbosa, and M.H.M. Eppink, Microalgae for the production of bulk chemicals and biofuels. Biofuels, Bioproducts and Biorefining, 2010. 4(3): p. 287-295.

24. Vanthoor-Koopmans, M., et al., Biorefinery of microalgae for food and fuel. Bioresource Technology, 2012. 135: p. 142-149. 
Section I

Extraction and separation using IL based two phase system 


\section{Chapter 2}

\section{Extraction of Proteins with ABS}

This chapter is published as a book chapter: Rupali K. Desai, Mathieu Streefland, René H. Wijffels and Michel H. M. Eppink (2016) Extraction of proteins using $A B S$

Ionic-Liquid-Based Aqueous Biphasic Systems: Fundamentals and Applications, 


\begin{abstract}
Over the past years, there has been an increasing trend in research on the extraction and purification of proteins using aqueous biphasic systems (ABS) formed by polymers e.g. polyethylene glycol, (PEG). In general, when dealing with protein purification processes, it is essential to maintain their native structure and functional stability. In this context, $A B S$, liquid-liquid systems where both phases are water-rich, provide a biocompatible medium for such attempts. More recently, it was shown that the versatility offered by $A B S$ is further enhanced by the introduction of ionic liquids (ILs) as alternative phase-forming components. This chapter describes and highlights the current progress on the field of proteins extraction and purification using IL-based ABS. The general approach for protein extraction using IL-based ABS and factors influencing the partitioning are discussed. In addition, the challenges to be overcome on the use of IL-based ABS for proteins extraction are also presented.
\end{abstract}

Keywords: Proteins, ionic liquids, aqueous biphasic system, extraction, purification, stability. 


\section{Introduction}

Proteins are an integral part of all living systems and have various applications in food and feed (both relatively low-value), and pharmaceuticals (high-value). Purification of proteins involves various unit operations using low to high resolution techniques to obtain proteins with desired purity and quality. Proteins, being fragile molecules, can be easily denatured by acid/base solutions, salts and high temperature. Therefore, mild operation conditions for their recovery and purification are required in order to maintain their nativity and functionality. With the current advances in biotechnology, a large increase in the titers of protein production was already observed; yet, the development of costeffective purification methods is still required. The high cost of protein purification continues to remain a bottleneck in downstream processing of proteins, and mainly for protein value-added biopharmaceuticals. On the other hand, in the field of food and feed, proteins are obtained from e.g. soya and also there has been a growing interest in 3 rd generation biofuels from microalgae. For instance, in fuel production processes, large amount of proteins are generated which could be used for feed and food [1-3]. In fact, to make these processes economically feasible it is necessary to refine other components from biomass. Proteins are a major fraction of algae biomass and are normally denatured by the solvents used for lipid extraction. The main challenge therefore lies in separating the proteins in their native form without affecting their functionality. Thus, depending on the biomass or initial medium, protein purification protocols vary and drive the development of more specific, robust and cost-effective methods [4].

Aqueous biphasic systems (ABS) based on polymers were first proposed by Albertsson [5], who studied their applicability in proteins extraction and purification. ABS allows the integration of concentration and purification processing steps and serve as an alternative approach to the traditional processes. Typical ABS are formed by mixing polymer-polymer and polymer-salt combinations above given concentrations to form two distinct aqueous phases, each one enriched in one of the phase-forming components. Both phases are water-rich ( $80-90 \% \mathrm{w} / \mathrm{w})$, and thus ABS can provide a mild and gentle environment for protein separation without affecting their native structure and stability [6, 7]. In addition to the largely investigated polymer-based ABS, in the last decade, ionic liquids (ILs)were proposed as alternative phase-forming components of ABS [8]. And because of the inherent properties of ILs, this possibility allowed the use of ABS in a new range of applications.

The interest on ILs as extractive solvents increased primarily because of their non-volatile nature, which is the major advantage over traditional organic volatile solvents. In addition to their non-volatility, ILs, being composed of cations and anions, can be more easily tuned to achieve specific properties, such as a tunable polarity, viscosity and solvent miscibility. Their tunable polarity enabled them to be used in biotransformations to increase substrate solubility, to dissolve enzymes and to tailor the reaction rate [9]. Moreover, due to their tailoring ability, ILs are also able to form ABS not only with inorganic salts, but also with polymers [10], carbohydrates [11] and amino acids [12]. The main advantage of IL-based 
$A B S$ over the conventional systems comprises their ability to tune and tailor the properties of the coexisting phases by permutation and combination of different cations and anions, thereby improving the selectivity of these systems for a wide variety of solutes [13].

Based on the advantages and large recent interest on IL-based ABS for separation purposes, this chapter describes the general approaches of protein purification described in the literature using ILbased $A B S$ and factors that influence the partitioning of proteins in these systems. The challenges in developing a successful ABS for extraction of proteins are also discussed. Finally, this chapter aims a better understanding on the mechanisms ruling proteins extraction using IL-based ABS. Figure 2.1 depicts a scheme on the approach required to use IL-based ABS for the extraction of proteins.

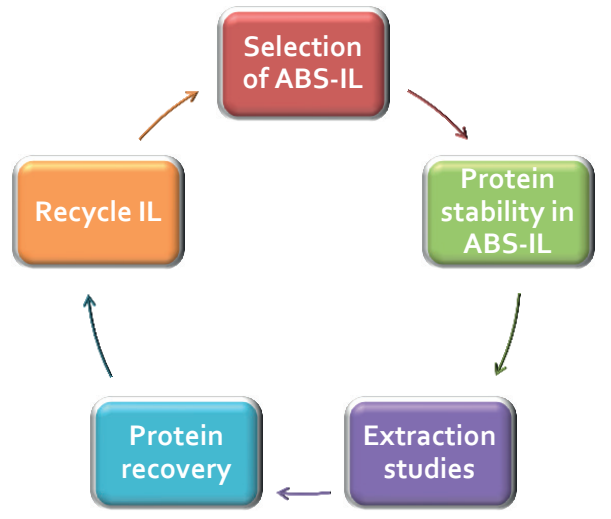

Figure 2.1 Approach required for proteins extraction using IL-based ABS

\section{Extraction of proteins/enzymes using IL-based ABS}

The extraction of proteins using IL-based ABS has been studied by different research groups, and for which a summary is given in Table 2.1. This table was adapted from [14] and updated to include more recent studies.

As a first point, only water-miscible ILs are able to form ABS since water-immiscible ILs do not form two aqueous-rich phases (see Table2.2). IL-based ABS are formed by mixing water-miscible ILs with salts, carbohydrates, amino acids and polymers $[8,10,12,15]$. The ability to form ABS with solutes other than salts has indeed been studied $[8,10,12,15]$, but their efficiency in extracting proteins is however scarcely studied. Although more promising than inorganic salts in what concerns the use of more biocompatible systems, these alternative systems suffer the drawback of only being able to form ABS with a limited number of ILs due to their low salting-out ability (carbohydrates, amino acids and polymers versus salts). 
Table 2.1 Investigated IL-based ABS for the extraction of proteins (updated from [14]).

\begin{tabular}{|c|c|c|}
\hline Protein & IL-based ABS & Reference \\
\hline $\begin{array}{l}\text { Bovine serum } \\
\text { albumin (BSA) }\end{array}$ & $\begin{array}{l}{\left[\mathrm{C}_{4} \mathrm{mim}\right] \mathrm{Cl} / \mathrm{K}_{2} \mathrm{HPO}_{4 \prime} \text { Ammoeng }} \\
110^{\mathrm{TM}} / \mathrm{K}_{2} \mathrm{HPO}_{4}-\mathrm{KH}_{2} \mathrm{PO}_{4 \prime} \\
{\left[\mathrm{C}_{n} \mathrm{mim}\right] \mathrm{Br}(n=4,6,8) / \mathrm{K}_{2} \mathrm{HPO}_{4,}} \\
{\left[\mathrm{C}_{4} \mathrm{mim}\right]\left[\mathrm{N}(\mathrm{CN})_{2}\right] / \mathrm{K}_{2} \mathrm{HPO}_{4 \prime}} \\
\mathrm{ILs} / \mathrm{K}_{2} \mathrm{HPO}_{4 \prime} \text { Guanidinium-based } \\
\mathrm{ILs} / \mathrm{K}_{2} \mathrm{HPO}_{4}\end{array}$ & $\begin{array}{l}{[16],[17],[18],} \\
{[19],[20],} \\
{[21],[22],[23]}\end{array}$ \\
\hline Ovalbumin & $\begin{array}{l}{\left[\mathrm{C}_{4} \mathrm{mim}\right] \mathrm{Cl} / \mathrm{K}_{2} \mathrm{HPO}_{4} \mathrm{ILs}^{a} / \mathrm{K}_{2} \mathrm{HPO}_{4 \prime}} \\
\text { Guanidinium-based ILs/ } / \mathrm{K}_{2} \mathrm{HPO}_{4}\end{array}$ & {$[24],[20],[21],[23]$} \\
\hline Lysozyme & $\begin{array}{l}\text { Ammoeng } 110^{\mathrm{TM}} / \mathrm{K}_{2} \mathrm{HPO}_{4}-\mathrm{KH}_{2} \mathrm{PO}_{4 \prime} \\
\text { Guanidinium-based ILs/ } / \mathrm{K}_{2} \mathrm{HPO}_{4}\end{array}$ & {$[17],[23]$} \\
\hline$\gamma$-globulin & {$\left[C_{n} \operatorname{mim}\right] \operatorname{Br}(n=4,6,8) / \mathrm{K}_{2} \mathrm{HPO}_{4}$} & [18] \\
\hline Myoglobin & $\begin{array}{l}{\left[\mathrm{C}_{4} \mathrm{mim}\right] \mathrm{Cl} / \mathrm{K}_{2} \mathrm{HPO}_{4 \prime} \text { Ammoeng }} \\
110^{\mathrm{TM}} / \mathrm{K}_{2} \mathrm{HPO}_{4}-\mathrm{KH}_{2} \mathrm{PO}_{4 \prime}\end{array}$ & {$[24],[17]$} \\
\hline Haemoglobin & $\begin{array}{l}{\left[\mathrm{C}_{4} \mathrm{mim}\right] \mathrm{Cl} / \mathrm{K}_{2} \mathrm{HPO}_{4} \mathrm{ILs}^{a} / \mathrm{K}_{2} \mathrm{HPO}_{4}} \\
\text { Hydroxyl ammonium ionic } \\
\text { liquids }{ }^{a} / \mathrm{K}_{2} \mathrm{HPO}_{4}\end{array}$ & {$[24],[20],[21]$} \\
\hline Cytochrome c & $\begin{array}{l}{\left[\mathrm{C}_{4} \mathrm{mim}\right] \mathrm{Cl} / \mathrm{K}_{2} \mathrm{HPO}_{4 \prime}\left[\mathrm{C}_{n} \mathrm{mim}\right] \mathrm{Br}(n=} \\
4,6,8) / \mathrm{K}_{2} \mathrm{HPO}_{4 \prime} \text { Amino-based } \\
\mathrm{ILs} / \mathrm{K}_{3} \mathrm{PO}_{4 \prime} \mathrm{Glycine}^{\prime} \text {-based } \\
\mathrm{ILs}^{a} / \mathrm{K}_{2} \mathrm{HPO}_{4}\end{array}$ & {$[24],[18],[25],[26]$} \\
\hline Fungal proteins & {$\left[\mathrm{C}_{4} \mathrm{mim}\right] \mathrm{Cl} / \mathrm{K}_{3} \mathrm{PO}_{4}$} & [27] \\
\hline Trypsin & $\begin{array}{l}\text { Ammoeng } 110^{\mathrm{TM}} / \mathrm{K}_{2} \mathrm{HPO}_{4}-\mathrm{KH}_{2} \mathrm{PO}_{4 \prime} \\
{\left[\mathrm{C}_{n} \mathrm{mim}\right] \mathrm{Br}(n=} \\
4,6,8) / \mathrm{K}_{2} \mathrm{HPO}_{4} \mathrm{ILs}^{a} / \mathrm{K}_{2} \mathrm{HPO}_{4 \prime} \\
\text { Guanidinium-based ILs/ } / \mathrm{K}_{2} \mathrm{HPO}_{4}\end{array}$ & {$[17],[18],[20],[23]$} \\
\hline Lipase CaL-A & {$\left[\mathrm{C}_{2} \mathrm{mim}\right]\left[\mathrm{C}_{4} \mathrm{SO}_{4}\right] /\left(\mathrm{NH}_{3}\right)_{2} \mathrm{SO}_{4}$} & {$[28]$} \\
\hline Lipase CaL-B & $\begin{array}{l}\text { Imidazolium-based ILs }{ }^{a} / \mathrm{K}_{2} \mathrm{HPO}_{4-}^{-} \\
\mathrm{KH}_{2} \mathrm{PO}_{4}\end{array}$ & {$[29]$} \\
\hline $\begin{array}{l}\text { Thermomyces } \\
\text { lanuginosus lipase } \\
(\mathrm{TIL})\end{array}$ & {$\left[\mathrm{C}_{2} \mathrm{mim}\right]\left[\mathrm{C}_{2} \mathrm{SO}_{4}\right] / \mathrm{K}_{2} \mathrm{CO}_{3}$} & [30] \\
\hline $\begin{array}{l}\text { Alcohol } \\
\text { dehydrogenases }\end{array}$ & $\begin{array}{l}\text { (Ammoeng } 100^{\mathrm{TM}} / \text { Ammoeng } \\
\left.101^{\mathrm{TM}} / \text { Ammoeng } 110^{\mathrm{TM}}\right) / \mathrm{K}_{2} \mathrm{HPO}_{4^{-}} \\
\mathrm{KH}_{2} \mathrm{PO}_{4}\end{array}$ & {$[13]$} \\
\hline $\begin{array}{l}\text { Horseradish } \\
\text { peroxidase }\end{array}$ & {$\left[\mathrm{C}_{4} \mathrm{mim}\right] \mathrm{Cl} / \mathrm{K}_{2} \mathrm{HPO}_{4}$} & [31] \\
\hline Rubisco & lolilyte $221 \mathrm{PG} / \mathrm{KH}_{2} \mathrm{PO}_{4}-\mathrm{Na}_{2} \mathrm{HPO}_{4}$ & {$[32]$} \\
\hline Wheat esterase & {$\left[\mathrm{C}_{4} \mathrm{mim}\right]\left[\mathrm{BF}_{4}\right] / \mathrm{NaH}_{2} \mathrm{PO}_{4}$} & [33] \\
\hline
\end{tabular}


Table 2.2 Commonly used cation/anions combination of water-miscible versus water-immiscible ILs.

\begin{tabular}{|c|c|c|}
\hline \multirow[t]{2}{*}{$\begin{array}{l}\text { Water miscible } \\
\text { ILs }\end{array}$} & Cations & $\begin{array}{l}\text { Imidazolium, Pyridinium, Ammonium, } \\
\text { Phosphonium }\end{array}$ \\
\hline & Anions & $\begin{array}{l}\text { Chloride,Bromide, Fluoride, Alkylsulphate, } \\
\text { Tosylate, Tetrafluoroborate, Dicyanamide }\end{array}$ \\
\hline \multirow[t]{2}{*}{$\begin{array}{l}\text { Water } \\
\text { immiscible ILs }\end{array}$} & Cations & $\begin{array}{l}\text { Imidazolium, Pyridinium, Ammonium, } \\
\text { Phosphonium }\end{array}$ \\
\hline & Anions & Bistriflamide, Hexafluorophophate \\
\hline
\end{tabular}

${ }^{a}$ Water immiscible ILs also contain water ( 2-6\%)

In general, most of the studies reported in the literature deal with imidazolium-based ILs composed of halogens or $\left[\mathrm{BF}_{4}\right]$ anions. Recently, $\mathrm{ABS}$ based on guanidinium-based ILs have been studied for proteins extraction $[22,23]$, and where it was shown that model proteins, such as BSA, could be extracted with high efficiency for the IL-rich phase without losing its native structure and maintain its stability. IL-based ABS could thus serve as potential platforms for protein extraction if the stability of proteins at the IL-rich phase is maintained. While most of the studies focused on the extraction efficiency of model proteins/enzymes, the studies carried out by Dreyer [17] and Pei [18] made an attempt to understand the mechanisms responsible for the high extractions attained.

\section{Stability of Proteins in IL-rich phases}

Proteins are complex macromolecules and require a gentle environment to maintain their structural and functional integrity. Changes in this environment, such as solvent concentration, $\mathrm{pH}$, ionic strength, and temperature, could result in denaturation of proteins. Thus, the primary criterion for any protein purification process is the ability to maintain the proteins' structural integrity and functionality. In this context, to use IL-based ABS for the purification of proteins it is necessary to understand their stability in aqueous solutions of ILs. There are some studies carried out to infer on protein-IL interactions [34, 35], and where model proteins have been used, namely BSA, lysozyme and cytochrome c. However, there are other proteins with higher commercial value, such as monoclonal antibodies, Rubisco (Ribulose-1,5-biphosphate Carboxylase Oxygenase), etc., that should be studied in what concerns their stability in aqueous solutions of ILs and their feasibility to be extracted by ABS. Although some hydrophobic ILs are able to stabilize enzymes [36, 37], they are not discussed in this chapter since these do not form ABS.

In the studies regarding the stability of proteins in aqueous solutions of ILs, the techniques employed to monitor the proteins structural and thermal stability include UV Spectroscopy, Fluorescence, Circular Dichroism (CD) ,Small Angle Neutron Scattering (SANS), Differential Scanning Calorimetry (DSC), Dynamic Light Scattering (DLS) and Size Exclusion Chromatography (SEC). The stability studies were designed to address the factors that influence the formation of $A B S$ and the stability of proteins, such 
as: (i) type of $\mathrm{IL}_{i}$ (ii) concentration of $\mathrm{IL}_{i}$ (iii) other process conditions, such as $\mathrm{pH}$, ionic strength and temperature; and (iv) protein properties, such as size, charge and surface hydrophobicity.

ABS consists of two aqueous-rich phases: an IL-rich phase and a phase rich in salt, polymer, amino acid or carbohydrate. The concentration of IL in the IL-rich phase of ABS can vary from 1.5-3.0 mol/kg [38], and thus it is prudent to study IL-protein interactions in aqueous solutions. Moreover, it was already shown that the concentration of IL has a strong influence on the protein stability $[32,35]$. In our recent study, we have shown that the protein's stability in aqueous solutions of ILs is influenced by the concentration of IL, and by the protein properties, such as size and complexity of the molecule [32]. In this study, the stability of BSA, IgG and Rubisco were studied in aqueous solutions of two ILs, Iolilyte 221 PG and Cyphos 108, at different concentrations [32]. It was found that as the concentration of the IL increases (0-50\%, v/v) the proteins start forming aggregates. Rubisco ( $540 \mathrm{kDa})$, being a large complex protein/enzyme that consists of eight large and small subunits, begins to aggregate at lower IL concentrations $(\sim 30 \%$, v/v), while BSA $(\sim 67 \mathrm{kDa})$, a smaller protein, forms no aggregates or only negligible aggregates at $50 \%$ v/V of IL(Iolilyte $221 \mathrm{PG})$. IgG ( 150 kDa), with an intermediate size, forms aggregates at 50\% (v/V) of lolilyte 221 PG. In this study [32], the aggregates formation was monitored using SEC and DLS studies. In an additional study, SANS results showed that human serum albumin and cytochrome $\mathrm{c}$ form aggregates at high concentrations $(50 \%, \mathrm{v} / \mathrm{v})$ of $\left[\mathrm{C}_{4} \mathrm{mim}\right] \mathrm{Cl}$ and retain their high order structure at lower IL concentrations (25\%, v/v) [39]. Lysozyme and interleukin-2 (IL-2) showed increased thermal stability in aqueous solutions up to $40 \%$ (w/w) of IL, although it is dependent on the $\mathrm{pH}$ [40], indicating thus that the charge of the protein also influences its stability in ILs aqueous solutions. Different ILs with varying "kosmotropicity" were also investigated for their effect on proteins structure and long term stability [41]. In this study, cytochrome c showed no significant changes in its structure when dissolved in hydrated choline di-hydrogen phosphate (containing $20 \% \mathrm{w} / \mathrm{w}$ of water). Cytochrome c additionally showed a higher thermal and long term stability, leading the authors to conclude that the "kosmotropicity" of ILs has strong implications on the proteins stability [41].

The influence of inorganic salts and ion-specific-induced precipitation of proteins is well described by the Hofmeister series [42]. Since ILs are also composed of ions, their influence on protein stability in aqueous solutions can also be explained, to some extent, by the Hofmeister series [34, 41, 43, 44]. lons can be classified as kosmotropes (water-structure makers) which stabilize proteins and chaotropes (water-structure breakers) which destabilize proteins. The rank of kosmotrope-chaotrope ions according to the Hofmeister series is shown in Figure.2.2. The most suitable combination to enhance protein stability comprises a kosmotropic anion and a chaotropic cation [45-47]. Accordingly to the example described above, the cytochrome $c$ stability in hydrated choline dihydrogen phosphate is a result of this type of ions combination. Though the stability of proteins in ILs can be explained by the Hofmeister series, some deviations were also found while following a reverse trend [44]. Large arrays of 
factors are responsible for the proteins stability in aqueous solutions of ILs, such as the ability to establish hydrogen-bond, electrostatic and dispersive interactions and hydrophobicity
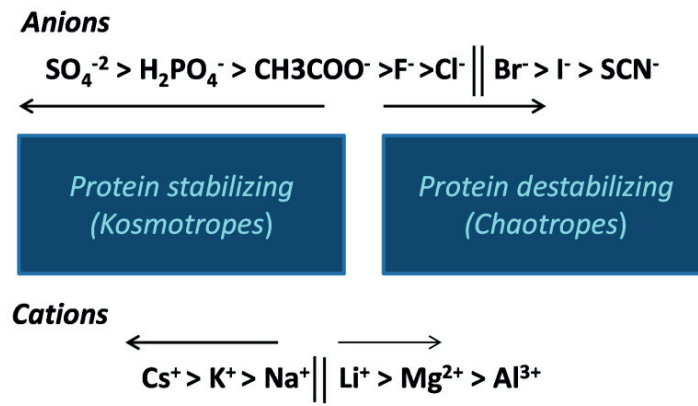

Figure 2.2 Hofmeister series and protein stability

\section{Partitioning Behavior of Proteins in IL-based ABS}

It has been shown that the partitioning of solutes in typical PEG-based ABS is primarily governed by the system properties, such as type and concentration of phase-forming components, $\mathrm{pH}$, temperature, and the solute properties, such as hydrophobicity, charge, molecular weight, etc. [48]. Thus, partition coefficients and selectivity can be tuned by modifying these parameters. The extraction of proteins using IL-based ABS has been studied by several authors (see Table 2.1), revealing that proteins partition preferentially to the IL-rich phase. Most of these studies are however empirical and to be able to use ILbased ABS as a separation tool on a preparative scale, it is mandatory to understand the mechanisms and factors influencing the partitioning of proteins in these systems.

Different authors have studied the influence of the phase-forming components, concentration, $\mathrm{pH}$ and temperature on the partitioning of proteins in IL-based ABS [20, 21, 32, 49]. Proteins distribution in ABS depends on their ability to interact with the phase-forming components and extraction conditions, so that the separation could be protein specific. Cao et.al. [31] studied the extraction of horseradish peroxidase in four alkylimidazolium-based ABS. The enzyme partitioned to the IL-rich phase but its activity decreases with the increase in the alkyl side chain length of the IL. In the same study, increasing the IL concentration favors the maintenance of the enzyme activity. Dreyer et al. [13] studied the feasibility of ABS formation with ammonium-based ILs and showed that Ammoeng 110 forms ABS more easily than Ammoeng 100 and Ammoeng 101. Ammoeng ILs contain an oligo-ethylene side chain in the cation which was expected to have a stabilizing effect on the enzyme (alcohol dehydrogenase) extracted. A low temperature for ABS formation together with ILs with oligo-ethylene side chains demonstrated to provide a gentle environment for protein extractions [13]. Desai et al. [32] showed that the partition coefficient of Rubisco increases as the IL and salt concentration increases; however, a decrease in the enzyme activity was observed with higher concentrations (>20\%, w/w) of IL. In 
summary, all these results indicate that the chaotropicity of the IL and its concentration influence the stability of the protein to be extracted.

The system parameters ( $\mathrm{pH}$ and temperature) also influence the partitioning of proteins to the IL-rich phase through the modification on the proteins charge and surface properties. Protein properties contributing to their partitioning in ABS can be summarized as follows [5]:

$$
\log K_{=} \log K_{\mathrm{o}}+\log K_{\mathrm{el}}+\log K_{\text {hphob }}+\log K_{\text {size }}+\log K_{\text {biosp }}+\log K_{\text {conf }}
$$

where $\mathrm{K}$ is the partition coefficient and el, hphob, biosp and conf are, respectively, electrostatic, hydrophobicity, biospecificity and configuration which contribute to the partition coefficient value, while $\mathrm{K}_{\mathrm{o}}$ represents additional factors.

Partitioning of proteins is governed, in a large extent, by the $\mathrm{pH}$ of the system. Depending on their isoelectric point, proteins carry a net positive or net negative charge at a given $\mathrm{pH}$. The extraction of BSA, myoglobin, lysozyme and trypsin using IL-based ABS at different $\mathrm{pH}$ values showed that proteins are preferentially transferred to the IL-rich phase as the $\mathrm{pH}$ increases [17]. On the other hand, the molecular weight of the protein also influences its partitioning in the biphasic system. Dreyer et al. [17] showed that larger proteins, such as BSA, are better extracted in the IL-rich phase while smaller proteins, like myoglobin, remain in the salt-buffer-rich phase. In a separate study, Rubisco, which is large protein $(540 \mathrm{kDa})$ is also extracted into the IL-rich phase [32].

Du et al. [16] studied the extraction of BSA from biological fluids using imidazolium-based ABS and observed that the electrostatic interactions and salting-out effect are the driving forces in proteins partitioning. In summary, research groups $[16,17]$ have shown that there is a strong correlation between the protein charge and its partitioning in IL-based ABS. Thus, indicating electrostatic interaction between the amino acids on the protein surface and IL cations to be the main driving force. On the other hand, Pei et al. [18] have shown that hydrophobic interactions are the main driving force for protein extraction in IL-based ABS. In the same study, the influence of temperature on the extraction of BSA was evaluated demonstrating that higher temperatures favor the partitioning of proteins to the IL-rich phase.

It could be summarized that the partitioning of proteins in IL-based ABS can be tuned by changing the phase-components and their composition, $\mathrm{pH}$ and temperature of the system. Nevertheless, partitioning in IL-based ABS is a quite complex phenomenon not influenced by a single factor, yet it is a result of a combined effect of these factors.

\section{Recovery of Proteins from the IL-rich Phase}

Like conventional ABS, proteins extraction using IL-based ABS involves two main steps: (i) forward extraction, i.e., extraction of the protein from the initial source/matrix into one of the phases (here, ILrich phase); and (ii) recovery of the (purified) protein from the IL-rich phase. 
In conventional $A B S$, proteins can be recovered by modification of system parameters, such as $\mathrm{pH}$, change in salt concentration or addition of other salts. The main goal is to achieve a high recovery of a protein with a high purity level without affecting the functionality of the protein. This is indeed one of the major lacunas in the literature since there are almost no attempts on the literature to this end. An isolated work was recently published by Pereira et al. [50] where the protein (BSA) was recovered by dialysis from the IL-rich phase, and allowing the further use of the ABS in a new extraction step. The authors [50] demonstrated the recovery of the protein and the IL reusability in three-step consecutive extractions, concluding that IL-based ABS can be adequately reused without losses on their extraction performance.

ILs being salts and proteins being macromolecules, their separation can be achieved by ultrafiltration and/or nanofiltration, induced precipitation and chromatographic techniques, such as size exclusion chromatography and by the use of affinity tags (HisTags) able to help in recovering the protein from the IL-rich phase by Immobilized Metal Affinity Chromatography (IMAC). Protein recovery studies are thus one of the major lacunas in the IL-based ABS field and must be investigated in the near future.

\section{Conclusions and Future Perspectives}

IL-based ABS is a promising platform for the extraction and purification of proteins. However, there are still some issues which need to be addressed to be able to use IL-based ABS on a commercial scale, namely.

1. Currently, studies on proteins of commercial importance are scarce; only few studies were performed, for instance for rubisco and alcohol dehydrogenases. Most studies in the literature address model proteins (BSA, lysozyme, etc.).

2. With a plethora of ILs available and the complex and variable nature of proteins it is difficult to generalize or to predict the behavior of proteins in IL-based ABS. However, the setup of a welldefined guideline with respect to some protein classes would be useful. A mechanistic modelling approach still seems to be far off.

3. Stability of proteins in ILs is the prime requirement to guarantee the viability of IL-based ABS for protein separation. Most studies on this line are focused on model proteins, such as BSA and lysozyme. A pragmatic approach would be to create a public and free available (online) database with respect to the functional stability of commercial proteins in IL-based systems.

4. More sophisticated analytical methods to quantify proteins in the IL-rich phase should be attempted to avoid interferences from the IL. Also for preparative chromatography, the stability and functionality of currently available resins needs to be determined.

5. The high costs of ILs are one of the major drawbacks when envisaging the large-scale application of IL-based ABS. The re-use of ILs in large scale applications is essential to guarantee the economic viability. 
6. The ILs used for ABS formation are water-soluble and hence can enter into the ecosystem. Thus, toxicity and biodegradation of ILs poses another concern and must be considered while designing protein extraction and separation processes.

All these points require not only extra efforts to study different IL-based ABS, but more focused studies on the use of biodegradable and biocompatible ILs and efficient IL recycling processes. Since polymers, such as PEG, are able to maintain and even increase the stability of some proteins, IL-PEG ABS seems as an interesting option for protein extraction. Progress in IL-based ABS would open up new applications on their use, especially in biorefinery of $3^{\text {rd }}$ generation biomass feedstocks (e.g., microalgae), where proteins could be separated from more hydrophobic components. IL-based ABS are novel systems and their use for proteins extraction is still in an early stage. Thus, there is ample scope for improvement in protein extractions using IL-based ABS and a strong requirement for further in depth investigations. 


\section{References}

1. Kiron, V., et al., Marine microalgae from biorefinery as a potential feed protein source for Atlantic salmon, common carp and whiteleg shrimp. Aquaculture Nutrition, 2012. 18(5): p. 521-531.

2. Schwenzfeier, A., P.A. Wierenga, and H. Gruppen, Isolation and characterization of soluble protein from the green microalgae Tetraselmis sp. Bioresource Technology, 2011. 102(19): $p$. 9121-9127.

3. Wijffels, R.H. and M.J. Barbosa, An outlook on microalgal biofuels. Science, 2010. 329(5993): p. 796-9.

4. Labrou, N.E., Protein Downstream Processing : Design, Development and Application of High and Low-Resolution Methods2014, Totowa, NJ: Humana Press.

5. Albertsson, P.-A., Partition of Proteins in Liquid Polymer-Polymer Two-Phase Systems. Nature, 1958. 182(4637): p. 709-711.

6. Rosa, P.A.J., et al., Aqueous two-phase systems: A viable platform in the manufacturing of biopharmaceuticals. Journal of Chromatography A, 2010. 1217(16): p. 2296-2305.

7. Rosa, P.A.J., et al., Aqueous two-phase extraction as a platform in the biomanufacturing industry: Economical and environmental sustainability. Biotechnology Advances, 2011. 29(6): p. 559-567.

8. Gutowski, K.E., et al., Controlling the aqueous miscibility of ionic liquids: aqueous biphasic systems of water-miscible ionic liquids and water-structuring salts for recycle, metathesis, and separations. J Am Chem Soc, 2003. 125(22): p. 6632-3.

9. Yang, Z., Ionic Liquids and Proteins: Academic and Some Practical Interactions, in Ionic Liquids in Biotransformations and Organocatalysis2012, John Wiley \& Sons, Inc. p. 15-71.

10. Freire, M.G., et al., Insight into the Interactions That Control the Phase Behaviour of New Aqueous Biphasic Systems Composed of Polyethylene Glycol Polymers and lonic Liquids. Chemistry - A European Journal, 2012.18(6): p. 1831-1839.

11. Wu, B., Y.M. Zhang, and H.P. Wang, Aqueous Biphasic Systems of Hydrophilic lonic Liquids + Sucrose for Separation. Journal of Chemical \& Engineering Data, 2008. 53(4): p. 983-985.

12. Zhang, J., et al., Mutual Coexistence Curve Measurement of Aqueous Biphasic Systems Composed of [bmim][BF4] and Glycine, l-Serine, and l-Proline, Respectively. Journal of Chemical \& Engineering Data, 2007. 52(6): p. 2488-2490.

13. Dreyer, S. and U. Kragl, lonic liquids for aqueous two-phase extraction and stabilization of enzymes. Biotechnol Bioeng, 2008. 99(6): p. 1416-24.

14. Freire, M.G., et al., Aqueous biphasic systems: a boost brought about by using ionic liquids. Chem Soc Rev, 2012. 41(14): p. 4966-4995.

15. Zhang, Y., et al., Aqueous biphasic systems composed of ionic liquid and fructose. Fluid Phase Equilibria, 2007. 257(2): p. 173-176.

16. Du, Z., Y.-L. Yu, and J.-H. Wang, Extraction of Proteins from Biological Fluids by Use of an lonic Liquid/Aqueous Two-Phase System. Chemistry-A European Journal, 2007. 13(7): p. 2130-2137.

17. Dreyer, S., P. Salim, and U. Kragl, Driving forces of protein partitioning in an ionic liquid-based aqueous two-phase system. Biochemical Engineering Journal, 2009. 46(2): p. 176-185.

18. Pei, Y., et al., lonic liquid-based aqueous two-phase extraction of selected proteins. Separation and Purification Technology, 2009. 64(3): p. 288-295.

19. PEI YuanChao, L.Z., LIU Li, WANG JianJi, WANG HuiYong, Selective separation of protein and saccharides by ionic liquids aqueous two-phase systems. SCIENCE CHINA Chemistry, 2010. 53(7): p. $1554-1560$.

20. Lin, X., et al., Extraction and separation of proteins by ionic liquid aqueous two-phase system. Analyst, 2013. 138(21): p. 6445-6453.

21. Chen, J., et al., Partition of proteins with extraction in aqueous two-phase system by hydroxyl ammonium-based ionic liquid. Analytical Methods, 2014. 6(12): p. 4067-4076.

22. Zeng, Q., et al., Extraction of proteins with ionic liquid aqueous two-phase system based on guanidine ionic liquid. Talanta, 2013. 116(0): p. 409-416.

23. Ding, $X_{\text {., }}$ et al., Design of functional guanidinium ionic liquid aqueous two-phase systems for the efficient purification of protein. Analytica Chimica Acta, 2014. 815(o): p. 22-32. 
24. Ruiz-Angel, M.J., et al., Solvent systems for countercurrent chromatography: An aqueous two phase liquid system based on a room temperature ionic liquid. Journal of Chromatography $A$, 2007. 1151(1-2): p. 65-73.

25. Wu, C., et al., Effect of anionic structure on the phase formation and hydrophobicity of amino acid ionic liquids aqueous two-phase systems. Journal of Chromatography A, 2011. 1218(48): p. 85878593.

26. $\mathrm{Wu}, \mathrm{C}$. , et al., Relative hydrophobicity between the phases and partition of cytochrome-c in glycine ionic liquids aqueous two-phase systems. Journal of Chromatography A, 2013. 1305(o): p. 1-6.

27. Yan, J.-K., et al., Facile and effective separation of polysaccharides and proteins from Cordyceps sinensis mycelia by ionic liquid aqueous two-phase system. Separation and Purification Technology, 2014. 135(0).

28. Deive, F.J., et al., Extraction of Candida antarctica lipase $A$ from aqueous solutions using imidazolium-based ionic liquids. Separation and Purification Technology, 2012. 97(0): p. 205210.

29. Ventura, S.P.M., et al., Design of ionic liquids for lipase purification. Journal of Chromatography B, 2011. 879(26): p. 2679-2687.

30. Deive, F.J., et al., lonic liquid-based aqueous biphasic system for lipase extraction. Green Chemistry, 2011. 13(2): p. 390-396.

31. Cao, Q., et al., Partition of horseradish peroxidase with maintained activity in aqueous biphasic system based on ionic liquid. Talanta, 2008. 77(1): p. 160-165.

32. Desai, R.K., et al., Extraction and stability of selected proteins in ionic liquid based aqueous two phase systems. Green Chemistry, 2014. 16(5): p. 2670-2679.

33. Jiang, B., et al., Extraction and purification of wheat-esterase using aqueous two-phase systems of ionic liquid and salt. 2014: p. 1-8.

34. Constantinescu, D., H. Weingärtner, and C. Herrmann, Protein Denaturation by lonic Liquids and the Hofmeister Series: A Case Study of Aqueous Solutions of Ribonuclease A. Angewandte Chemie International Edition, 2007. 46(46): p. 8887-8889.

35. Takekiyo, T., et al., High lonic Liquid Concentration-Induced Structural Change of Protein in Aqueous Solution: A Case Study of Lysozyme. The Journal of Physical Chemistry B, 2012. 116(36): p. 11092-11097.

36. Zhang, W.-G., et al., Penicillin acylase catalysis in the presence of ionic liquids. 2006. 29(5-6): p. 379-383.

37. Nara, S.J., J.R. Harjani, and M.M. Salunkhe, Lipase-catalysed transesterification in ionic liquids and organic solvents: a comparative study. Tetrahedron Letters, 2002. 43(16): p. 2979-2982.

38. Li, Z., et al., lonic liquid-based aqueous two-phase systems and their applications in green separation processes. TrAC Trends in Analytical Chemistry, 2010. 29(11): p. 1336-1346.

39. Baker, G.A. and W.T. Heller, Small-angle neutron scattering studies of model protein denaturation in aqueous solutions of the ionic liquid 1-butyl-3-methylimidazolium chloride. Chemical Engineering Journal, 2009. 147(1): p. 6-12.

40. Weaver, K.D., et al., Structure and function of proteins in hydrated choline dihydrogen phosphate ionic liquid. Physical Chemistry Chemical Physics, 2012. 14(2): p. 790-801.

41. Fujita, K., et al., Solubility and Stability of Cytochrome $c$ in Hydrated lonic Liquids: Effect of Oxo Acid Residues and Kosmotropicity. Biomacromolecules, 2007. 8(7): p. 2080-2086.

42. Hofmeister, F., Zur Lehre von der Wirkung der Salze - Zweite Mittheilung. 1888. 24(4-5): p. 247260.

43. Ru, M.T., et al., On the Salt-Induced Activation of Lyophilized Enzymes in Organic Solvents: Effect of Salt Kosmotropicity on Enzyme Activity. J Am Chem Soc, 2000. 122(8): p. 1565-1571.

44. Zhao, H., et al., Effect of kosmotropicity of ionic liquids on the enzyme stability in aqueous solutions. Bioorganic Chemistry, 2006. 34(1): p. 15-25.

45. Zhao, H., Effect of ions and other compatible solutes on enzyme activity, and its implication for biocatalysis using ionic liquids. 2005. 37(1-6): p. 16-25.

46. Baldwin, R.L., How Hofmeister ion interactions affect protein stability. Biophysical Journal, 1996. 71(4): p. 2056-63. 
47. Collins, K.D. and M.W. Washabaugh, The Hofmeister effect and the behaviour of water at interfaces. Q. Rev.Biophys, 1985. 18(4): p. 323-422.

48. Albertsson, P.A.., Partition of cell particles and macromolecules : seperation and purification of biomolecules, cell organelles, membranes, and cells in aqueous polymer two-phase systems and their use in biochemical analysis and biotechnology1986, New York [etc.]: Wiley.

49. Dreyer, S.E., Aqueous two phase extraction of proteins and enzymes using tetraalkylammoniumbased ionic liquids, 2008, University of Rostock.

50. Pereira, M.M., et al., Enhanced extraction of bovine serum albumin with aqueous biphasic systems of phosphonium- and ammonium-based ionic liquids. Journal of Biotechnology, 2015. 206: p. 1725 . 


\section{Chapter 3}

\section{Extraction and stability of selected proteins in ionic liquid based aqueous two phase systems}

This chapter is published as:

Rupali K. Desai, Mathieu Streefland, René H. Wijffels and Michel H. M. Eppink (2014) Extraction and stability of selected proteins in ionic liquid based aqueous two phase systems Green chemistry 16, pg. 2770-2679 


\section{Abstract}

Ionic liquid-based aqueous two-phase extraction of a plant protein, Rubisco (Ribulose-1, 5-biphosphate carboxylase oxygenase), using lolilyte 221 PG and sodium potassium phosphate buffer was investigated as a new alternative extraction method and compared with a conventional PEG-based two-phase system. The influence of various factors, such as concentration of phase components, $\mathrm{pH}$ and temperature on partitioning of Rubisco, was evaluated by design of experiments. Rubisco partitions to the ionic liquid (IL) phase and the partition coefficient for IL based two-phase system were 3-4 times higher than in a PEG-based system. Additionally, studies were done in aqueous solution of IL with varying concentrations to develop a relationship between IL concentration and protein stability. In addition to Rubisco, the stability of BSA and $\lg G_{1}$ was investigated in aqueous solution of two ionic liquids: Iolilyte $221 \mathrm{PG}$ and Cyphos 108. No fragmentation or aggregation was observed at 10\% w/w concentration of the ionic liquid. However, all three proteins studied formed aggregates at 50\% w/w concentration of ionic liquid. This indicates a narrow range of IL concentration for their application in protein extraction.

Key Words: Rubisco, Ionic Liquid, ATPS, BSA, IgG1, Bio-refinery 


\section{Introduction}

Aqueous two phase extraction of biomolecules has been widely studied over the past decades. First used by Albertsson [1] in the 1950's, the technique has gained attention because it combines several early processing steps such as clarification, concentration and primary purification in one step. The technique is used as a mild primary recovery step for reducing the processing volumes [2]. Aqueous two phase systems (ATPS) are formed by combining two aqueous solutions of polymer and polymer, polymer and salt or salt and salt. When these phase components are mixed beyond a certain critical concentration they separate in two distinct aqueous phases. Selective partitioning of the target molecule depends upon the affinity of the molecule for the phase component used (Polymer type, salt) and system parameters such as $\mathrm{pH}$, temperature and tie line length. PEG is known to stabilise proteins and high water content ( $80-90 \%)$ in the bulk of the two phases provides a gentle environment for the protein. Thus, aqueous two phase extraction is a mild and the most suitable for extracting biologically active molecules [3-6]. This system has further developed by implementing a new class of extractants, "ionic liquids", to form an aqueous biphasic system. ATPS based on ionic liquids are formed by combining an ionic liquid (IL) solution with a salt solution [7], thus replacing the polymer component of the conventional polymer-salt two phase system.

lonic liquids are salts, composed solely of ions with a melting point below $100^{\circ} \mathrm{C}$. These ILs when compared to organic solvents have low vapour pressure, high solvation capacity and better thermal and chemical stability.

Ionic liquids are emerging as the new class of solvents with tuneable properties. The physical properties of ionic liquids such as polarity, hydrophobicity, viscosity can be controlled by permutation and combination of anions and cations. This high tunability makes them a desirable class of extractants in liquid-liquid extraction. Ionic liquids are studied in many fields, ranging from inorganic synthesis [8], extraction of metals [9] to biocatalysis [10]. Despite the several interesting features, most ILs suffers the drawback of being expensive and poorly biodegradable. Nevertheless ILs could be attractive if they could be regenerated and reused.

Aqueous two phase extraction studies with ionic liquids normally involve the use of imidazolium ionic liquid as the cation. Coutinho and co-workers [11] have done some ATPS studies based on ionic liquid with phosphonium as the cation. The Kragl group [12] studied an ammonium based ionic liquid Ammoeng 110 which is effective in forming aqueous two-phase and purifying enzymes (two different alcohol dehydrogenases); this IL can stabilize the enzymes and enhances the solubility of hydrophobic substrates. In another study extraction of proteins from biological fluid has been investigated using ILbased ATPS [13]. IL based ATPS have been mainly studied for extracting small proteins such as BSA, myoglobin, amino acids and small molecules such as caffeine, vanillin, penicillin and testosterone [1417]. Apart from this, most of the research using ionic liquids focuses on formation and characterisation 
of two phase system while a few studies have been done on protein stability in ATPS $[18,19]$.

Leveraging on the advantages offered by ATPS and coupling the unique features of IL, such as controlled hydrophobicity, polarity and miscibility, could provide selective extraction of proteins from the biomass. Use of IL based ATPS for extracting commercially important proteins is not well explored. It is thus important to study the extraction of commercial proteins and how it affects the stability of the protein after being extracted in the ionic liquid rich phase.

In this work, studies were done to systematically understand the relationship between IL concentration and protein stability with ATPS system. Thus, extraction of pure Rubisco (purity $~ 80 \%$ ) in IL based ATPS (Iolilyte 221 PG/Sodium-potassium phosphate ATPS) was evaluated as it would be the most interesting target for such an application. The influence of different process parameters on extraction were studied and compared with conventional two phase system (PEG/Potassium Citrate ATPS). Additionally the stability of Rubisco, together with two other model proteins BSA and IgG1 in aqueous solution of IL was studied.

The ionic liquid selected on the basis of literature study [17] are: Iolilyte $221 \mathrm{PG}$-an ammonium based ionic liquid with oligopropyleneglycol unit containing side chain and Cyphos 108 (Tributyl(methyl) phosphonium methylsulfate)- an phosphonium based ionic liquid.

The commercial proteins selected are: Rubisco-a plant protein; Monoclonal antibody (lgG1)-a therapeutic protein; and Bovine Serum Albumin (BSA)-a model protein. BSA and IgG1 were selected for the study in an effort to understand the influence of ionic liquids on proteins with varying size, complexity and isoelectric point (IEP) (Table 1). Rubisco is the most abundant protein found in nature and amounts to nearly $50 \%$ of the total protein found in green parts of plants and microalgae. There has been a growing interest in this protein, as it has a high potential to be used as an ingredient in human / animal food [20]. Microalgae have a big potential to be a source for biofuel production. However in order to make this economically feasible, more products from microalgae need to be derived [21]. Thus, purification and efficient separation of microalgal proteins, namely Rubisco is important from the bio-refinery perspective [22].

\section{Experimental}

\section{Materials}

Polyethylene glycol (PEG) 400, 1000 and 3350 and potassium citrate tribasic were obtained from Sigma. Sodium phosphate, potassium phosphate and citric acid were purchased from Merck. lonic liquids, lolilyte 221 PG and Cyphos 108 were procured from lolitec. The structure of the ionic liquids used is shown in Figure 3.1 Rubisco and BSA were purchased from Sigma. IgG1 was generously provided by Synthon B.V. Netherlands. The three proteins selected (BSA, IgG1 and Rubisco) widely differ from each other in terms of source, structural complexity, isoelectric point (pl) and molecular weight (Table 3.1). 
Table 3.1 Properties of Proteins

\begin{tabular}{cccccc}
\hline Proteins & $\begin{array}{c}\text { Molecular } \\
\text { weight, kDa }\end{array}$ & pl & $\begin{array}{c}\text { No. of } \\
\text { subunits }\end{array}$ & $\begin{array}{c}\text { Mol.wt of sub } \\
\text { units kDa }\end{array}$ & $\begin{array}{c}\text { Bond between } \\
\text { subunits }\end{array}$ \\
\hline BSA & 67 & 4.7 & Monomer & - & - \\
$\lg G_{1}$ & 150 & 9.1 & Four $\left(\mathrm{L}_{2} \mathrm{~S}_{2}\right)$ & $\begin{array}{c}\text { Large }-50 \\
\text { Small }-25\end{array}$ & $\begin{array}{c}\text { Covalently linked } \\
\text { subunits } \\
\text { Large }-55\end{array}$ \\
Rubisco & 540 & 5.5 & Eight $\left(\mathrm{L}_{8} \mathrm{~S}_{8}\right)$ & $\begin{array}{c}\text { Non-Covalently } \\
\text { linked subunits }\end{array}$ \\
\hline
\end{tabular}

a)<smiles>CC[N+](C)(CC)CCC(C)(C)OCC(C)C(C)O</smiles>

b)

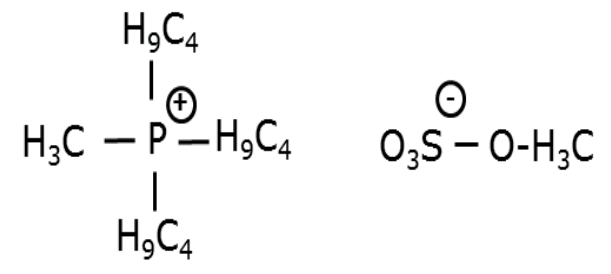

Figure 3.1 Structures of (a) lolilyte 221 PG and (b) Cyphos 108.

\section{Methods}

Aqueous two phase system based on polymer (PEG-Salt)

Potassium citrate buffer was prepared by mixing appropriate quantities of $40 \% \mathrm{w} / \mathrm{w}$ citric acid with $40 \%$ $\mathrm{w} / \mathrm{w}$ potassium citrate tribasic to attain the desired $\mathrm{pH}$. Citrate salt was selected due to its biodegradability and low environmental polluting properties. Biphasic system was prepared by mixing appropriate amounts of $50 \% \mathrm{w} / \mathrm{w}$ stock solutions of PEG, $50 \% \mathrm{w} / \mathrm{w}$ stock solution of potassium citrate, water and Rubisco solution (stock solution $2 \% \mathrm{w} / \mathrm{w}$ ) to a final weight of $5 \mathrm{~g}$. The final protein concentration in the system was $0.4 \mathrm{mg} / \mathrm{g}$. The systems were mixed using a vortex mixture and incubated at $30^{\circ} \mathrm{C}$ for $30 \mathrm{~min}$. The system was then centrifuged at $2500 \mathrm{rpm}$ for $10 \mathrm{~min}$ to ensure complete separation of phases. The volume of top and bottom phase was measured and samples from respective phases were taken and analysed for the Rubisco content at $280 \mathrm{~nm}$. 
Aqueous two phase system based on ionic liquid (IL-Salt)

Two phase system of ionic liquid salt was prepared by mixing appropriate amounts of lolilyte 221 PG, sodium potassium phosphate buffer, protein solution and water to a final wt. of $5 \mathrm{~g}$. The buffer was prepared by mixing appropriate quantities of $40 \% \mathrm{w} / \mathrm{W}$ di basic potassium phosphate $\left(\mathrm{K}_{2} \mathrm{HPO}_{4}\right)$ with $40 \% \mathrm{w} / \mathrm{w}$ mono basic sodium phosphate $\left(\mathrm{NaH}_{2} \mathrm{PO}_{4}\right)$ until the desired $\mathrm{pH}$ was reached. $\mathrm{K}_{2} \mathrm{HPO}_{4}$ and $\mathrm{NaH}_{2} \mathrm{PO}_{4}$ were used to prepare the buffer due to the low solubility of their respective mono and dibasic salts. The system was mixed and incubated for 30 minutes at temperatures selected for the study. Samples from bottom phase were withdrawn and analysed for the Rubisco content at $280 \mathrm{~nm}$. The yield in the IL-rich top phase was calculated by mass balance to avoid possible interference from ionic liquid.

\section{Design of experiments}

Modde v.9.1 Design of Experiments (DOE) software (MKS Umetrics, Sweden) was used to study the effect of different factors on the partitioning of Rubisco in PEG-Salt and lonic liquid-salt two phase systems. A central composite face centred design (CCF) was used for both systems. Four independent variables (factors) at three levels and three replicates at the centre point were studied for the two systems. The coded value for each factor studied for the two systems are shown in Table 3.2 and 3.3.

Table 3.2 Factors and value levels used in CCF design for PEG/Potassium citrate system in \% w/w

\begin{tabular}{ccccc}
\hline Variables & Factors & $\begin{array}{c}\text { Low value } \\
(-1)\end{array}$ & $\begin{array}{c}\text { Centre } \\
\text { value } \\
\text { (0) }\end{array}$ & $\begin{array}{c}\text { High value } \\
(+1)\end{array}$ \\
\hline PEG molecular weight & $\mathrm{X}_{1}$ & 400 & 1000 & 6000 \\
PEG concentration \% w/w & $\mathrm{X}_{2}$ & 24 & $25 \cdot 5$ & 27 \\
Buffer concentration \% w/w & $\mathrm{X}_{3}$ & 24 & 26 & 28 \\
$\mathrm{pH}$ & $\mathrm{X}_{4}$ & 6 & 7 & 8 \\
\hline
\end{tabular}

Table 3.3 Factors and value levels used in CCF for lolilyte 221 PG/Sodium -Potassium phosphate system

\begin{tabular}{ccccc}
\hline Variables & Factors & $\begin{array}{c}\text { Low Value } \\
(-1)\end{array}$ & $\begin{array}{c}\text { Centre Value } \\
(\mathbf{0})\end{array}$ & $\begin{array}{c}\text { High Value } \\
(+\mathbf{1})\end{array}$ \\
\hline Iolilyte 221 PG concentration \% w/w & $\mathrm{X}_{1}$ & 12 & 16 & 20 \\
Buffer concentration \% w/w & $\mathrm{X}_{2}$ & 20 & 22.5 & 25 \\
$\mathrm{pH}$ & $\mathrm{X}_{3}$ & 6 & 7 & 8 \\
Temperature ${ }^{\circ} \mathrm{C}$ & $\mathrm{X}_{4}$ & 15 & 25 & 35 \\
\hline
\end{tabular}

The two response variables studied were partition coefficient $\left(K_{p}\right) Y_{1}$ and yield $\left(Y_{e}\right) Y_{2}$. The distribution of Rubisco in ATPS was determined by measuring the partition coefficient $K_{p}$ which is calculated as the ratio of Rubisco concentration in the upper phase to that in the lower phase. 


$$
K_{p}=\frac{C_{t}}{C_{b}}
$$

The yield $\left(\mathrm{Y}_{\mathrm{e}}\right)$ is calculated as the percentage of the amount of Rubisco in the top phase to the initial amount for PEG based system and for IL based system it is calculated as:

$$
Y_{e}=100-\frac{C_{b} \times V_{b}}{\text { Initial Amount }} \times 100
$$

Response surface methodology was used to optimise the extraction and the responses were fitted in a quadratic (second order) polynomial regression model to understand the effect of different interactions on the responses. The model's validity and significance were evaluated using the analysis of variance (ANOVA).

\section{Stability in ionic liquid solutions}

The effect of ionic liquid on the three proteins was investigated by incubating the proteins in different concentration of aqueous ionic liquid solutions. The samples were prepared by mixing the ionic liquid with water and adding the protein at a concentration of $2 \mathrm{mg} / \mathrm{ml}$. The concentration lolilyte $221 \mathrm{PG}$ and Cyphos 108 was increased from 10-50\% v/v. The stability of proteins was then analysed by gel electrophoresis and size exclusion chromatography (SEC-HPLC). The concentration of ionic liquid in the top phase of ATPS could vary from $20-60 \% \mathrm{w} / \mathrm{w}$. Therefore the top phase of the ATPS was also analysed for protein stability using gel electrophoresis and size exclusion chromatography.

\section{Analytical techniques}

\section{UV Spectroscopy}

The amount of Rubisco in both PEG-Salt and IL-Salt biphasic systems was analysed by measuring the absorbance at $280 \mathrm{~nm}$. All samples were analysed against blanks having the same composition but without protein to avoid interference from the phase components.

\section{Rubisco Activity}

Rubisco activity is measured spectrophotometrically using NADH-linked enzyme coupled system [23]. The final reaction mixture (3ml) contains $259 \mathrm{mM}$ Tris, $5 \mathrm{mM}$ magnesium chloride, $67 \mathrm{mM}$ potassium bicarbonate, $0.2 \mathrm{mM}$ ß-nicotinamide adenine dinucleotide, reduced form, $5 \mathrm{mM}$ adenosine 5'triphosphate, $5 \mathrm{mM}$ glutathione, reduced form, $0.5 \mathrm{mM}$ D-ribulose 1,5 di-phosphate, 5 units alphaglycerophosphate dehydrogenase trios phosphate isomerase, and 5 units glyceraldehyde-3-phosphate dehydrogenase/3-phosphoglyceric phosphokinase. Rubisco is added and the oxidation of NADH is measured by monitoring the change in absorbance at $340 \mathrm{~nm}$ over a period of 6 minutes. The enzyme activity is then calculated from the rate of $\mathrm{NADH}$ oxidation using an extinction coefficient of $6.22 \mathrm{mM}^{-1}$.

\section{Size exclusion chromatography (SEC-HPLC)}

The stability of the protein, in terms of fragmentation and/or aggregate formation, was analysed by SEC-HPLC (Thermo Separation Products $\mathrm{P}_{4000}$ pump and AS3000 auto sampler and Ultimate 3000 
Diode array detector) using Biosep-SEC-S-3000 column (Phenomenex $300 \times 7.8 \mathrm{~mm}$ column, $5 \mu$ particle size). The mobile phase was $0.1 \mathrm{M}$ sodium phosphate buffer $\mathrm{pH} 7$ and $0.3 \mathrm{M}$ sodium chloride. The samples were centrifuged at $11000 \mathrm{rpm}$ for 1 minute to remove any insoluble particles prior to injection (inj. volume $20 \mu \mathrm{l}$ ). The samples were run in an isocratic mode at a flow rate of $1 \mathrm{ml} / \mathrm{min}$ and the protein was detected at $280 \mathrm{~nm}$.

\section{Electrophoresis}

To investigate the formation of fragments and aggregates and to confirm that the protein retains its native form, the samples were further analysed by native gel electrophoresis. The samples from the top and bottom phase were diluted with native sample buffer in the ratio 1:2. The samples were then applied on 4-20\% Criterion TGX, Tris glycine precast gel and run with 10X Tris glycine native buffer at $125 \mathrm{~V}$ for 75 minutes. SDS- gel electrophoresis was performed using precast Criterion XT Bis-Tris gel $12 \%$. The samples were mixed with the sample buffer, reducing agent and heated at $95^{\circ} \mathrm{C}$ for 5 minutes. The samples were applied on the precast gels and then run using 3-(N-morpholino) propane sulfonic acid (MOPS) buffer at constant voltage of $200 \mathrm{~V}$. The gel (both native and reduced gels) was stained with coomassie brilliant blue R250. All the reagents used for gel electrophoresis were procured

Dynamic light scattering (DLS)

Dynamic light scattering is a non-invasive technique which measures size and size distribution of proteins, particles and other molecules in liquid solution. It measures the fluctuation in light intensity as a function of time. Hydrodynamic radius of proteins in aqueous ionic liquid solution were analysed by Zetasizer Nano S System from Malvern Ltd. The light scattering was measured at a constant temperature of $25^{\circ} \mathrm{C}$ and scattering angle of $173^{\circ}$. The samples were measured in $40 \mu$ disposable cuvettes. The viscosity and refractive index of the dispersant, lolilyte $221 \mathrm{PG}$, was set at 1.29 mPa.s and 1.346 for $10 \% \mathrm{v} / \mathrm{v} ; 2.49 \mathrm{mPa}$.s and 1.37 for $25 \% \mathrm{v} / \mathrm{v}$ and $9.8478 \mathrm{mPa}$.s and 1.403 for $50 \% \mathrm{v} / \mathrm{v}$ respectively.

\section{Results and Discussion}

In this work, partitioning of Rubisco was studied in two different ATPSs; polymer-salt and IL-salt. Influence of system components: type of polymer, salt and ionic liquid and system parameters: $\mathrm{pH}$, temperature on the extraction of Rubisco was investigated using DoE. Furthermore, the stability of proteins (BSA, IgG1 and Rubisco) in different concentration of aqueous solutions of ionic liquid was investigated using Dynamic Light Scattering (DLS), size exclusion chromatography (SEC-HPLC) and gel electrophoresis (SDS-PAGE) and is discussed in this section.

\section{Partitioning of Rubisco in PEG/salt system}

\section{Effect of system components}

Different PEG molecular weights were studied to understand its effect on partitioning of Rubisco in aqueous two phase system. The protein partitioned preferentially to the PEG phase (Figure 3.2). 
However, with increase in the chain length of PEG the yield decreases due to precipitation of Rubisco at the interface. This could be attributed to the fact that an increase in the chain length of PEG decreases the free volume available in the top phase [24]. Thus there is not enough space to accommodate Rubisco, which is a large protein. Precipitation of Rubisco with increase in the molecular weight is also associated to the increase in hydrophobicity of the top phase. PEG 400 was selected for further studies since it showed good recovery and partitioning with no precipitation of Rubisco.

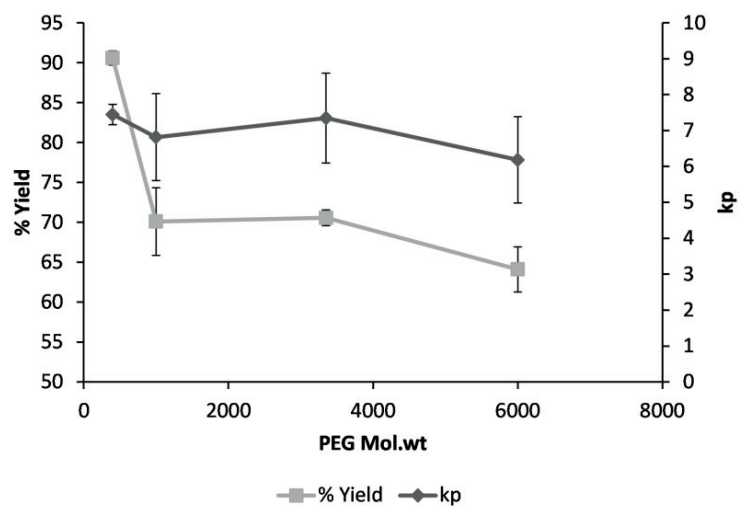

Figure 3.2 Effect of molecular weight on partition coefficient $K_{p}$ and Yield

Different concentrations of salt and PEG were studied in order to evaluate their effect on partitioning of Rubisco. The salt concentration was increased from $24 \% \mathrm{w} / \mathrm{w}$ to $28 \% \mathrm{w} / \mathrm{w}$ and PEG concentration was increased from $24 \% \mathrm{w} / \mathrm{w}$ to $27 \% \mathrm{w} / \mathrm{w}$. As shown in Figure $3.3 \mathrm{a}$ and $3.3 \mathrm{~b}$ there is marginal increase in the partition coefficient and recovery of Rubisco with increase in concentrations of phase components.

\section{Effect of system parameter}

The effect of $\mathrm{pH}$ on partitioning of Rubisco was evaluated by varying the $\mathrm{pH}$ from 6-8. The net charge on the protein varies with the $\mathrm{pH}$ of the ATPS and depending on the pl of the protein it influences the partitioning of protein between the two phases. Rubisco partitioned preferentially to the top phase at all $\mathrm{pH}$ studied. The partitioning to the top phase can be explained by the electrostatic interaction between the biomolecule and PEG [25]. From the previous studies by different authors [3, 25, 26], it is observed that negatively charged proteins partition to the PEG phase. Since the isoelectric point of Rubisco is between $5 \cdot 5-5 \cdot 7$, it is negatively charged at all the $\mathrm{pH}$ studied and thus partitions to the PEG phase. The response contour plots (Figure $3.3 \mathrm{C}$ and $3.3 \mathrm{~d}$ ) shows that an optimum extraction efficiency of $\sim 93 \%$ and partition coefficient of $\sim 12$ is achieved at $\mathrm{pH}$ close to neutral $\sim 7$.

\section{Partitioning of Rubisco in IL/salt system}

\section{Effect of system components}

As observed for the PEG based ATPS, partitioning in IL-based ATPS is also influenced by several parameters such as concentration of $\mathrm{IL}$ and salt, $\mathrm{pH}$ and temperature. The effect of varying 
concentration of phase components such as IL and salt on partitioning was investigated. Rubisco is partitioned preferentially to the top phase as the ionic liquid and salt concentration was increased from $12 \% \mathrm{w} / \mathrm{w}$ to $20 \% \mathrm{w} / \mathrm{w}$ and $20 \% \mathrm{w} / \mathrm{w}$ to $25 \% \mathrm{w} / \mathrm{w}$ respectively. The partition coefficient increases from 20 to 45 as the concentration of ionic liquid and salt is increased (Figure 3.4a). A corresponding increase in the yield of Rubisco was observed (Figure 3.4b). This trend of increased partition coefficient and yield is observed at $\mathrm{pH} 7$ and temperature of $25^{\circ} \mathrm{C}$. It is interesting to note that the partition coefficient obtained with the ionic liquid based ATPS is of the order 3-4 higher than PEG/salt system. These findings are in agreement with those done by Ruiz-Angel [27]. Ruiz-Angel [27] have reported that the partitioning of myoglobin, cytochrome $C$, haemoglobin and ovalbumin to the ionic liquid phase is of the magnitude 2-3 higher and is attributed to the vast difference in the polarity of the PEG rich phase and ionic liquid rich phase. The main driving force for partitioning of the protein to the ionic liquid phase is not well understood, though there have been some studies done in this direction $[14,17]$. However, these studies suggest that the partitioning of Rubisco to the IL-rich top phase could be attributed to a combined effect of hydrophobic interaction, salting out effect and electrostatic interaction between the positively charged ammonium cation of the ionic liquid and the negatively charged amino acid residues at the surface of the protein.

\section{Effect of system parameters}

The influence of temperature and $\mathrm{pH}$ on formation of aqueous two phase is assessed by different authors [28] [29]. The effect of $\mathrm{pH}$ on partitioning of Rubisco was studied in the range 6-8. The studies show that the partitioning of Rubisco increases with the increase in $\mathrm{pH}$ (Figure $3.5 \mathrm{a}, \mathrm{b}$ ). Whereas, there is no significant change in the yield when the temperature is increased from $15^{\circ} \mathrm{C}$ to $35^{\circ} \mathrm{C}$ (Figure $3.5 \mathrm{C}$, d). 
a)

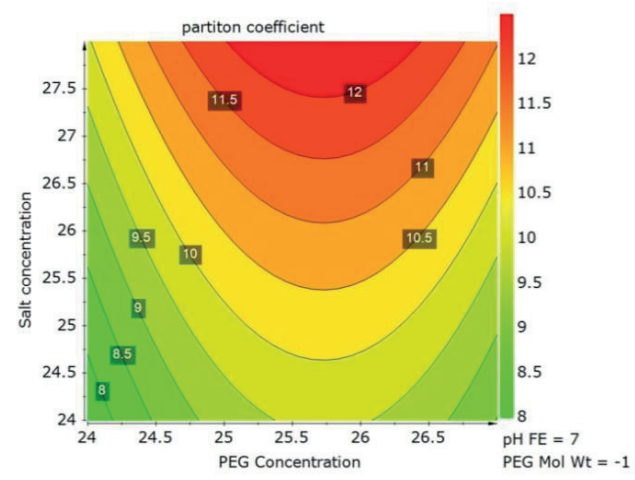

c)

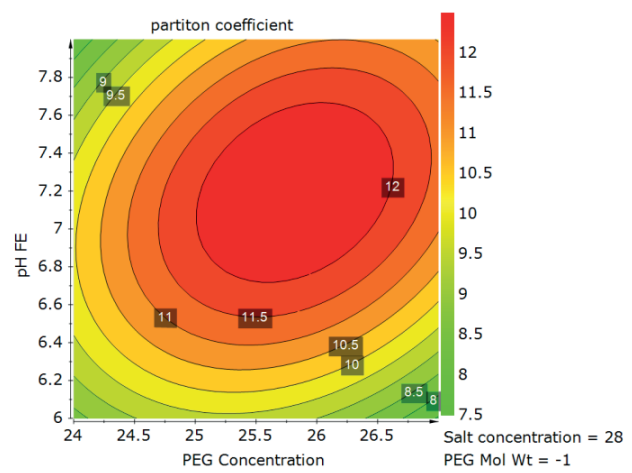

b)

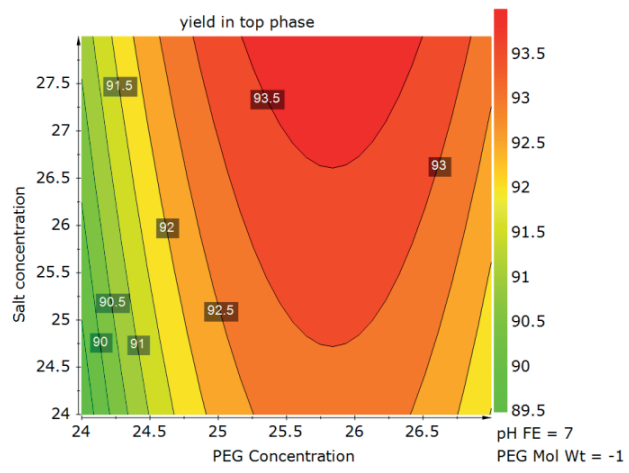

d)

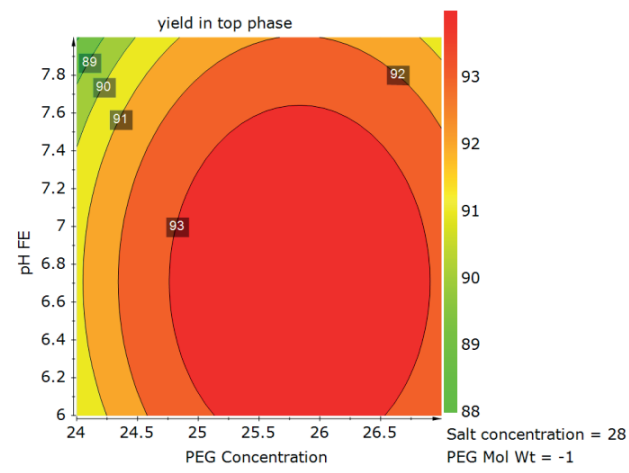

Figure 3.3 Contour plots of PEG and salt concentration effects on a) Partition coefficient, b) Yield of Rubisco and Effect of $\mathrm{pH}$ on c) Partition coefficient and d) Yield of Rubisco

a)

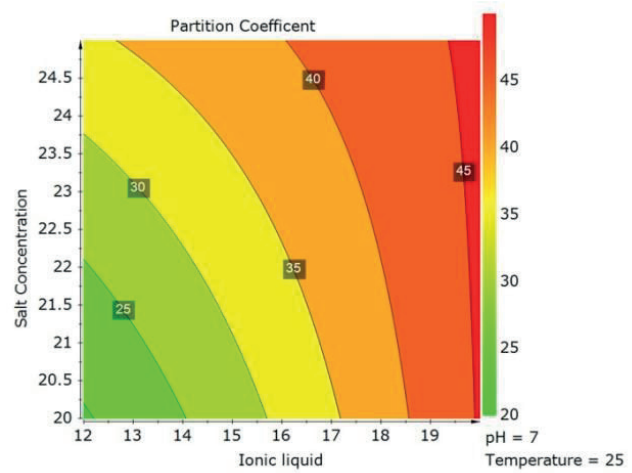

b)

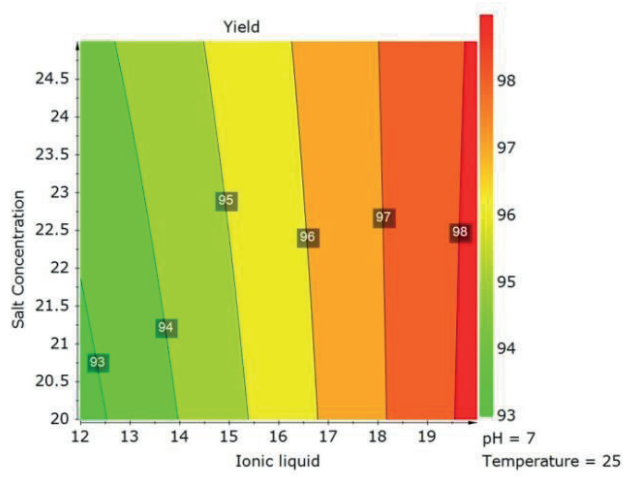

Figure 3.4 Contour plots of effect of $I L$ and salt concentration on a) Partition coefficient and b) Yield of Rubisco 
a)

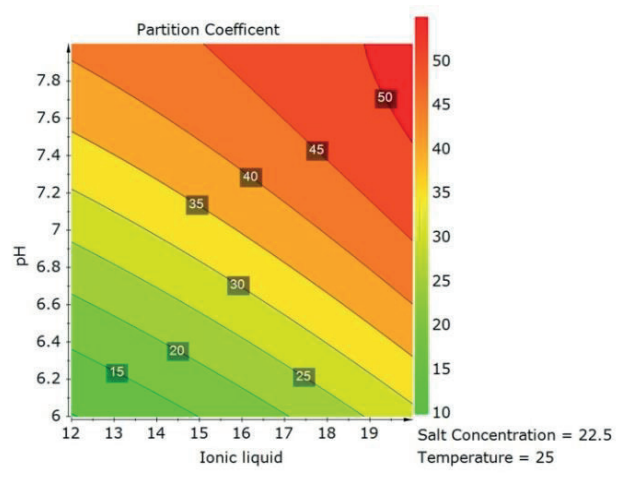

c)

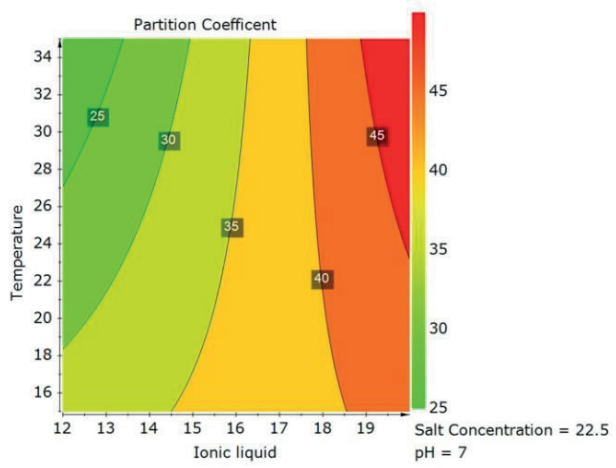

b)

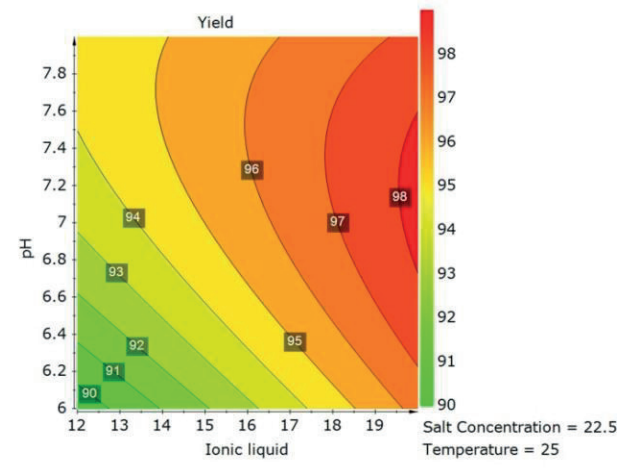

d)

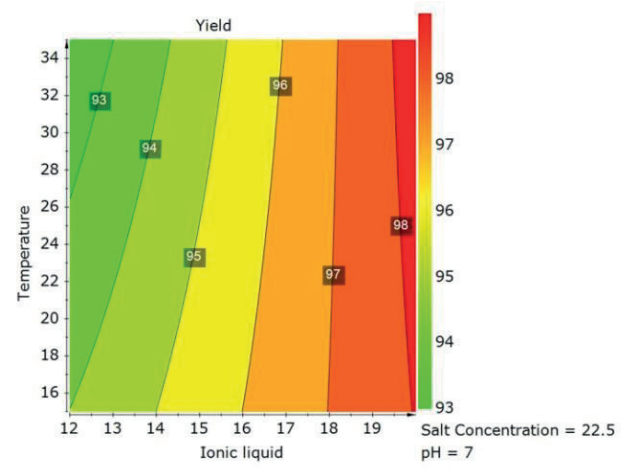

Figure 3.5 Contour plots of effect of $\mathrm{pH}$ on a) Partition coefficient b) Yield and Effect of Temperature on c) Partition coefficient d) Yield of Rubisco

Model fit and Analysis

A second order polynomial regression model was used to calculate the response contour plot for each response variable. These plots help to visualize the relationship between the variables and the responses [30]. The coefficient of the model's independent variable describes the effect of the variables on the response. The effects that had less than $95 \%$ significance were considered insignificant and discarded. The following reduced regression models were obtained for the responses; partition coefficient and yield for the two systems:

\section{PEG/Potassium citrate ATPS}

$$
\begin{gathered}
K_{p}=0.958+0.0315 X_{1}+0.022 X_{2}+0.0166 X_{3}+0.0734 X_{4}+0.046 X_{1} X_{4}-0.040 X_{1} X_{3}+0.0464 X_{2} X_{4} \\
+0.11 X_{1}^{2}-0.0743 X_{2}^{2}-0.096 X_{4}^{2} \\
R^{2}=0.85 \\
Y_{e}=-1.365-0.175 X_{1}+0.053 X_{2}+0.0115 X_{3}-0.040 X_{4}-0.022 X_{1} X_{3}-0.044 X_{1} X_{4}-0.046 X_{3} X_{4}+0.356 X_{1}^{2} \\
-0.121 X_{2}^{2}-0.07 X_{4}^{2} \\
R^{2}=0.91
\end{gathered}
$$




\section{lolilyte 221PG/Sodium Potassium phosphate system}

$$
\begin{gathered}
K_{p}=-0.263+0.188 X_{1}+0.085 X_{2}+0.307 X_{3}-0.028 X_{4}-0.080 X_{1} X_{2}-0.095 X_{1} X_{3}+0.096 X_{1} X_{4}-0.11 X_{2} X_{4} \\
-0.11 X_{3}^{2} \\
R^{2}=0.92 \\
Y_{e}=1.98+0.011 X_{1}+0.0009 X_{2}+0.006 X_{3}-0.001 X_{4}-0.001 X_{1} X_{2}-0.004 X_{1} X_{3}+0.002 X_{1} X_{4}-0.002 X_{2} X_{4} \\
-0.006 X_{3}^{2} \\
R^{2}=0.92
\end{gathered}
$$

The value of $R^{2}$ defines how well the model fits the data. In the model fit, the observed $R^{2}$ value shows a good correlation with the predicted values. The statistical significance of regression model was evaluated by the analysis of variance (ANOVA). The ANOVA analysis (see Appendix, Table 1) performed on the two systems shows that the model is significant. The first F-test, which compares variation in regression model and residuals, is satisfied when $p<0.05$. The second test also known as the lack of fit test, compares the model and replicate errors and is satisfied when $p>0.05$. According to the ANOVA, all parameters, PEG mol. wt., PEG and salt concentration and pH have significant influence on the partitioning $\left(K_{p}\right)$ of Rubisco in PEG based ATPS. However, the influence of PEG mol. wt. on yield is very prominent. Rubisco precipitates at high mol. wt. PEG and thus low yields. Similarly for the IL based ATPS, as seen in the response contour plots (Figure3.4 and 3.5) IL, salt and pH substantially influences the partitioning of the Rubisco to the IL phase.

\section{Stability of the protein}

Proteins are complex macromolecules and retain their structural and functional stability in native environment. Small changes in the protein environment such as temperature, $\mathrm{pH}$ and solvent can alter the native fold of the protein. Studies on protein interaction with ionic liquid have been performed by different authors [31-33].

The partition coefficient obtained for the IL/salt ATPS is much higher than the PEG based systems. Nevertheless the stability of the protein in the extracted phase is a prerequisite. The samples of the ILrich top phase were analysed by gel electrophoresis and SEC-HPLC. In the SEC-chromatogram (Figure 3.6), the band of Rubisco in the top phase is not visible. This result is in accordance with the native gel which shows a very faint band (data not shown). This indicates that Rubisco does not retain its native structure in the IL rich phase.

Although the starting concentration of IL-based ATPS was varied from $12-20 \% \mathrm{w} / \mathrm{w}$, depending on the partitioning and resulting volumes of each phase, the concentration of ionic liquid in IL rich phase can vary considerably. Therefore, to understand the relationship between ionic liquid concentration and protein stability, pure Rubisco was dissolved in increasing amount of lolilyte 221 PG and samples were run on SEC-HPLC.

The SEC-HPLC chromatogram (Figure 3.7a) shows a progressive decrease in Rubisco peak intensity with increase in ionic liquid concentration. Additionally, there is no visible fragmentation of Rubisco 
observed in the SEC chromatogram. This is further confirmed by gel electrophoresis (Figure 3.7b). However, there is some amount which does not migrate and remains in the well. These studies indicate probably, formation of high molecular weight aggregates with increasing concentration of ionic liquid. The aggregates are too large to pass through the SEC column and hence not observed in SEC chromatogram. Under denaturing conditions (use of SDS and $\beta$-mercaptoethanol) these aggregates are reduced to the Rubisco subunits ( 55 and $13 \mathrm{kDa}$ ) and migrate through the gel (Figure 3.7b). However, at higher concentration of the ionic liquid, some amount of protein is still observed in the well under denaturing condition. This indicates that the aggregates so formed are linked by both noncovalent and/or disulphide linkages.

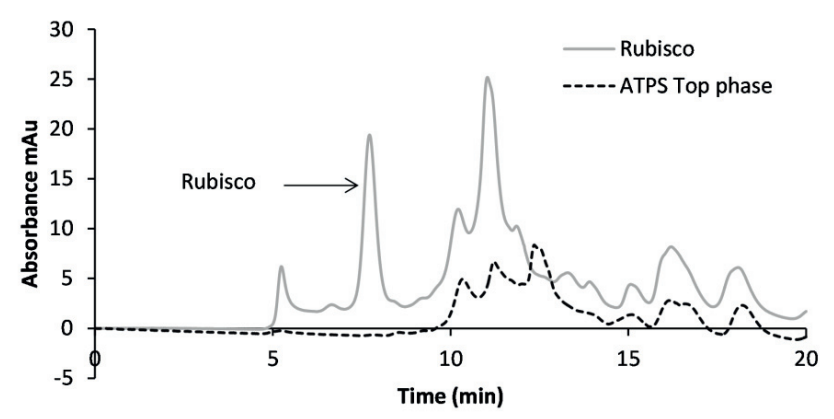

Figure 3.6 Size exclusion chromatography-IL/Salt ATPS top phase

a)

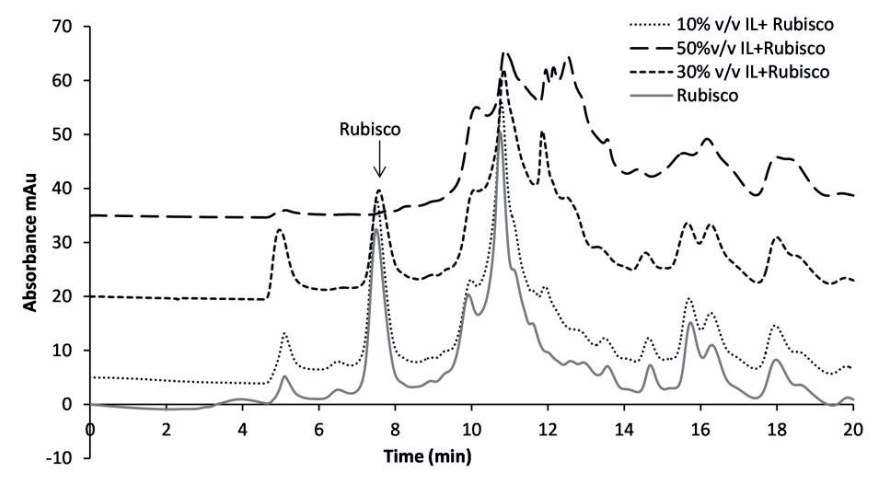


b)

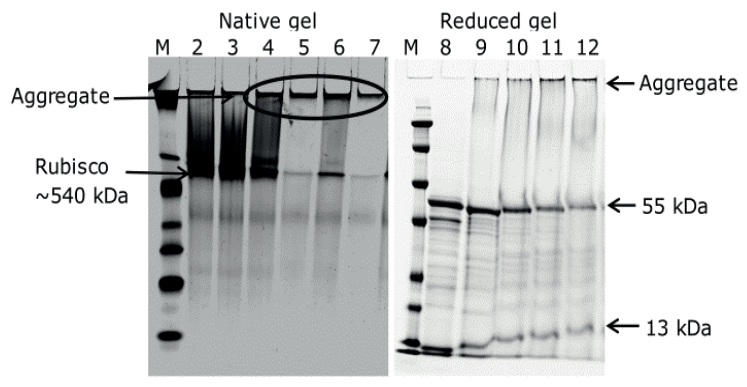

c)

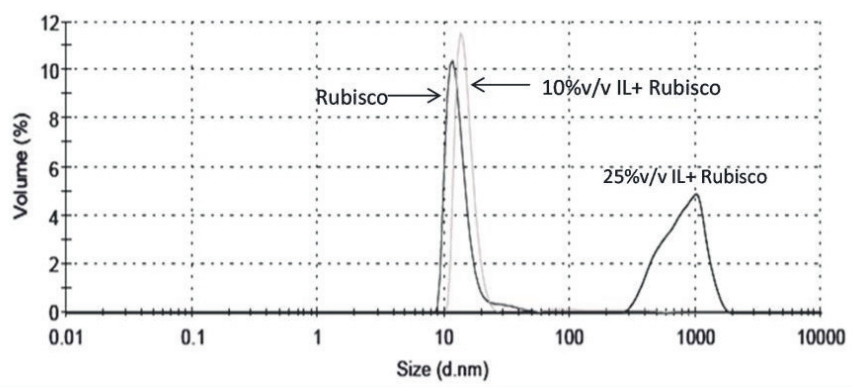

d)

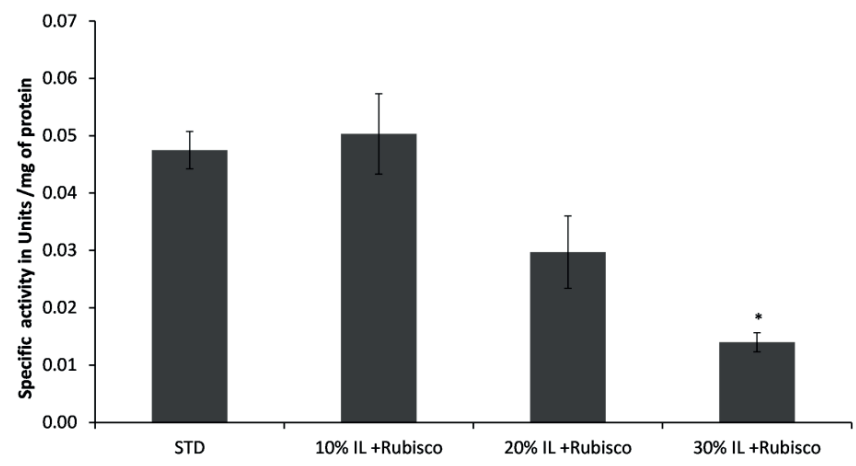

Figure 3.7 Effect of increasing concentration of lolilyte 221 PG on Rubisco(a) Size exclusion chromatography (b) Native gel electrophoresis: Standard Rubisco Lane 2, 8; Rubisco +10\%IL in lane 3,9; Rubisco +30\% IL in lane 4, 10; Rubisco +40\% IL in lane 6,11; Rubisco +50\% IL in lane 5,12; Rubisco +60\% IL in lane 7 (c) Dynamic light scattering (d) Rubisco Specific Activity in presence of ionic liquid *t-test -significantly different from the standard

The hypothesis that high molecular weight aggregates were formed was further confirmed by DLS studies (Figure 3.7c). The DLS study shows that the hydrodynamic radius of standard Rubisco and Rubisco in $10 \% \mathrm{v} / \mathrm{v}$ lolilyte $221 \mathrm{PG}$ is similar. As the concentration is increased to $25 \% \mathrm{v} / \mathrm{v}$, Rubisco formed an aggregate which is shown by an increase in the hydrodynamic radius. Rubisco activity in 
presence of different concentrations of ionic liquid was also monitored (Figure3. $7 \mathrm{~d}$ ). The study showed a decrease in enzyme activity with increase in ionic liquid concentration. All these results illustrate that the absence of Rubisco peak from the top phase of the aqueous two phase system is associated with the formation of high molecular weight aggregates. The study done by Dreyer [12] on lolilyte 221 PG/Potassium phosphate aqueous two phase system shows that the concentration of lolilyte 221 PG in the top phase can be up to $40 \% \mathrm{w} / \mathrm{w}$ or higher depending on the initial ionic liquid concentration in the system. This confirms that high concentration of ionic liquid in the top phase leads to aggregation.

We also studied the behaviour of BSA and $\lg G_{1}$ in aqueous solution containing increasing concentration of the lolilyte 221 PG. Aqueous two phase extraction of BSA in lolilyte 221 PG/Phosphate was done by Dreyer [17]. The study showed that BSA was extracted with an efficiency of 85-100\% and has improved thermal stability in presence of ionic liquid. Our studies reveal that at high concentration of Iolilyte 221 PG (50\% v/v) there is marginal decrease in peak intensity (Figure.3.8a). The SEC results together with DLS study shows aggregation of BSA at 50\% v/v of lolilyte 221PG (Figure 3.8b). Baker and Heller [34] reported aggregation of human serum albumin at 50\% v/v concentration of ionic liquid, 1-butyl-3methylimidazolium chloride. $\lg G_{1}$ on the other hand too showed aggregate formation at higher concentration (Figure 3.8c). The SEC-HPLC chromatogram shows no aggregation or fragmentation of $\lg \mathrm{G}_{1}$ and $\mathrm{BSA}$ at $10 \% \mathrm{v} / \mathrm{v}$. The higher aggregation susceptibility of Rubisco (at $25 \% \mathrm{IL}$ concentration) compared to BSA ( $50 \%$ IL concentration) could be related to the complexity of the structure, as BSA consist of a single globular subunit and Rubisco consist of 8 large and 8 small subunits linked by noncovalent bonds. So Rubisco is more sensitive for aggregation as different subunit might dissociate from each other and tend to form aggregates. Thus, we hypothesize that aggregation is also influenced by size/complexity (Table 3.1) of the protein.

a)

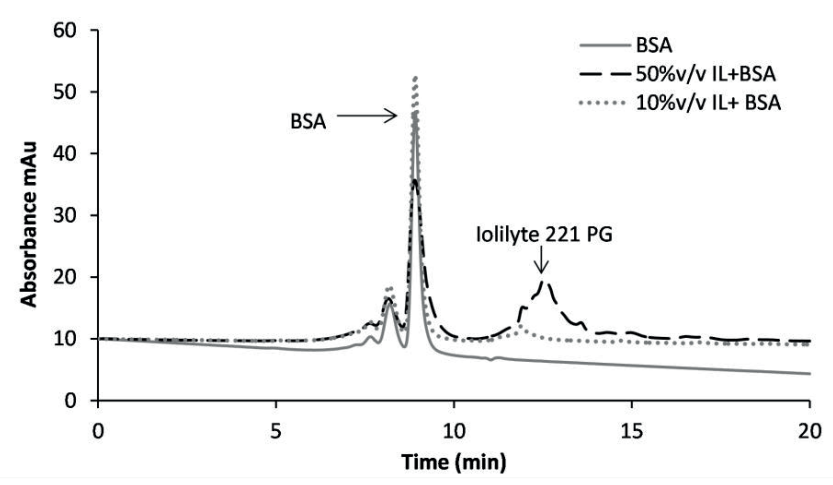


b)

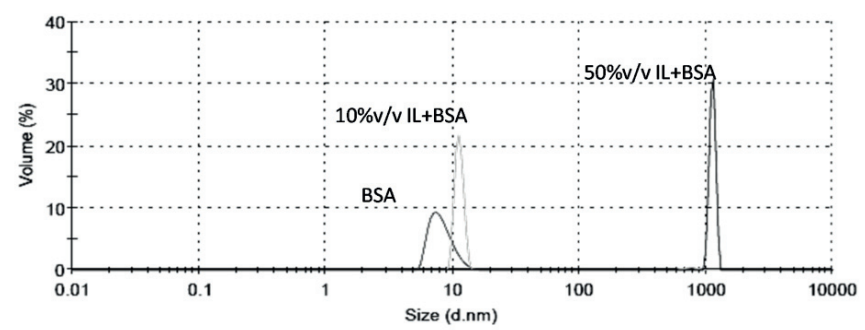

c)

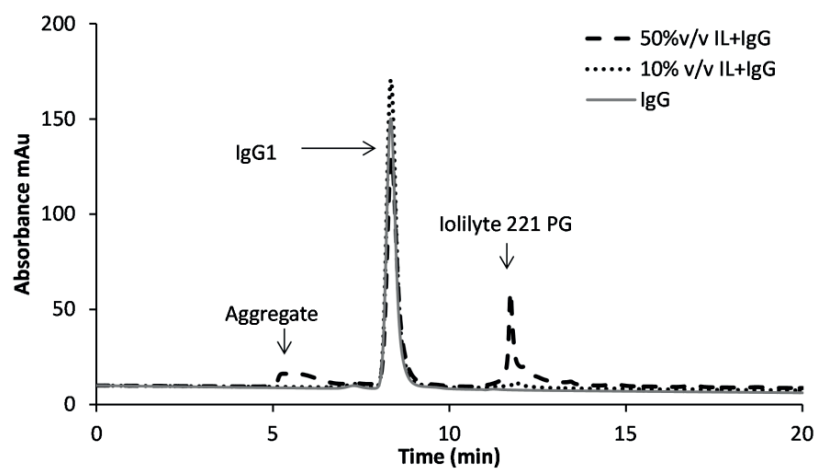

Figure 3.8 Effect of increasing concentration lolilyte 221 PG on (a) BSA-SEC HPLC chromatogram (b) BSADLS (c) IgG1-SEC-HPLC chromatogram

Additionally, the behaviour of the proteins was studied in phosphonium based ionic liquid, Cyphos 108. $\operatorname{IgG} 1$ and Rubisco precipitated with increasing concentration of ionic liquid whereas BSA remained in solution at all concentrations tested. As the concentration of Cyphos 108 was increased to 20\% v/v there is considerable decrease in the BSA peak intensity (Figure 3.9). However, increasing the concentration further from $30 \% \mathrm{v} / \mathrm{v}$ to $50 \% \mathrm{v} / \mathrm{v}$ there is increase in the BSA peak intensity. Simultaneous increase in the peak intensity at lower retention time $(\sim 5 \mathrm{~min})$ is also observed. This indicates the formation of high molecular weight species (aggregates). However, these results exhibit a complex behaviour and require advanced analysis for understanding the underlying phenomenon.

Among the two ionic liquids studied the phosphonium based ionic liquid, Cyphos 108 affects the protein structure more than lolilyte $221 \mathrm{PG}$. This could be attributed to the acidic nature of aqueous solution of Cyphos 108 which caused unfolding of protein and subsequent aggregation. The acidic nature of aqueous solution of Cyphos 108 is contributed by the anion methyl sulphate which is hydrolysed in water to produce $\mathrm{HSO}_{4}{ }^{-}$ion [35]. In a separate study on BSA in polymer based drug delivery system degradation in acidic microenvironment by aggregate formation and hydrolysis is reported [36]. Overall the preliminary studies on the three proteins shows that they retain the native form at low concentration of lolilyte 221 PG $\sim 10 \% \mathrm{v} / \mathrm{v}$. 


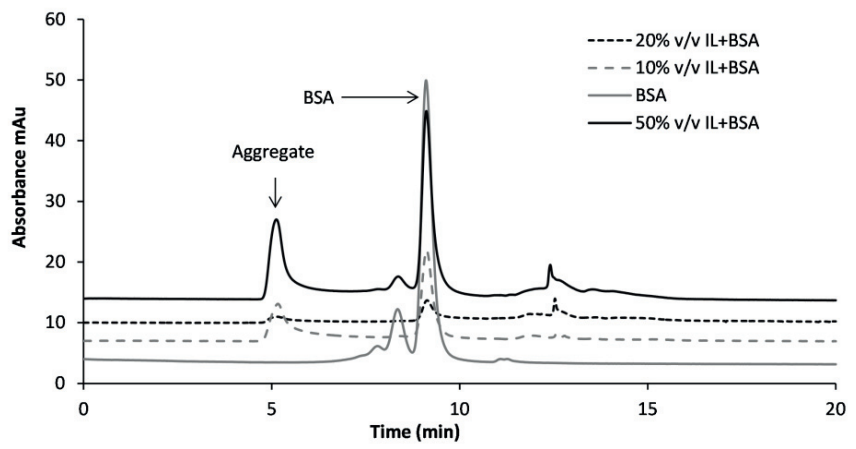

Figure 3.9 Size exclusion chromatography of BSA in increasing concentration Cyphos 108

\section{Conclusions}

The purpose of this study was to evaluate the extraction of a large complex protein; Rubisco in IL based ATPS and the stability of proteins (BSA, IgG1 and Rubisco) in aqueous ionic liquid solutions. Aqueous two phase extraction of Rubisco was investigated in PEG/Potassium citrate system and lolilyte 221 PG/Sodium-Potassium Phosphate system. The results demonstrate that ionic liquid based ATPS showed higher partitioning of Rubisco than PEG based system. However the SEC-HPLC studies shows lack of structural stability of Rubisco. This is further supported by the studies done in aqueous solution of lolilyte 221 PG. Similar studies on BSA and IgG1 in lolilyte 221 PG showed formation of aggregates at higher concentration of ionic liquid. BSA in aqueous Cyphos 108 solution formed aggregates and IgG1 and Rubisco were precipitated with increasing concentration.

The empirical findings in the study suggest that higher concentration of the ionic liquids tested, results in protein aggregation. The study also reveals that the size and complexity of the protein influences protein aggregation and subsequent stability in the ionic liquid. From the study done using Cyphos 108 it is evident that the anion also strongly influences the stability of protein. A careful selection of IL with respect to anion can help in designing an IL suitable for extracting protein biomolecules. The current investigation shows that the Rubisco is structurally and functionally stable at $\sim 10 \% \mathrm{v} / \mathrm{v}$ concentration of ionic liquid. Nevertheless it is important to understand that each IL is different and one size fits all does not apply. To summarize, these results help in understanding the behaviour of protein in high concentration of IL.

\section{Acknowledgements}

The authors would like to thank Technology Foundation STW (Project No 11410) and Institute for sustainable process technology (ISPT) for the financial support. 
Appendix

Table 1 ANOVA table for PEG/Potassium Citrate and lolilyte/Sodium Potassium Phosphate ATPS

\section{A. PEG/Potassium citrate buffer system}

\begin{tabular}{ccccccc}
\hline Response variable & Source & $D F$ & SS & MS (variance) & $F$ & $p$ \\
\hline $\mathrm{Y}_{1}\left(K_{p}\right)$ & Total & 25 & 21.8679 & 0.874716 & & \\
& Total Corrected & 24 & 0.295046 & 0.0122936 & & \\
& Regression & 10 & 0.251596 & 0.0251596 & 8.1066 & 0.000 \\
& Residual & 14 & 0.04345 & 0.003104 & & \\
& Lack of Fit & 12 & 0.039773 & 0.003314 & 1.80241 & 0.412 \\
& (Model Error) & & & & & \\
& Pure Error & 2 & 0.003678 & 0.001839 & & \\
& (Replicate Error) & & & & & \\
& Total & 25 & 41.0448 & 1.64179 & & \\
& Total Corrected & 24 & 1.16592 & 0.04858 & & \\
& Regression & 10 & 1.06163 & 0.106163 & 14.2511 & 0.000 \\
& $\quad$ Residual & 14 & 0.104293 & 0.007449 & & \\
& Lack of Fit & 12 & 0.100979 & 0.008415 & 5.07991 & 0.1760 \\
& (Model Error) & & & & & \\
\hline Pure Error & 2 & 0.003313 & 0.001657 & & \\
& (Replicate Error) & 2 & & & &
\end{tabular}

B. Iolilyte 221 PG/Sodium-Potassium Phosphate buffer system

\begin{tabular}{|c|c|c|c|c|c|c|}
\hline Response variable & Source & $D F$ & SS & MS (variance) & $F$ & $P$ \\
\hline \multirow[t]{6}{*}{$Y_{1}\left(K_{p}\right)$} & Total & 21 & 2.25375 & 0.107321 & \multirow{4}{*}{13.5559} & \multirow{4}{*}{0.000} \\
\hline & Total Corrected & 20 & 1.16974 & 0.0584869 & & \\
\hline & Regression & 9 & 1.07299 & 0.119222 & & \\
\hline & Residual & 11 & 0.0967427 & 0.00879479 & & \\
\hline & $\begin{array}{l}\text { Lack of Fit } \\
\text { (Model Error) }\end{array}$ & 9 & 0.0944359 & 0.0104929 & \multirow[t]{2}{*}{9.09748} & \multirow[t]{2}{*}{0.103} \\
\hline & $\begin{array}{c}\text { Pure Error } \\
\text { (Replicate Error) }\end{array}$ & 2 & 0.00230676 & 0.00115338 & & \\
\hline \multirow[t]{6}{*}{$Y_{2}\left(Y_{e}\right)$} & Total & 21 & 82.36 & 3.92191 & \multirow{4}{*}{14.0105} & \multirow{4}{*}{0.000} \\
\hline & Total Corrected & 20 & 0.00106812 & $5.34058 e-005$ & & \\
\hline & Regression & 9 & 0.000982413 & 0.000109157 & & \\
\hline & Residual & 11 & $8.570211 \mathrm{e}-005$ & $7.7911 \mathrm{e}-006$ & & \\
\hline & $\begin{array}{c}\text { Lack of Fit } \\
\text { (Model Error) }\end{array}$ & 9 & $8.3292 \mathrm{e}-005$ & $9.25466 \mathrm{e}-006$ & \multirow[t]{2}{*}{7.67977} & \multirow[t]{2}{*}{0.120} \\
\hline & $\begin{array}{c}\text { Pure Error } \\
\text { (Replicate Error) }\end{array}$ & 2 & $2.41014 \mathrm{e}-006$ & $1.20507 \mathrm{e}-006$ & & \\
\hline
\end{tabular}




\section{References}

1. Albertsson, P.-A., Partition of Proteins in Liquid Polymer-Polymer Two-Phase Systems. 1958. 182(4637): p. 709-711.

2. Huddleston, J., et al., The molecular basis of partitioning in aqueous two-phase systems. Trends in Biotechnology, 1991. 9(1): p. 381-388.

3. Schmidt, A.S., A.M. Ventom, and J.A. Asenjo, Partitioning and purification of $\alpha$-amylase in aqueous two-phase systems. Enzyme and Microbial Technology, 1994. 16(2): p. 131-142.

4. Asenjo, J.A., et al., Separation and purification of recombinant proteins from Escherichia coli with aqueous two-phase systems. J Chromatogr A, 1994. 668(1): p. 129-37.

5. Selber, K., et al., Large-scale separation and production of engineered proteins, designed for facilitated recovery in detergent-based aqueous two-phase extraction systems. Process Biochemistry, 2004. 39(7): p. 889-896.

6. Rosa, P.A.J., et al., Aqueous two-phase systems: A viable platform in the manufacturing of biopharmaceuticals. Journal of Chromatography A, 2010. 1217(16): p. 2296-2305.

7. Gutowski, K.E., et al., Controlling the aqueous miscibility of ionic liquids: aqueous biphasic systems of water-miscible ionic liquids and water-structuring salts for recycle, metathesis, and separations. J Am Chem Soc, 2003. 125(22): p. 6632-3.

8. Welton, T., et al., Inorganic Synthesis, in Ionic Liquids in Synthesis 2008 , Wiley-VCH Verlag GmbH \& Co. KGaA. p. 569-617.

9. Visser, A.E., et al., Task-specific ionic liquids for the extraction of metal ions from aqueous solutions. Chemical Communications, 2001(1): p. 135-136.

10. Sheldon, R.A., et al., Biocatalysis in ionic liquids. Green Chemistry, 2002. 4(2): p. 147-151.

11. Louros, C.L., et al., Extraction of biomolecules using phosphonium-based ionic liquids $+K(3) P O(4)$ aqueous biphasic systems. Int J Mol Sci, 2010. 11(4): p. 1777-91.

12. Dreyer, S. and U. Kragl, lonic liquids for aqueous two-phase extraction and stabilization of enzymes. Biotechnol Bioeng, 2008. 99(6): p. 1416-24.

13. Du, Z., Y.-L. Yu, and J.-H. Wang, Extraction of Proteins from Biological Fluids by Use of an lonic Liquid/Aqueous Two-Phase System. Chemistry-A European Journal, 2007. 13(7): p. 2130-2137.

14. Pei, Y., et al., Ionic liquid-based aqueous two-phase extraction of selected proteins. Separation and Purification Technology, 2009. 64(3): p. 288-295.

15. Zafarani-Moattar, M.T. and S. Hamzehzadeh, Partitioning of amino acids in the aqueous biphasic system containing the water-miscible ionic liquid 1-butyl-3-methylimidazolium bromide and the water-structuring salt potassium citrate. Biotechnol Prog, 2011. 27(4): p. 986-997.

16. Cláudio, A.F.M., et al., Extraction of vanillin using ionic-liquid-based aqueous two-phase systems. Separation and Purification Technology, 2010. 75(1): p. 39-47.

17. Dreyer, S., P. Salim, and U. Kragl, Driving forces of protein partitioning in an ionic liquid-based aqueous two-phase system. Biochemical Engineering Journal, 2009. 46(2): p. 176-185.

18. Shahriari, S., et al., Role of the Hofmeister series in the formation of ionic-liquid-based aqueous biphasic systems. J Phys Chem B, 2012. 116(24): p. 7252-8.

19. Bridges, N.J., K.E. Gutowski, and R.D. Rogers, Investigation of aqueous biphasic systems formed from solutions of chaotropic salts with kosmotropic salts (salt-salt ABS). Green Chemistry, 2007. 9(2): p. 177-183.

20. Barbeau, W.E. and J.E. Kinsella, Ribulose bisphosphate carboxylase/oxygenase (rubisco) from green leaves-potential as a food protein. Food Reviews International, 1988. 4(1): p. 93-127.

21. Wijffels, R.H. and M.J. Barbosa, An outlook on microalgal biofuels. Science, 2010. 329(5993): p. 796-9.

22. Vanthoor-Koopmans, M., et al., Biorefinery of microalgae for food and fuel. Bioresource Technology, 2012. 135: p. 142-149.

23. Lilley, R.M. and D.A. Walker, An improved spectrophotometric assay for ribulosebisphosphate carboxylase. Biochimica et Biophysica Acta (BBA) - Enzymology, 1974- 358(1): p. 226-229.

24. Ibarra-Herrera, C.C., O. Aguilar, and M. Rito-Palomares, Application of an aqueous two-phase systems strategy for the potential recovery of a recombinant protein from alfalfa (Medicago sativa). Separation and Purification Technology, 2011. 77(1): p. 94-98. 
25. Asenjo, J.A., et al., Model for predicting the partition behaviour of proteins in aqueous two-phase systems. Journal of Chromatography A, 1994. 668(1): p. 47-54.

26. Azevedo, A.M., et al., Partitioning of human antibodies in polyethylene glycol-sodium citrate aqueous two-phase systems. Separation and Purification Technology, 2009. 65(1): p. 14-21.

27. Ruiz-Angel, M.J., et al., Solvent systems for countercurrent chromatography: An aqueous two phase liquid system based on a room temperature ionic liquid. Journal of Chromatography $A$, 2007. 1151(1-2): p. 65-73.

28. Dreyer, S.E., Aqueous two phase extraction of proteins and enzymes using tetraalkylammoniumbased ionic liquids, 2008, University of Rostock.

29. Zafarani-Moattar, M.T. and S. Hamzehzadeh, Phase Diagrams for the Aqueous Two-Phase Ternary System Containing the lonic Liquid 1-Butyl-3-methylimidazolium Bromide and Tripotassium Citrate at $T=(278.15,298.15$, and 318.15$) \mathrm{K}$. Journal of Chemical \& Engineering Data, 2008. 54(3): p. 833-841.

30. Qiao, D., et al., Extraction optimized by using response surface methodology, purification and preliminary characterization of polysaccharides from Hyriopsis cumingii. Carbohydrate Polymers, 2009. 76(3): p. 422-429.

31. Weaver, K.D., et al., Structure and function of proteins in hydrated choline dihydrogen phosphate ionic liquid. Physical Chemistry Chemical Physics, 2012. 14(2): p. 790-801.

32. Micaelo, N.M. and C.M. Soares, Protein Structure and Dynamics in Ionic Liquids. Insights from Molecular Dynamics Simulation Studies. The Journal of Physical Chemistry B, 2008. 112(9): p. 2566-2572.

33. Takekiyo, T., et al., High Ionic Liquid Concentration-Induced Structural Change of Protein in Aqueous Solution: A Case Study of Lysozyme. The Journal of Physical Chemistry B, 2012. 116(36): p. 11092-11097.

34. Baker, G.A. and W.T. Heller, Small-angle neutron scattering studies of model protein denaturation in aqueous solutions of the ionic liquid 1-butyl-3-methylimidazolium chloride. Chemical Engineering Journal, 2009. 147(1): p. 6-12.

35. Cui, X., et al., The Influence of the Acidity of Ionic Liquids on Catalysis. ChemSusChem, 2010. 3(9): p. 1043-1047.

36. Estey, T., et al., BSA degradation under acidic conditions: A model for protein instability during release from PLGA delivery systems. Journal of Pharmaceutical Sciences, 2006. 95(7): p. 16261639 . 


\section{Chapter 4}

\section{Mild separation concept for functional biomolecules using IL based emulsions}

Submitted as

Rupali K. Desai, Heléne Monteille, Xiaohua Li Boelo Schuur, J. Mieke Kleijn, Frans A. M. Leermakers, Joris Sprakel, René H. Wijffels, and Michel H. M. Eppink' Mild separation concept for functional biomolecules using IL based emulsions 


\section{Abstract}

Fractionation of complex matrices such as biomass (e.g. microalgae) into diverse functional (fragile) biomolecules using a biorefinery concept without disrupting the biomolecules functionalities is a real challenge. Separation of diverse functional (fragile) biomolecules from complex matrices such as biomass (e.g. microalgae) in a biorefinery concept is a real challenge. Known separation processes are designed for single product recovery such as hydrophilic proteins or hydrophobic pigments, discarding the other products as waste. Here we present a novel process for separation of hydrophobic and hydrophilic biomolecules from complex matrices such as microalgae using an ionic liquid-based emulsion stabilised by microgel particles in one step while keeping product integrity. The pigments are extracted in the hydrophobic ionic liquid core and proteins in the aqueous continuous phase. In contrary to most solvent extraction procedures, with this procedure, the proteins retain their nativity opening up an extractive pathway to fully functioning proteins. A perspective towards continuous separation of this novel concept is also presented. 


\section{Introduction}

Two-phase systems have long being exploited for separation and purification of biomolecules in chemical and biotech industries. Liquid-liquid extraction techniques such aqueous two-phase systems have been used for primary isolation and separation of water soluble molecules such as proteins [1] whereas, water-organic solvent-based two-phase systems have been used for extraction of hydrophobic molecules such as pigments, lipids, small molecules, etc $[2,3]$. Despite advantages, these techniques are focussed on recovery of single components. For a truly biobased economy complete utilization of biomass is needed, which is, depending on the type of biomass, a valuable source of phenols, alkaloids, proteins, pigments and lipids. Moreover, product value needs to be protected without degrading fragile biomolecules such as proteins towards low value products. For complete utilization of biomass it is necessary to separate the components within a biorefinery concept into hydrophilic and hydrophobic components before further fractionation [4]. In conventional processes such as biphasic systems using organic solvents, the water-insoluble biomolecules such as pigments, fats and lipids can be recovered. However, these solvents may affect the structure and functionality of water-soluble biomolecules like proteins and enzymes [5, 6]. Therefore, it is of high importance to develop novel techniques and methods that facilitate simultaneous extraction of hydrophobic components (e.g. lipids, pigments) and hydrophilic (fragile) biomolecules from biomass without influencing their functionality and retaining the high value.

Emulsion-based separation systems could provide a solution for simultaneous extraction of biomolecules from biomass. These systems are formed by dispersion of one immiscible liquid in another liquid phase and kinetically stabilised by surfactants [7]. They have been used for both food and cosmetics as well as for separation of biomolecules, in most cases focusing on the isolation of a single product. Reversed micelles, a water-in-organic solvent microemulsion, have been used to extract proteins and enzymes [8]. A disadvantage is the poor back extraction of biomolecules from the hydrophilic core [9] damaging the product as well.

Recently there is a growing interest in ionic liquid (IL) based emulsions and microemulsions [10], due to the unique properties of ILs such as tunability [11] and negligible vapour pressure. ILs are liquid salts at temperatures below $100^{\circ} \mathrm{C}$ and composed of ions. ILs are potential candidates for extraction [12] and pre-treatment processes [13]. There are very few studies on the use of IL-based microemulsions as extraction media [14, 15]. Chen et.al. [14] have studied the extraction of herbal compounds with different polarities using such a microemulsion. The system described however is suitable only for analytical purposes and cannot be used for large scale application. In another study [15], a dual ionic liquid-based microemulsion, wherein one IL is a surfactant and other as a substitute for organic solvent, was used for selective extraction of haemoglobin from whole blood, yet again single product recovery. This article describes the simultaneous separation and extraction of hydrophobic and hydrophilic components from biomass using an ionic liquid emulsion stabilised by polyNIPAm microgel particles. 
For this purpose microalgal biomass is used as an example. Apart from being a potential source for biofuels, microalgal biomass contains other value added components such as proteins, pigments and carbohydrates. In this article we show by gel electrophoresis that the major hydrophilic component, i.e. the protein Rubisco retains its native conformation. In addition, the possibility of continuous processing using IL-based emulsions is discussed.

\section{Materials and Methods}

\section{Materials}

The ionic liquid Cyphos 109 (trihexyl(tetradecyl)phosphonium bistriflamide, purity 98\%) was ordered from lolitec and used without prior treatment. Poly-NIPAM microgel particles were synthetized and characterized as described previously [16]. Spray dried Haematococcus pluvialis cells were provided by Feyecon B.V (Weesp, Netherlands). N-isopropylacrylamide (NIPAm), N,N-methylbisacrylamide (BIS), methacrylic acid (MA), potassium persulfate (KPS), styrene, sodium dodecyl sulphate (SDS) and phosphoric acid were purchased from Sigma Aldrich. Organic solvents such as methanol, tertiary methyl butyl ether and acetone were also purchased from Sigma Aldrich. Standard astaxanthin ( 97\% purity) was purchased from Ehrenstorfer $\mathrm{GmBH}$. Milli $\mathrm{Q}$ water was used for all studies. The material for electrophoresis was bought from Biorad and the staining kit was purchased from Thermo Fisher Scientific.

\section{Methods}

\section{Preparation and separation using microgel stabilised emulsion}

The microgel-stabilized emulsion is prepared by diluting a stock solution of microgel particles $(23 \mathrm{~g} / \mathrm{l})$ to the desired concentration with Milli-Q water and an aqueous cell suspension (disrupted cells) and then adding it to the ionic liquid. The cell loading of the aqueous phase was kept constant at $15 \mathrm{~g} / \mathrm{l}$ for all studies. Two ratios of aqueous phase to IL phase (1:9 and 3:7) and two concentrations of microgel particles in the aqueous phase $(0.5 \mathrm{~g} / \mathrm{l}$ and $1 \mathrm{~g} / \mathrm{l})$ were investigated. These ratios were selected as they are within the working window of the emulsion i.e. 1:9 to $4: 6$. Outside this range the emulsion is not stable. The samples were mixed by using a vortex tube shaker to facilitate separation of proteins and pigments in the aqueous and IL phase respectively. The separation of hydrophilic and hydrophobic components from the cells was determined after different mixing times ( 1 - 180 minutes). The emulsion was broken by centrifugation at $5000 \mathrm{rpm}$ for 5 minutes. The aqueous phase was analysed for protein content and the IL phase for pigment content. The measurements are done in duplicate and for continuous studies one sample was taken for each time point.

\section{Protein analysis}

After breaking the emulsion, the aqueous phase is analysed for total soluble protein content. The supernatant of disrupted $H$. Puvialis cells in water was analysed for total soluble protein as control. 
Protein content was determined with a commercial assay kit (DC ${ }^{\text {TM }}$ Protein assay, Bio-Rad, U.S.) using bovine serum albumin (Sigma-Aldrich A7030) as protein standard. The microplate assay protocol was used and the absorbance was measured at $750 \mathrm{~nm}$ using a microplate reader (Infinite M200, Switzerland)). The protein is expressed as the percentage of total protein in the cells:

$$
\% \text { of Total protein }=\left(\frac{\text { Total soluble protein in aq. phase of emulsion }}{\text { Total soluble protein in cell }}\right) \times 100
$$

\section{Gel electrophoresis}

The conformation of the proteins after separation using the IL-in-water emulsion was checked by gel electrophoresis. The aqueous phase was diluted 1:1 with native sample buffer. About $25 \mu$ of the diluted sample was then applied on 4-20\% Criterion TGX, Tris glycine precast gel and run with 10x Tris glycine native buffer at $125 \mathrm{~V}$ for 75 minutes. The gel was stained using a Pierce ${ }^{\mathrm{TM}}$ Silver Stain Kit.

Pigment analysis

The pigment content in the IL phase was analysed by HPLC using a Thermo Scientific system coupled with DAD-Dionex 3000. Chromeleon software version 7 was used for controlling the system and for data acquisition. The method used is adapted from Fuji Chemical Industry Co., LTD, (http://www.fujihealthscience.com/assay-method_astareal-l10.pdf). The samples were analysed using an YMC carotenoid column of $4.6 \times 250 \mathrm{~mm}, 5 \mu$. A gradient program was run as shown in Table 4.2 using a ternary mobile phase comprising of methanol, tertiary methyl butyl ether and $1 \% \mathrm{v} / \mathrm{v}$ phosphoric acid. The flow rate was set at $1 \mathrm{ml} / \mathrm{min}$ and the detection was performed at a $\lambda_{\max }$ of 480 $\mathrm{nm}$. The column temperature was set at $35^{\circ} \mathrm{C}$. A calibration curve in the concentration range of $1-11$ $\mu \mathrm{g} / \mathrm{ml}$ was obtained to determine the amount of astaxanthin in the samples. The standards were run in duplicate. The samples were diluted using acetone.

Table4.2: HPLC gradient program

\begin{tabular}{cccc}
\hline $\begin{array}{c}\text { Time } \\
(\text { min) }\end{array}$ & Methanol & $\begin{array}{c}\text { Tertiary } \\
\text { methyl } \\
\text { butyl ether }\end{array}$ & $\begin{array}{c}1 \% \text { v/v } \\
\text { Phosphoric } \\
\text { acid }\end{array}$ \\
\hline 0 & 81 & 15 & 4 \\
15 & 66 & 30 & 4 \\
23 & 16 & 80 & 4 \\
27 & 16 & 80 & 4 \\
27.1 & 81 & 15 & 4 \\
35 & 81 & 15 & 4 \\
\hline
\end{tabular}




\section{Results and Discussion}

\section{Separation using emulsion}

The potential of the microgel-stabilized IL emulsion to separate the hydrophilic and hydrophobic components from microalgae biomass was investigated. Cell suspension of broken H. Pluvialis cells and microgel particles was added to IL and vortexed for different time intervals up to 180 minutes. Samples were taken after different mixing times and analysed for protein and pigment content showing the efficiency of extraction. It was observed that the pigments are extracted in the discontinuous IL phase (Figure 4.1) and subsequent analysis of the aqueous phase confirmed accumulation of proteins in the continuous aqueous phase. These results confirm the separation of hydrophilic and hydrophobic components in a single step.

Some of the key factors influencing the extraction efficiency of these components were investigated: the microgel particle concentration and the ratio of IL to aqueous phase. It is observed that as the relative amount of IL is increased from 1:9 to 3:7, the amount of astaxanthin extracted after 180 minutes increases from $52 \%$ to $62 \%$ of the total astaxanthin present in the cells (Figure 4.2). In our previous studies [17] we have shown that the microgel particles stabilises the IL water interface. These particles consist of a porous polymer network and allow free transport of molecules across the interface. Increasing the microgel particle concentration from $0.5 \mathrm{~g} / \mathrm{l}$ to $1 \mathrm{~g} / \mathrm{l}$ leads to an increase in the extraction efficiency of the pigment up to 120 minutes (Figure 4.3). This can be explained by an increase in the total interface between the water and IL phases, which speeds up the separation process.

Almost all soluble proteins remain in the aqueous phase (Figure 4.4) for all concentration and ratios studied. Additionally, the nativity of the proteins after the separation process was investigated using native gel electrophoresis. As seen in Figure 4.5, the band for the biomarker protein Rubisco (Ribulose1, 5-biphosphate carboxylase oxygenase), which is the main protein in the microalgae, is intact and the protein is not broken into its subunits (non-covalently linked 8 large sub units of 55 kDa each and 8 small subunits of $13 \mathrm{kDa}$ each) indicating that the proteins are not denatured in the process of separation.

The extraction efficiency of astaxanthin is lower compared to conventional solvent extractions methods [2] and can be attributed to mass transfer limitation as the pigment has to be extracted from the cells and move across the microgel particles to the IL phase where it is soluble. However, the extraction could be optimised further by modifying biomass loading, using a monodisperse emulsion, use of another IL, etc. The results demonstrate the feasibility of using microgel-stabilised IL emulsions for separating hydrophilic and hydrophobic components from a complex matrix such as microalgal biomass and simultaneously retaining the functionality of separated components 
a)

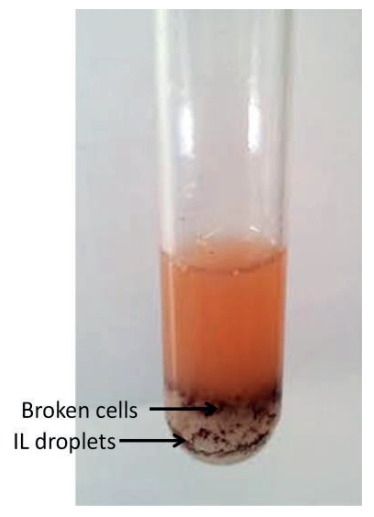

b)

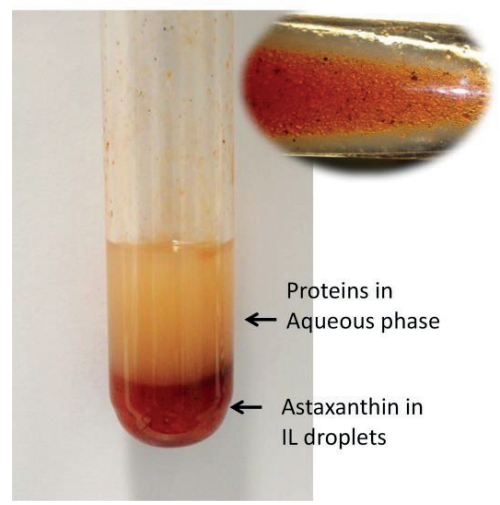

Figure 4.1 Emulsion containing H.Pluvialis cell suspension a) Before mixing b) After mixing the emulsion; aq phase and IL droplets containing proteins and astaxanthin respectively; (inset) is the macroscopic picture of $\mathrm{IL}$ droplets formed in the emulsion

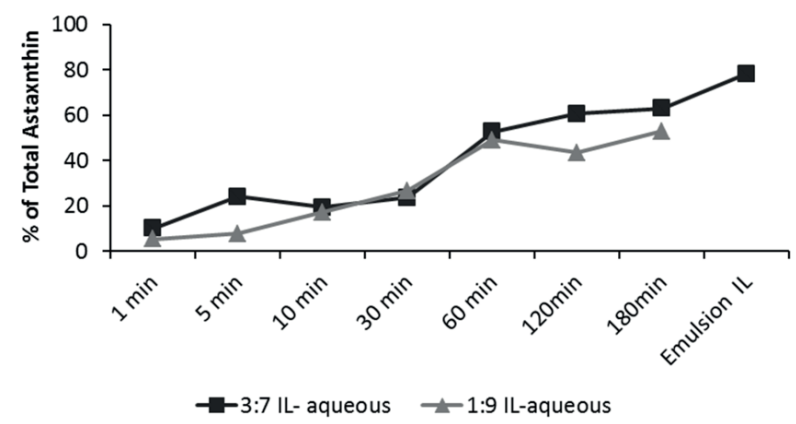

Figure 4.2 Effect of IL-aqueous phase ratio at microgel concentration of $0.5 \mathrm{~g} / \mathrm{l}$ on astaxanthin extraction efficiency

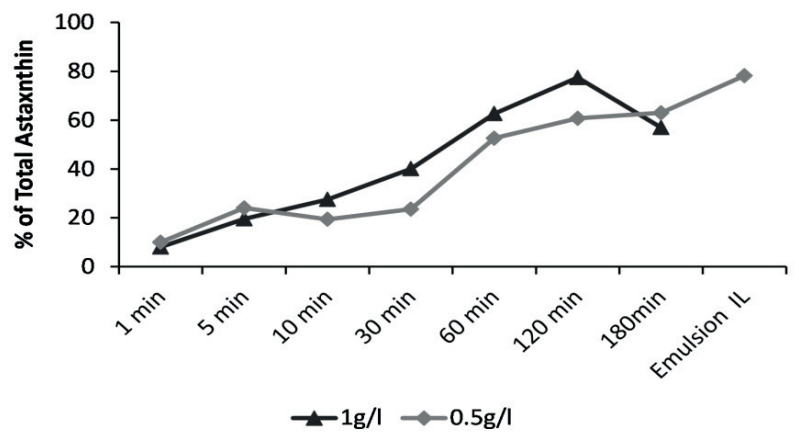

Figure 4.3 Effect of microgel particle concentration at IL: aqueous ratio of 3:7 on astaxanthin extraction efficiency 


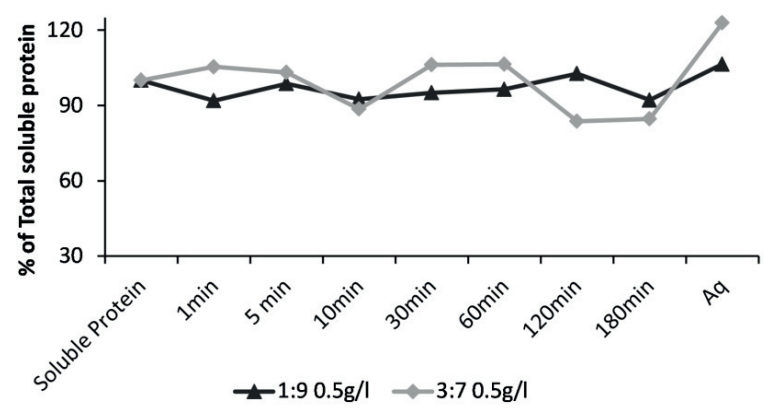

Figure 4.4 Effect on extraction yield of total soluble protein with IL: aqueous ratios of 1:9 and 3:7 at microgel particle concentration of $0.5 \mathrm{~g} / \mathrm{L}$

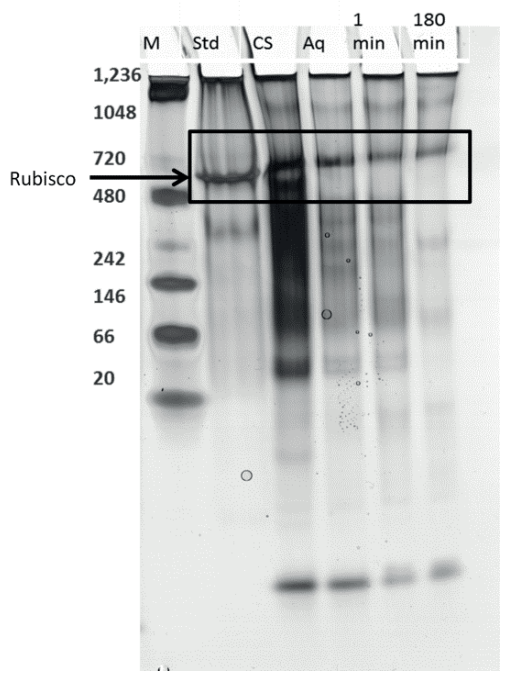

Figure 4.5 Gel electrophoresis (native): M- Molecular weight marker, Std-Rubisco standard, CS- control sample supernatant after cell disruption, Aq-aqueous phase of emulsion before adding ionic liquid containing the disrupted cells in the same amount as the samples and 1min - aqueous phase after 1 min mixing and 180 min - aqueous phase after 180 min mixing.

\section{Continuous extraction process}

A continuous process is preferred over a batch system, primarily because it is less time consuming. As a proof of concept for the use of microgel-stabilized IL emulsions in a continuous separation process, a test run was made using the setup depicted in Figure 4.6. The flow rates were set such that the ratio of the IL phase to the water phase in the mixing vessel is $3: 7$. The cell suspension was mixed with the aqueous microgel solution under magnetic stirring and was equilibrated for initial 30 minutes followed by running in continuous mode until 10ominutes. Samples were taken from the vessel at different time intervals, centrifuged to break the emulsion and finally analysed. It was observed that astaxanthin extraction efficiency was $\sim 45 \%$ and that the protein content was $\geq 85 \%$ (see Figure 4.7 ) after 30 minutes 
and comparable to the batch experiment with similar residence time. However, further improvements in the set-up such as use of different static mixers, would help by increasing the contact time between the phases and thus improving the mass transfer rates. Additionally, the separation between the phases can be enhanced by using temperature controlled settler since the polyNIPAm particles collapse at temperatures higher than $32^{\circ} \mathrm{C}$, which promotes the breaking of emulsion [17].

a

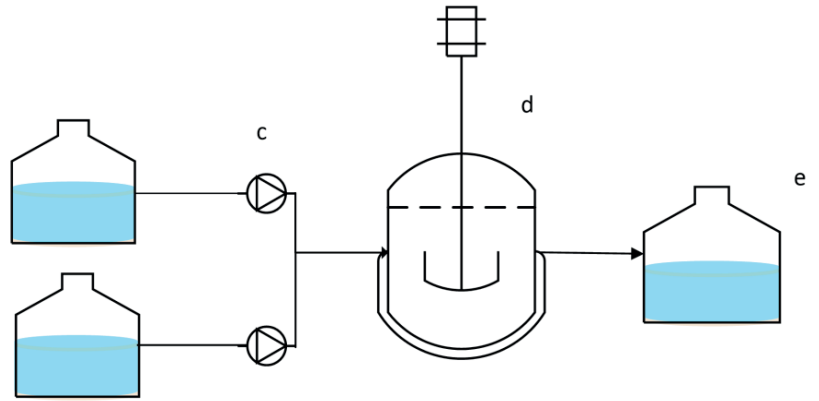

Figure 4.6 Schematic of continuous set up: a) Ionic liquid- Cyphos 109; b) Cell suspension + Microgel particles; c) Peristaltic Pump; d) Mixing vessel; e) Collection Tank

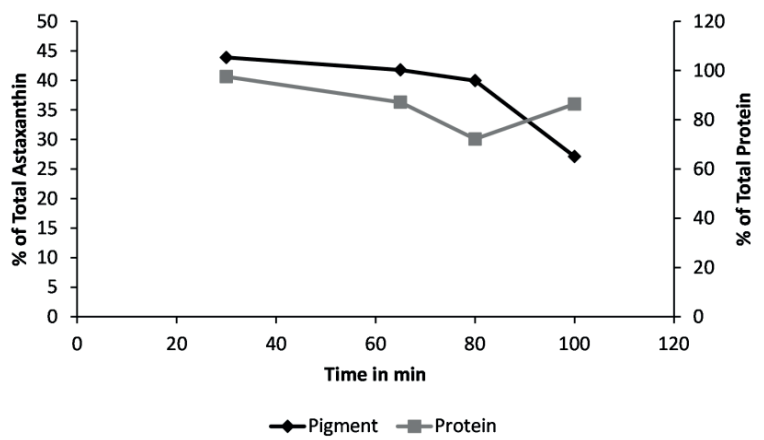

Figure 4.7 Extraction yields of astaxanthin and proteins in continuous set-up

\section{Conclusion}

The potential of microgel-stabilised IL-in-water emulsions for simultaneous separation of hydrophilic and hydrophobic components from a complex matrix was investigated in this work using microalgal biomass as an example. The hydrophobic pigment, astaxanthin from H.Pluvialis cracked cells is extracted in the IL droplets and the proteins remain in the continuous aqueous phase of the emulsion. The astaxanthin extraction efficiency obtained in the process was $\sim 62 \%$ and that of proteins in aqueous phase is $\geq 80 \%$. The proteins recovered in the aqueous phase remained in their native state after separation, which is not the case for other methods such as alkaline or solvent extraction which lead to denaturation. A perspective and approach for continuous processing is also presented. Indeed further optimization studies would be needed to improve process kinetics and economics. The system provides a promising novel alternative not only for separation of diverse biomolecules from complex matrix but 
could be extended for analytical applications as well. Future research should thus be concentrated on separation of biomolecules from complex matrix and finding newer application of this system. 


\section{Supplementary information}

Characterisation of Core shell microgel particles

The core as well as the core-shell microgels were characterized by dynamic light scattering:

$\mathrm{Rh}$ (cores) $=60 \mathrm{~nm}$

$\mathrm{Rh}$ (core shell microgels) $=365 \mathrm{~nm}$

The emulsion is polydisperse and the droplets are 100-200 $\mu$ in size 


\section{References}

1. Albertsson, P.-A., Partition of Proteins in Liquid Polymer-Polymer Two-Phase Systems. Nature, 1958. 182(4637): p. 709-711.

2. Yin, C., et al., Efficient Extraction of Astaxanthin from Phaffia rhodozyma with Polar and Nonpolar Solvents after Acid Washing. Chinese Journal of Chemical Engineering, 2013. 21(7): p. 776780.

3. Cuellar-Bermudez, S.P., et al., Extraction and purification of high-value metabolites from microalgae: essential lipids, astaxanthin and phycobiliproteins. Microbial Biotechnology, 2015. 8(2): p. 190-209.

4. Vanthoor-Koopmans, M., et al., Biorefinery of microalgae for food and fuel. Bioresource Technology, 2012. 135: p. 142-149.

5. Wu, Y.V. and G.E. Inglett, Denaturation of plant proteins related to functionality and food applications. A Review. Journal of Food Science, 1974. 39(2): p. 218-225.

6. Klibanov, A.M., Why are enzymes less active in organic solvents than in water? Trends in Biotechnology, 1997. 15(3): p. 97-101.

7. Burguera, J.L. and M. Burguera, Analytical applications of emulsions and microemulsions. Talanta, 2012. 96: p. 11-20.

8. Luisi, P.L., et al., Reverse micelles as hosts for proteins and small molecules. Biochimica et Biophysica Acta (BBA) - Reviews on Biomembranes, 1988. 947(1): p. 209-246.

9. Melo, E.P., M.R. Aires-Barros, and J.M.S. Cabral, Reverse micelles and protein biotechnology, in Biotechnology Annual Review2001, Elsevier. p. 87-129.

10. Qiu, Z. and J. Texter, Ionic liquids in microemulsions. Current Opinion in Colloid \& Interface Science, 2008. 13(4): p. 252-262.

11. Freemantle, M., Designer Solvents. Chemical \& Engineering News Archive, 1998. 76(13): p. 3237.

12. Rogers, R.D. and K.R. Seddon, Chemistry. Ionic liquids--solvents of the future? Science, 2003. 302(5646): p. 792-3.

13. Rosatella, A.A. and C.A.M. Afonso, CHAPTER 2 The Dissolution of Biomass in lonic Liquids Towards Pre-Treatment Approach, in lonic Liquids in the Biorefinery Concept: Challenges and Perspectives 2016, The Royal Society of Chemistry. p. 38-64.

14. Chen, J., et al., Environmentally friendly ionic liquid-in-water microemulsions for extraction of hydrophilic and lipophilic components from Flos Chrysanthemi. Analyst, 2013. 138(20): p. 59335941.

15. Mao, Q.-X., et al., A dual-ionic liquid microemulsion system for the selective isolation of hemoglobin. RSC Advances, 2014. 4(16): p. 8177-8182.

16. Monteillet, H., et al., Ultrastrong Anchoring Yet Barrier-Free Adsorption of Composite Microgels at Liquid Interfaces. Advanced Materials Interfaces, 2014. 1(7): p. n/a-n/a.

17. Monteillet, H., et al., Multi-responsive ionic liquid emulsions stabilized by microgels. Chem Commun (Camb), 2014. 50(81): p. 12197-200. 
Section II

Pre-treatment using ionic liquids 


\section{Chapter 5}

\section{Novel astaxanthin extraction from Haematococcus pluvialis using cell permeabilising ionic liquids}

This chapter has been published as:

Rupali K. Desai, Mathieu Streefland, Rene H. Wijffels and Michel H.M. Eppink (2016) Novel astaxanthin extraction from Haematococcus pluvialis using cell permeabilising ionic liquids 
Abstract

Haematococcus pluvialis ( $H$. pluvialis) is a natural source of the food colorant astaxanthin. It is characterised by a thick resistant cell wall composed of a non-hydrolysable biopolymer, sporopollenin. High energy-consuming mechanical disruption is required to improve the extractability of astaxanthin. Opposed to that, this study uses a novel technology with ionic liquids (ILs) to permeabilise the Haematococcal cyst cell under mild conditions of temperature and improve the extraction of astaxanthin. The study shows that $\geq 70 \%$ astaxanthin can be extracted from intact $\mathrm{H}$. pluvialis cells using 1-ethyl-3methylimidazolium di-butylphosphate (EMIM DBP) at a concentration of $40 \% \mathrm{w} / \mathrm{w}$ in a water solution and temperature of $45^{\circ} \mathrm{C}$. Ionic liquids serve as a promising pre-treatment step for extraction of pigments from intact $H$. pluvialis cells. The results obtained opens new avenues for processing of algal biomass. 


\section{Introduction}

Besides being a promising source for biofuels, microalgae also contain high value products such as pigments, carbohydrates and proteins. H. pluvialis, an unicellular green microalgae is a natural source of astaxanthin (3,3'dihydroxy- $\beta, \beta^{\prime}$-carotene-4,4'-dione). Astaxanthin a red-orange ketocarotenoid, is widely used as colour additive in aquaculture and in cosmetics. Astaxanthin also has antioxidant properties which have potential health benefit in animals and humans $[1,2]$. All this combined with high market value drives the research in astaxanthin production and particularly from natural sources such as algae, yeast and crustacean by-products [3].

H. pluvialis forms non-motile aplanospores or resting cells under nutritional limitations or environmental stress. Astaxanthin accumulates in these cells as a mixture of mono and di-esters under growth limiting conditions [4-6] and can constitute up to $1-5 \%$ of the alga's dry weight $[7,8]$. The thick cell wall increases the mechanical and chemical resistance of the cell, which necessitates the use of mechanical rupture of the cell to extract the astaxanthin. In aquaculture, $H$. pluvialis is used as feed supplement for improving the colour of salmons and crustacean species to obtain a better market price for these products. Ruptured cells are preferred over intact cells as the latter do not cause pigmentation.

In order to optimally utilize all these algal components, a versatile biorefinery approach for microalgae is urgently needed. One of the major bottlenecks in setting up an algal biorefinery process are the high costs involved due to energy-intensive unit operations [9]. Usually mechanical cell disruption methods such as bead milling or high pressure homogenisation are used. Reducing energy consumption in this step would improve the overall process economics.

In this paper we demonstrate that a possible solution for this is the use of ionic liquids in the extraction process. Ionic liquids (ILs) are salts composed of loosely held anions and cations and, unlike inorganic salts, are liquid over a wide range of temperatures. Ionic liquids have been widely studied as extracting agents and as replacements of organic solvents in various applications such as extraction of metals, alkaloids, proteins, etc. [10-12]. Recently, ILs have also been used to dissolve algae biomass at temperatures above $100^{\circ} \mathrm{C}[13]$ and together with co-solvents such as methanol [14, 15]. Sun A Choi et al. [16] showed that lipid could be extracted from microalgae using a blend of different ILs. Task specific ILs in combination with ultrasonication has been used to extract astaxanthin from shrimp waste [17]. Del Sesto et. al.[18] studied the extraction of botryococcenes and isoprenoids using immiscible ILs as extracting agents. Most of these studies focus on the use of ILs as an extracting agent. Teixeira [13] has nicely depicted complete hydrolysis of Chlorella and Neochloris algae cells to its constituents using ILs. However, high temperatures above $100^{\circ} \mathrm{C}$ are needed which could have an effect on protein and carbohydrate recovery. Different chemical, physical and mechanical methods for disruption of $H$. pluvialis have been studied [19]. The studies done by Mendes-Pinto [19] showed that mechanical disruption (e.g. homogenisation) and autoclave treatment are very effective in cell disruption and 
subsequent extraction of astaxanthin. Safi and co-workers [20] studied the extraction of protein using different disruption methods from microalgae including $H$. pluvialis. The study also showed that high pressure disruption of the cell yielded most of the proteins from $H$. pluvialis.

Most of the studies mentioned above for extraction of astaxanthin from $H$. pluvalis involve high energy input such as high temperature (above $100^{\circ} \mathrm{C}$ ) and pressure. In this paper we propose the possibility of using ILs as permeabilising agents for thick cell wall $H$. pluvialis under mild conditions. Several ILs were tested for their ability to permeabilise the cells under mild temperatures (below $100^{\circ} \mathrm{C}$ ) and subsequently extract astaxanthin using ethyl acetate (EA). We demonstrate efficient extraction of astaxanthin from $H$. pluvialis without any mechanical cell disruption. This article underlines the potential of using ILs as pre-fractionation of micro algal cells for selective intracellular product recovery.

\section{Experimental}

\section{Materials}

Dried H. pluvialis intact cells were provided by Feyecon (Weesp, The Netherlands). The cells were spray dried and the astaxanthin content was $\sim 3.2 \%$. The ionic liquids (purity above 95\%) used were procured from Iolitec and Sigma and were used without further purification (Table 5.1). Three classes of ILs were used for the study; imidazolium, ammonium and phosphonium. The imidazolium IL were selected such that Sr. No. 1,3 and 4 (see table 5.1) varied in the anion but cation was the same and Sr. No. 1 and2 (see Table 5.1) have the same anion and different cation. Organic solvents and chemicals used in the study, ethyl acetate, methanol, tertiary methyl butyl ether, and phosphoric acid were purchased from Sigma. Standard astaxanthin ( 97\% purity) was bought from Ehrenstorfer $\mathrm{GmBH}$.

Table 5 1: List of lonic liquids used in the study

\begin{tabular}{lll}
\hline Sr. No. & Ionic Liquid Names & Abbreviations \\
\hline 1 & 1-Butyl-3-methylimidazolium dibutylphosphate & BMIM DBP \\
2 & 1-Ethyl-3-methylimidazolium dibutylphosphate & EMIM DBP \\
3 & 1-Butyl-3-methylimidazolium acetate & BMIM Acetate \\
4 & 1-Butyl-3-methylimidazolium Dicynamide & BMIM DCA \\
5 & Iolilyte 221 PG & - \\
6 & Tributylmethylphosphonium methyl sulfate (Cyphos 108) & TBP SO4 \\
7 & Triisobutylmethylphosphonium tosylate (Cyphos 106) & TBP TOS \\
\hline
\end{tabular}

\section{Permeabilisation/Pre-Treatment with Ionic Liquid}

Dried $H$. pluvialis cells ( $10 \mathrm{mg}$ ) were treated with $2.1 \mathrm{ml}$ of IL at different temperatures, $25^{\circ} \mathrm{C}, 45^{\circ} \mathrm{C}, 55^{\circ} \mathrm{C}$ and $65^{\circ} \mathrm{C}$ for 90 minutes. The ionic liquid was separated from the cells by centrifuging the cells at 3000 rpm for 10 minutes to ensure complete separation of the ionic liquid. The IL treated cells were further 
treated with $2 \mathrm{ml}$ of ethyl acetate and mixed in a tube rotator for 1 hour. Ethyl acetate was separated and cells were treated with fresh $2 \mathrm{ml}$ of ethyl acetate for an additional 1 hour. The ethyl acetate layer was pooled and evaporated under $\mathrm{N}_{2}$. The extent of cell permeability was determined by measuring the amount of astaxanthin extracted. The extracted astaxanthin was then re-suspended and diluted with methanol and analysed by HPLC. The IL layer was diluted with methanol and analysed by HPLC for astaxanthin content. Different IL concentrations (IL-water) $80 \%, 60 \%$ and 40\% w/w were studied. The control sample was prepared by breaking the cells using bead beater followed by extraction with chloroform - methanol.

\section{HPLC analysis}

HPLC analysis was performed using a Thermo Scientific system coupled with DAD (Dionex 3000). Chromeleon software version 7 was used for controlling the system and for data acquisition. The samples were analysed using YMC carotenoid column $4.6 \times 250 \mathrm{~mm}, 5 \mu$. A ternary mobile phase comprising of methanol, tertiary methyl butyl ether and $1 \% \mathrm{v} / \mathrm{v}$ phosphoric acid was used. The flow rate was set at $1 \mathrm{ml} / \mathrm{min}$ and the detection was done at a $\lambda_{\max } 480 \mathrm{~nm}$. The column temperature was set at $35^{\circ} \mathrm{C}$. The gradient program used is described in Table 5.2 (adapted from Fuji Chemical Industry Co., LTD, http://www.fujihealthscience.com/assay-method_astareal-l10.pdf). A calibration curve in concentration range of $1-11 \mu \mathrm{g} / \mathrm{ml}$ was prepared to determine the amount of astaxanthin in the samples. The standards were run in duplicate.

Table 5.2: HPLC Gradient Program

\begin{tabular}{cccc}
\hline $\begin{array}{c}\text { Time } \\
\text { (min) }\end{array}$ & Methanol & $\begin{array}{l}\text { Tertiary } \\
\text { methyl } \\
\text { butyl ether }\end{array}$ & $\begin{array}{l}\text { 1\% v/v } \\
\text { Phosphoric } \\
\text { acid }\end{array}$ \\
\hline 0 & 81 & 15 & 4 \\
15 & 66 & 30 & 4 \\
23 & 16 & 80 & 4 \\
27 & 16 & 80 & 4 \\
27.1 & 81 & 15 & 4 \\
35 & 81 & 15 & 4 \\
\hline
\end{tabular}

Light Microscopy and Surface electron microscopy (SEM)

H. pluvialis cells after treatment with IL were observed under the light microscope (Olympus) with 6oX magnification. IL treated and non-treated cells were analysed at $2 \mathrm{kV}$ at room temperature in a field emission electron microscope (Magellan 400, FEl, and The Netherlands) and the images were digitally recorded. The samples were glued on sample holders by carbon adhesives tabs and subsequently sputter coated with 1onm Iridium (MED 020, Leica, Austria).

\section{Reusability of ionic liquid}

After pre-treatment of the $H$. Pluvialis cells with ionic liquid, the IL was separated by centrifugation. The IL was then tested for presence of pigment and degradation of IL if any by ${ }^{1} \mathrm{H} N M R$ (Bruker $\left.400 \mathrm{H}\right)$. The 
IL without any treatment was reused with fresh cells and the cells were treated in a manner similar to the one described above. The amount of pigment extracted subsequently with ethyl acetate was analysed by HPLC. Reusability of the ionic liquid without treatment was tested three times. The amount of astaxanthin extracted after each reuse was compared with the cells treated with fresh IL.

\section{Results and discussion}

Different ILs (see Table 5.1) were evaluated for their ability to enhance permeability of $H$. pluvialis and simultaneous extraction of astaxanthin from $H$. pluvialis at different temperatures and concentrations. Samples were investigated using light microscopy to better understand the mechanism of action of ILS in astaxanthin extraction.

\section{Effect of temperature}

The influence of temperature on $\mathrm{H}$. pluvialis cell permeability in presence of $80 \% \mathrm{w} / \mathrm{w}$ ionic liquid-water solution was investigated at different temperatures: $25^{\circ} \mathrm{C}, 45^{\circ} \mathrm{C}$ and $55^{\circ} \mathrm{C}$. Among the different classes of ionic liquids tested, intact cells treated with imidazolium based ionic liquid (BMIM DBP, EMIM DBP, BMIM Acetate, BMIM DCA) were able to extract astaxanthin more efficiently than those treated with phosphonium (TBP TOS and TBP $\mathrm{SO}_{4}$ ) and ammonium (lolilyte $221 \mathrm{PG}$ ) based ionic liquids. The amount of astaxanthin extracted after treatment with BMIM DBP and EMIM DBP was higher than BMIM Acetate and BMIM DCA. Influence of imidazolium based ILs were also studied at an additional temperature of $65^{\circ} \mathrm{C}$. The extraction efficiency of astaxanthin measured for cells treated with imidazolium ILs was much higher compared to the other ILs and thus to have an upper limit for the temperature, extraction study was extended to $65^{\circ} \mathrm{C}$. The permeability was measured by release of astaxanthin which was extracted from ionic liquid pre-treated cells using ethyl acetate. As shown in Figure 5.1, the amount of astaxanthin extracted when intact cells pre-treated with acetone, lolilyte 221 PG and phosphonium IL was $\sim 3-5 \%$ at all tested temperatures whereas for BMIM DBP it increased from $\sim 22 \%$ to $\sim 65 \%$ and for EMIM DBP it increased from $36 \%$ to $\sim 70 \%$ with temperature increase from $25^{\circ} \mathrm{C}$ to $45^{\circ} \mathrm{C}$. Increase in temperature from $25^{\circ} \mathrm{C}$ to $45^{\circ} \mathrm{C}$ did not increase the extraction of astaxanthin for BMIM acetate and BMIM DCA. Intact $H$. pluvialis cells treated with acetone and ethyl acetate under similar conditions could release only $\sim 5-6 \%$ of total astaxanthin. The results show that the anion has an impact on the cell wall. The long chain of the anion could play a role in dissolving some components of encysted Haematococcus cell wall. Brandt et al [21] has studied the solubility of wood chips in imidazolium based ionic liquids with different anions. The study attributed the low solubility of wood chips treated with BMIM DCA to lower capability of DCA anion to break the hydrogen network in cellulose and the acetate ions effectively solubilised cellulose. The Haematococcal cell wall is composed of non-hydrolysable polymer, mainly mannan polymer [22]. Based on these results, we postulate two hypotheses i) the mannan polymer present in the cell wall has a different solubility than cellulose ii) complex arrangement of the polymer together with other cell wall component leading to different 
solubilisation among imidazolium based ILs. However detailed study with respect to cell wall composition and effect of IL on dissolving the cell wall components is needed before any conclusive decision could be made.

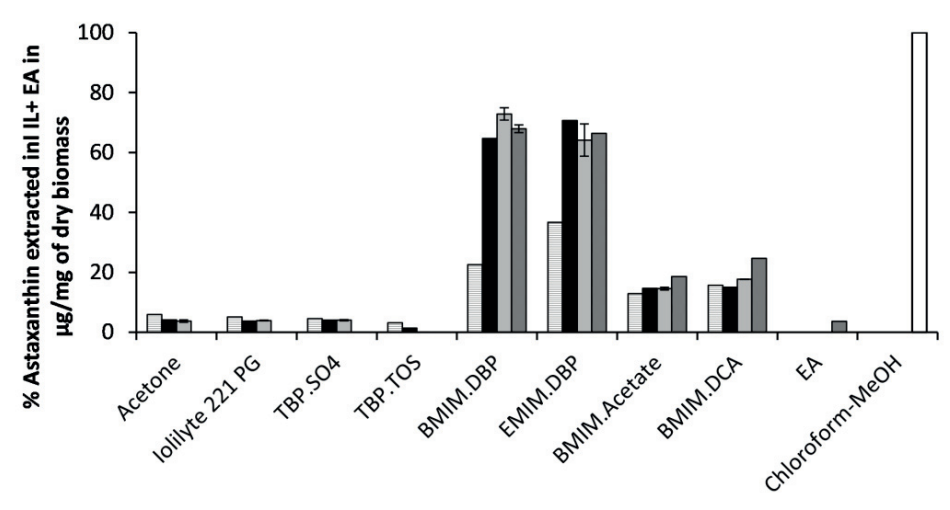

曰25 deg C $\square 45 \mathrm{Deg} C \square 55 \mathrm{deg} C \square 65 \mathrm{deg} C$

Figure 5.1 Effect of temperature on algal cell permeability for the different ILs

\section{Effect of IL concentration}

The pre-treatment of $H$. pluvialis cells was performed using different concentrations of ionic liquidwater solutions ranging from $20 \% \mathrm{w} / \mathrm{w}$ to $80 \% \mathrm{w} / \mathrm{w}$ at $45^{\circ} \mathrm{C}$ for $90 \mathrm{~min}$. The concentration studies were performed using only imidazolium ILs (BMIM DBP, EMIM DBP, BMIM Acetate, BMIM DCA) since the temperature studies showed that they performed better than the other ILs. As the IL concentration increases from $20 \% \mathrm{w} / \mathrm{w}$ to $80 \% \mathrm{w} / \mathrm{w}$, the total amount of astaxanthin (astaxanthin in EA layer + IL layer) extracted increases from $6.77 \%$ to $62.25 \%$ for BMIM DBP and from $12 \%$ to $77.04 \%$ for EMIM DBP. The results show that pre-treatment of algal cells with IL concentrations above $40 \%$ did not further increase astaxanthin extraction efficiency. On the other hand the amount of astaxanthin lost to the IL increases from $\sim 2 \%$ to $18 \%$ (Figure $5.2 \mathrm{a}-\mathrm{b}$ ) when the IL concentration increases from $20 \%$ to $80 \%$. Pre-treatment with IL apparently weakens the cell wall due to which astaxanthin is leaked out of the cell and in the next step extracted using ethyl acetate after removing the IL from the cells. However, some amount of astaxanthin that is leaked out dissolves in the IL (Figure 5.2b). The amount of astaxanthin that goes to the IL depends on the water content. Water miscible ILs used in this study has low solubility $(\sim 120 \mu \mathrm{g} / \mathrm{ml}$ in 80\% BMIM DBP and $\sim 66 \mu \mathrm{g} / \mathrm{ml}$ in 80\% BMIM DCA) for astaxanthin (data not shown) and solubility further reduces with increase in water content. This explains negligible loss of astaxanthin to the IL phase at low IL concentration and thus eliminating the need to mechanically break the cells to extract astaxanthin. Additionally, the IL could be reused when the concentration of IL used is $40 \% \mathrm{w} / \mathrm{w}$. We found that EMIM DBP showed maximum extraction efficiency of $\sim 77 \%$ among all the ILs tested. This is a good step in overcoming the costs associated with IL usage. 
a) Amount extracted using ethyl acetate (EA) after pre-treatment with IL

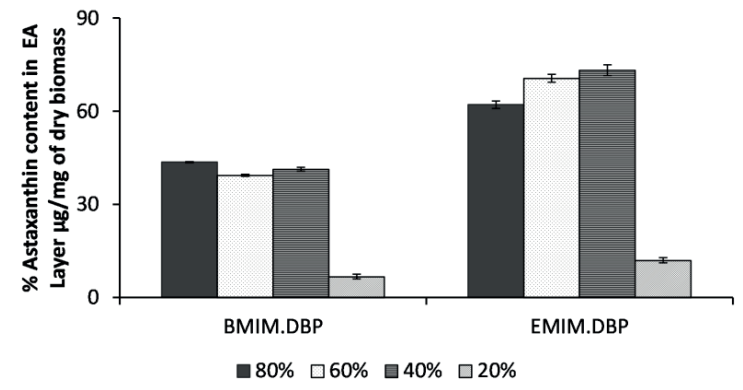

b) Amount dissolved in IL after pre-treatment with IL

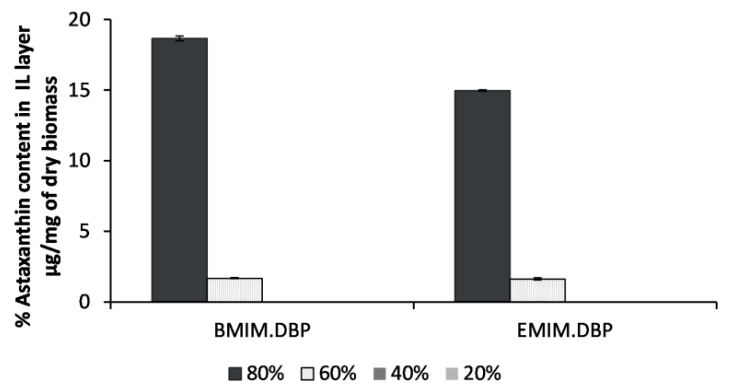

Figure 5.2 Effect of IL concentration on cell permeability

\section{Light Microscopy and SEM}

In order to understand the combined effect of the $\mathrm{IL}$ and solvent on the cell surface the cells were studied under microscope with 6oX resolution and also by SEM. Light microscopy and SEM studies were done only on cells treated with EMIM DBP, as it gave the best extraction efficiency. Light microscopy shows that the cells were intact and colourless after treatment with $\mathrm{IL}$ and subsequent extraction with solvent (Figure 5.3c-d), whereas cells treated with acetone or ethyl acetate under similar conditions remain intact with astaxanthin inside the cell (Figure 5.3a-b). This confirms our idea that IL permeabilises or weakens the cell wall and allows subsequent leaching of astaxanthin by the organic solvent. The SEM studies showed that untreated freeze dried cells (Figure5.4a) appeared to have a wrinkled surface but did not show any "pitting" or cavities on the cell surface. The ethyl acetate treated cells also showed surface characteristics similar to untreated cells (Figure 5.4b). For the cells treated with $\mathrm{IL}$, it was difficult to observe any changes on the cell surface mainly because of formation of a thin film around the cells which could not be removed by the solvent (Figure 5.4c-d). Although the surface characteristics were not visible, the cells looked intact. Indeed, this film could point at the possible mechanism of action of ILs in the application discussed here. 
a)

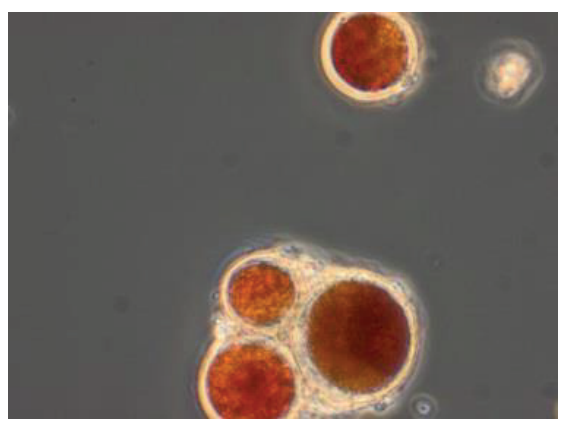

c)

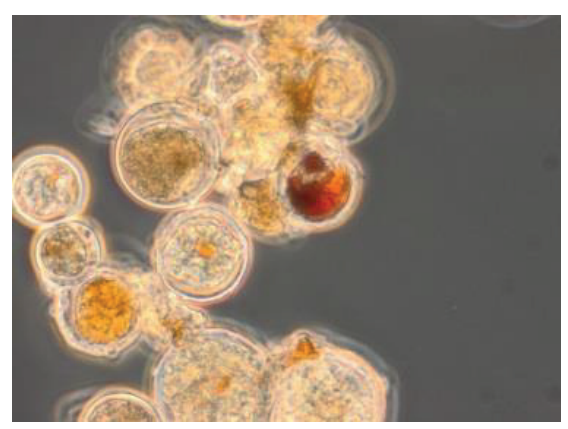

b)

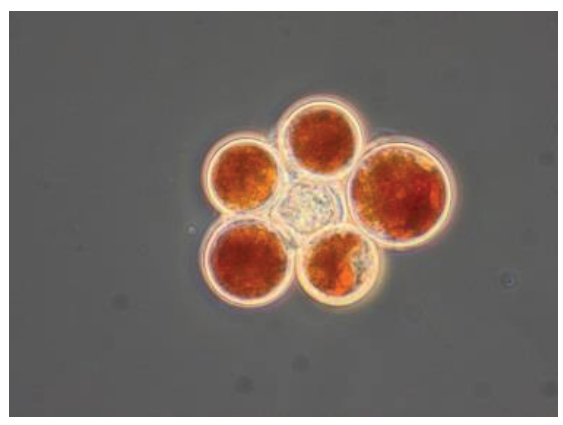

d)

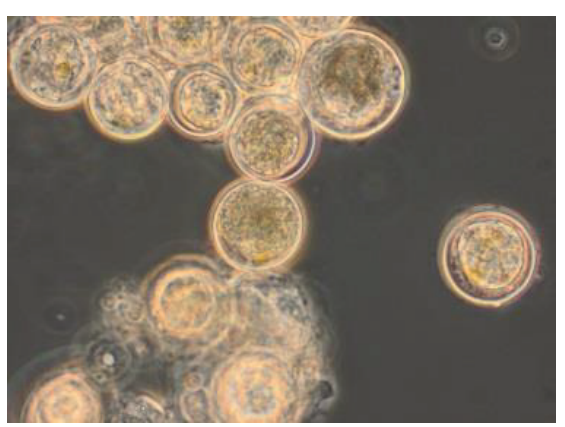

Figure 5.3 Microscopy of $\mathrm{H}$. pluvialis a) Acetone at $45^{\circ} \mathrm{C}$; b) Ethyl acetate at $65^{\circ} \mathrm{C} ; \mathrm{C}$ ) BMIM-DBP at $45^{\circ} \mathrm{C}$; d) $E M I M-D B P$ at $45^{\circ} \mathrm{C}$

a)

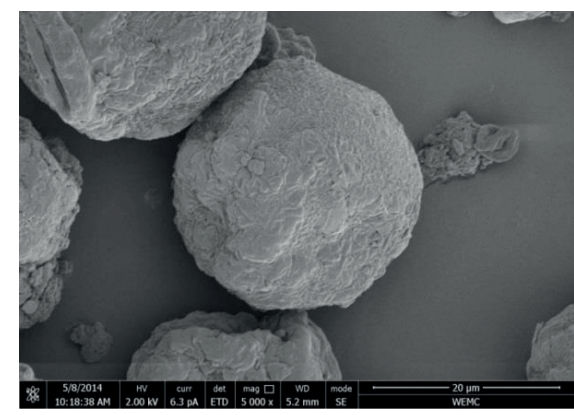

c)

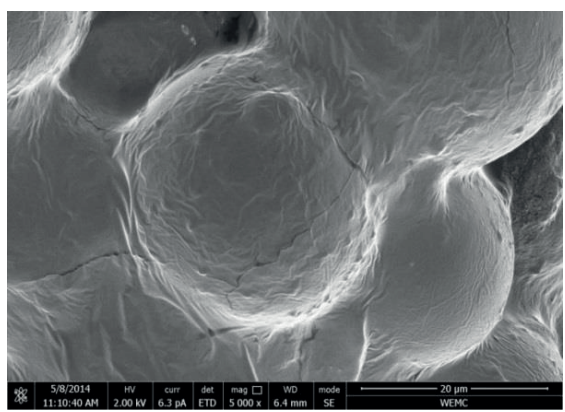

b)

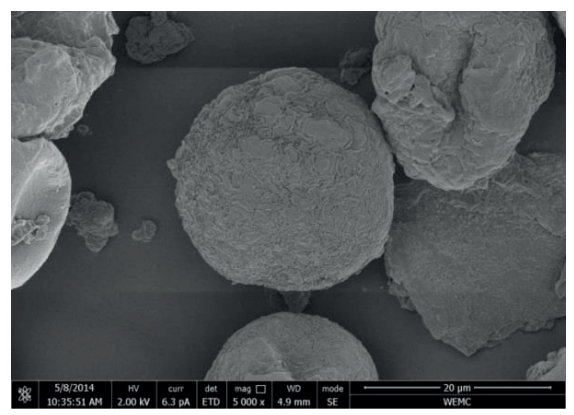

d)

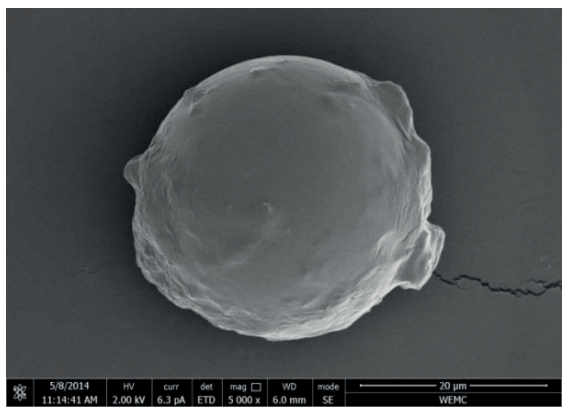

Figure 5.4 a) Untreated freeze dried cells (Control); b) EA at $45^{\circ} \mathrm{C} ; \mathrm{c}$ ) EMIM at $45^{\circ} \mathrm{C}$; d) EMIM+EA at $45^{\circ} \mathrm{C}$ 


\section{Hypothesis for mechanism of action}

H. pluvialis cells undergo considerable changes during morphogenesis from a vegetative flagellate to an aplanospores. The aplanospores have a robust cell wall accounting for $16 \%$ of its dry weight [22]. As described by Christoph Hagen [22] H. pluvialis cell wall is very robust and is made of highly resistant outer trilaminar sheath and a very thick secondary wall (see Figure 5.5). The trilaminar sheath is made up of sporopollenin-like material (algenan), a nonhydrolyzable aliphatic biopolymer. The secondary wall, just beneath the trilaminar sheath is composed mainly of non-fibrillar mannan polymer [22]. Hydrophilic ILs are known to dissolve cellulose by disrupting the hydrogen bond network of cellulose [23]. Teixeira [13] also showed that algae can be completely hydrolysed into its components by IL in presence of water at high temperatures (above $100^{\circ} \mathrm{C}$ ). We hypothesize that the solubilisation of components of the outer layer of $H$. pluvialis leads to permeabilisation and thus release of astaxanthin. Since the cell wall is composed of mannan polymer, we hypothesize that the polymer structure is partially disrupted by the ionic liquid thus forming tiny holes/passage in the cell wall and paving the way for the solvent to penetrate and extract the astaxanthin. Although, surface characteristics were not clear from SEM studies due to film formation, changes in cell wall morphology could still be confirmed by the intact cells observed under the microscope (Figure 5.3a-d). A possible reason for formation of film around cell treated with ILs could be the release of polysaccharides from the encysted cell or by interaction of the IL with released polysaccharides. Ionic liquids are known to solubilise polysaccharides from lignocellulosic biomass $[24,25]$. Polar ionic liquid with low viscosity and high hydrogen bonding capacity are important parameters in dissolution of polysaccharides consisting mainly of cellulose [2628]. In this article we observed that the extent of permeabilisation varied for cells treated with imidazolium IL with different anions. Abe et al has shown that the anion influences the hydrogen bonding capacity and subsequently polysaccharide dissolution. The study also shows that lolilyte 221 PG, TBP $\mathrm{SO}_{4}$ and TBP TOS were less effective than imidazolium based ILs in permeabilising the cell wall which indicates that the cation also plays a role in solubilising the cell wall component. We could thus hypothesize that the permeabilisation of the cell wall is due to possible interaction between the cell wall polysaccharides and IL. Further detailed study on the cell wall composition together with its solubility in IL could explain the underlying principle. This study is beyond the scope of this article. Permeabilisation of algal cell wall using IL is a novel separation tool to obtain pigments from microalgal cell and could be extended to lipid extraction without compromising on fragile water soluble components like proteins [29]. 


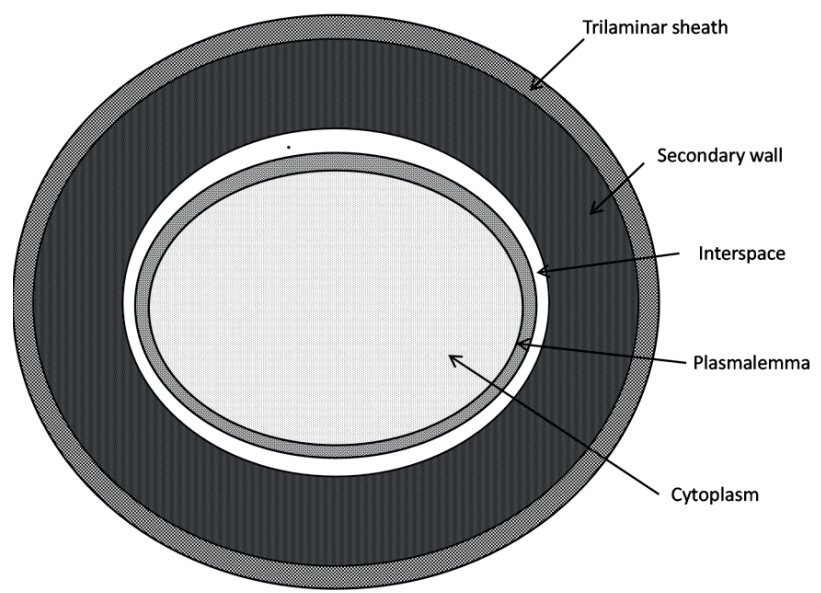

Figure 5.5 Schematic of H.pluvialis cell wall (adapted from Hagen, C.S. et al. [22])

\section{Reusability of Ionic liquid}

The reusability of the ionic liquid is imperative for scale up. To be able to determine this, reusability studies were performed by using the same IL solution for pre-treating four sets of fresh $H$. Pluvialis cells. The efficiency of the IL was tested by measuring the ability of the IL to permeabilise the cell and thus release of astaxanthin. The amount of astaxanthin that could be extracted using re-used IL was comparable with the control (see Figure 5.6). The IL could be used three times without any treatment and without affecting the efficiency of permeabilisation. A decrease in the efficiency of permeabilisation was observed when used for the fourth time to permeabilise the cells. The ionic liquid layer was tested for presence of pigment after each reuse and it was observed that the amount of pigment in the IL phase after three reuse cycles was negligible $(\sim 0.5 \mu \mathrm{g} / \mathrm{ml}$ i.e. $1.68 \%$ of total astaxanthin extracted after 4 extractions). The ${ }^{1} \mathrm{H}$ NMR spectra of IL before and after 3 times reuse were comparable (see Figure 5.7).

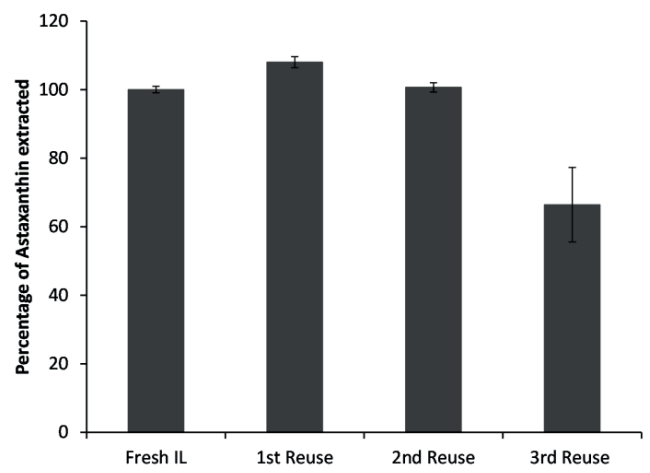

Figure 5.6 Reusability of Ionic liquid 


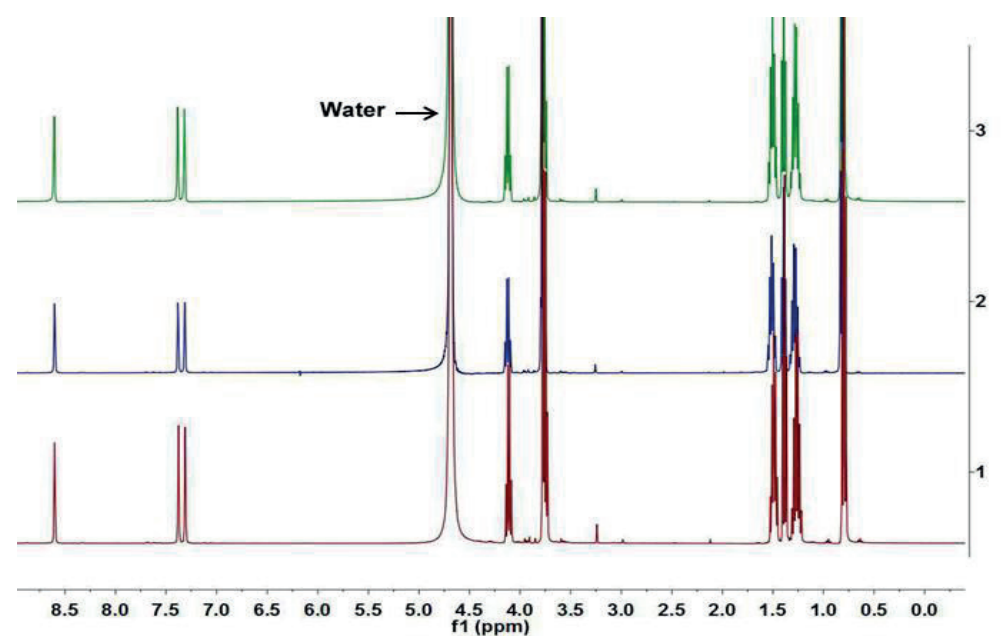

Figure 5.7 ${ }^{1}$ H NMR Spectra of 1. Fresh 40\% EMIMDBP in water, 2.IL after $3^{\text {rd }}$ reuse, $3.1 \mathrm{~L}$ after $1^{\text {st }}$ reuse

\section{Conclusions}

This paper highlights the potential of using ILs to permeabilise H. pluvialis. The haematococcal cyst has a robust cell wall and requires mechanical disruption to extract astaxanthin. The data clearly show that $H$. pluvialis cells are permeabilised by hydrophilic ILs under mild conditions of temperature (below $100^{\circ} \mathrm{C}$ ) and atmospheric pressure. After pre-treatment with IL, astaxanthin is subsequently extracted using ethyl acetate with high efficiency while the cell wall is kept intact. Amongst the different ILs studied, astaxanthin extraction efficiencies obtained with EMIM DBP were the highest (more than $70 \%$ ). The study shows that the cells can be permeabilised with $40 \% \mathrm{w} / \mathrm{w}$ IL with negligible loss of pigment to the IL phase. In addition the ionic liquid could be used three times without affecting its efficiency to permeabilise the cells. This opens up the possibility of reusing the expensive ILs. Knowing that energy demand drives the overall production cost [13] mechanical cell disruption is the most energy consuming step, and replacing with ionic liquid would have an impact on the overall cost. However, for exact estimations, ionic liquid process should be performed using industrial scale equipment. While the initial findings are promising, further research is necessary to optimise the process parameters in terms of extraction efficiency, use of wet biomass, solid to liquid ratio and to extend the application to other microalgae. A better understanding of the exact mechanism of action would be of great benefit in this. This paper underlines the potential of using ILs in extraction of hydrophobic biomolecules (e.g. pigments) under mild conditions as a replacement of mechanical techniques or harsh conditions. This allows the co-extraction of several classes of hydrophobic biomolecules for different applications from the same cell substrate, whereas the more hydrophilic biomolecules (e.g. proteins) are fractionated more efficiently after cell disruption without compromising the functionality. In this way cell can truly become multi-purpose factories. 


\section{Acknowledgements}

The authors would like to thank Technology Foundation STW and Institute for Sustainable Process Technology (ISPT) for the financial support. We would like to thank Wageningen Electron Microscopy centre for their help in taking SEM pictures, NMR spectroscopy centre for helping with the ${ }^{1} \mathrm{H}$ NMR experiments and Feyecon (Weesp, The Netherlands) for providing the H. pluvialis cells. 


\section{References}

1. Augusti, P.R., et al., Effect of astaxanthin on kidney function impairment and oxidative stress induced by mercuric chloride in rats. Food and Chemical Toxicology, 2008. 46(1): p. 212-219.

2. Kobayashi, M., et al., Antioxidant role of astaxanthin in the green alga Haematococcus pluvialis. Applied Microbiology and Biotechnology, 1997. 48(3): p. 351-356.

3. Higuera-Ciapara, I., L. Felix-Valenzuela, and F.M. Goycoolea, Astaxanthin: A review of its chemistry and applications. Critical Reviews in Food Science and Nutrition, 2006. 46(2): p. 185196.

4. Fan, L., A. Vonshak, and S. Boussiba, Effect of temperature and irradiance on growth of haematococcus pluvialis (chlorophyceae)1. Journal of Phycology, 1994. 30(5): p. 829-833.

5. Boussiba, S. and A. Vonshak, Astaxanthin Accumulation in the Green Alga Haematococcus pluvialis1. Plant and Cell Physiology, 1991. 32(7): p. 1077-1082.

6. Harker, M., A.J. Tsavalos, and A.J. Young, Factors responsible for astaxanthin formation in the Chlorophyte Haematococcus pluvialis. Bioresource Technology, 1996. 55(3): p. 207-214.

7. Borowitzka, M.A., Algal Biotechnology Products and Processes - Matching Science and Economics. Journal of Applied Phycology, 1992. 4(3): p. 267-279.

8. Harker, M., A.J. Tsavalos, and A.J. Young, Autotrophic growth and carotenoid production of Haematococcus pluvialis in a 30 liter air-lift photobioreactor. Journal of Fermentation and Bioengineering, 1996. 82(2): p. 113-118.

9. Wijffels, R.H. and M.J. Barbosa, An outlook on microalgal biofuels. Science, 2010. 329(5993): p. 796-9.

10. Louros, C.L., et al., Extraction of biomolecules using phosphonium-based ionic liquids $+K(3) P O(4)$ aqueous biphasic systems. Int J Mol Sci, 2010. 11(4): p. 1777-91.

11. Desai, R.K., et al., Extraction and stability of selected proteins in ionic liquid based aqueous two phase systems. Green Chemistry, 2014. 16(5): p. 2670-2679.

12. Visser, A.E., et al., Task-specific ionic liquids for the extraction of metal ions from aqueous solutions. Chemical Communications, 2001(1): p. 135-136.

13. Teixeira, R.E., Energy-efficient extraction of fuel and chemical feedstocks from algae. Green Chemistry, 2012. 14(2): p. 419-427.

14. Kim, Y.-H., et al., lonic liquid-mediated extraction of lipids from algal biomass. Bioresource Technology, 2012. 109(0): p. 312-315.

15. Young, G., et al., Lipid extraction from biomass using co-solvent mixtures of ionic liquids and polar covalent molecules. Separation and Purification Technology, 2010. 72(1): p. 118-121.

16. Choi, S.-A., et al., Effects of ionic liquid mixtures on lipid extraction from Chlorella vulgaris. Renewable Energy, 2014. 65(0): p. 169-174.

17. $\mathrm{Bi}, \mathrm{W}$., et al., Task-specific ionic liquid-assisted extraction and separation of astaxanthin from shrimp waste. J Chromatogr B Analyt Technol Biomed Life Sci, 2010. 878(24): p. 2243-8.

18. Lovejoy, K.S., et al., Evaluation of ionic liquids on phototrophic microbes and their use in biofuel extraction and isolation. Journal of Applied Phycology, 2012. 25(4): p. 973-981.

19. Mendes-Pinto, M.M., et al., Evaluation of different cell disruption processes on encysted cells of Haematococcus pluvialis: effects on astaxanthin recovery and implications for bio-availability. Journal of Applied Phycology, 2001. 13(1): p. 19-24.

20. Safi, C., et al., Aqueous extraction of proteins from microalgae: Effect of different cell disruption methods. Algal Research, 2014. 3(0): p. 61-65.

21. Brandt, A., et al., The effect of the ionic liquid anion in the pretreatment of pine wood chips. Green Chemistry, 2010. 12(4): p. 672-679.

22. Hagen, C., S. Siegmund, and W. Braune, Ultrastructural and chemical changes in the cell wall of Haematococcus pluvialis (Volvocales, Chlorophyta) during aplanospore formation. European Journal of Phycology, 2002. 37(2): p. 217-226.

23. Swatloski, R.P., et al., Dissolution of Cellose with lonic Liquids. J Am Chem Soc, 2002. 124(18): p. 4974-4975. 
24. Abe, M., Y. Fukaya, and H. Ohno, Extraction of polysaccharides from bran with phosphonate or phosphinate-derived ionic liquids under short mixing time and low temperature. Green Chemistry, 2010. 12(7): p. 1274-1280.

25. Kilpelainen, I., et al., Dissolution of wood in ionic liquids. J Agric Food Chem, 2007. 55(22): p. 9142-8.

26. Fukaya, Y., et al., Cellulose dissolution with polar ionic liquids under mild conditions: required factors for anions. Green Chemistry, 2008. 10(1): p. 44-46.

27. Fukaya, Y., A. Sugimoto, and H. Ohno, Superior solubility of polysaccharides in low viscosity, polar, and halogen-free 1,3-dialkylimidazolium formates. Biomacromolecules, 2006. 7(12): p. 3295-7.

28. Zavrel, M., et al., High-throughput screening for ionic liquids dissolving (ligno-)cellulose. Bioresource Technology, 2009. 100(9): p. 2580-7.

29. Yoo, G., et al., An effective, cost-efficient extraction method of biomass from wet microalgae with a functional polymeric membrane. Green Chemistry, 2014. 16(1): p. 312-319. 


\section{Chapter 6}

\section{Novel selective fractionation technology for fragile biomolecules from Neochloris oleoabundans using ionic liquids}

To be submitted as:

Rupali K. Desai, Maria Salvador Fernandez Mathieu Streefland, René H. Wijffels and Michel H.M. Eppink Novel selective fractionation technology for fragile biomolecules from Neochloris oleoabundans using ionic liquids 


\begin{abstract}
Microalgae are a promising source for proteins, lipids and carbohydrates for the food/feed and biofuel industry. To make microalgae production economically feasible it is necessary to optimally use all produced compounds keeping full functionality. Therefore biorefining of microalgae is the key to lower the cost of algal products using mild and effective processing techniques. In this article we have tested the feasibility of few aqueous solutions of imidazolium and phosponium ionic liquids to selectively fractionate $N$. oleoabundans biomass into a hydrophilic fraction (proteins, carbohydrates) and a hydrophobic fraction (lipids). The results showed that Tributylmethylphosphonium methyl sulfate (Cyphos 108) could permeabilise fresh intact cells of $N$. oleoabundans to yield $68 \%$ of total lipids and obtain after cell disruption $80 \%$ of total proteins and $77 \%$ of total carbohydrates. Moreover, the proteins so obtained kept their native form explaining the novelty of this concept. A perspective on ionic liquid based microalgal biorefinery is also discussed.
\end{abstract}

\title{
Broader Context
}

Growing energy demands and depleting fossil fuels together with the impact of using these fossil resources on the environment drives the need to develop alternative source for fuel/energy production. Although, microalgae are considered as promising feedstock for biofuel production, the primary bottleneck lies in high cost of production. Apart from lipids, the microalgae also contain other value added components such as carbohydrates and proteins. Thus, using a biorefinery approach would help circumvent the problem of high cost. While the current processes use organic solvent for extraction of proteins from microalgae, use of solvent denatures the protein. In this article we show the feasibility of selectively separating the hydrophobic (lipids) from hydrophilic (proteins, carbohydrates) using ionic liquids without affecting the protein stability. The possible role of ionic liquids in fractionating microalgal biomass could pave way towards development of microalgal biorefinery. 


\section{Introduction}

Microalgae are promising feedstocks for biofuel production. These photosynthetic microorganism have high lipid productivity and do not compete for arable land when compared to terrestrial oleaginous crops [1]. Microalgae have a very tough cell wall and thus require energy intensive unit operations to break open the cell and release the intracellular content. Thus, despite the high lipid productivity, the energy input to separate the lipids is much higher than the energy obtained from the biomass indicating the necessity to use less energy intensive unit operations. Apart from lipids, microalgae are also good sources for proteins, carbohydrates and pigments. Utilization of these value added coproducts for food, cosmetics, health and chemicals would help in making the process economically feasible [2].

The current processes are mainly focussed on recovery of single component from microalgae mainly lipids for biodiesel production [3]. Most commonly organic solvents are used for extraction of lipids. The Soxhlet [4] method uses hexane as a solvent and the Bligh and Dyer's [5] method uses chloroform and methanol mixture as a solvent for extraction. As these processes are designed to extract one component, it leaves the biomass unsuitable for recovering other components. Additionally, lipids can also be extracted using sub and supercritical fluids [6], however these methods have high energy requirements and thus impact the overall economics of the process. In a study done by Ursu et.al protein extraction was done using alkaline condition. However, the proteins precipitated under alkaline condition had lower functional properties [7]. It is thus prudent to develop a mild process to fractionate the biomass into its components such that their functional integrity is retained.

Conventional extraction processes based on volatile organic solvents poses safety concerns and is toxic. It is thus necessary to develop newer methods to address these issues. Some of these methods include use of supercritical fluids and recently ionic liquids (IL)

Ionic liquids are salts which are liquid at temperatures below $100^{\circ} \mathrm{C}$. They are composed of cations and anions and have negligible vapour pressure. They are known as designer solvents as their properties such as polarity, viscosity can be tailored by using a different combination of cation and anion [8]. This makes IL an attractive solvent for liquid-liquid extraction. ILs were used for lipid extraction from microalgae at elevated temperatures and together with co-solvents such as methanol [9, 10]. Studies using mixtures of ILs have also been performed to extract lipids from algae biomass [11] and dissolution of microalgae in ILs were also demonstrated [12]. Teixeira in his studies have shown energy efficient deconstruction of algae biomass by dissolution and hydrolysis of microalgae in ILs at temperatures above $100^{\circ} \mathrm{C}$ [13]. Olkiewicz, M., et al.[14] showed $\sim 75 \%$ lipid and $93 \%$ FAMEs recovery using hydrated phosphonium IL under ambient temperature condition. All these studies have established the potential of ILs to extract lipids from microalgae with high efficiency. While, both Teixeira and Olkiewicz, M., et al have qualitatively demonstrated that all components of microalgae (lipids, proteins and carbohydrates) can be recovered in one process after hydrolysing the microalgae, it does not give any indication about 
recovery of proteins and carbohydrates and the stability of the more fragile proteins. Most of these studies address the recovery and extraction efficiency of lipids from microalgae while recovery of other components such as the high value proteins and carbohydrates are not addressed showing the single component isolation strategy. A recent study by Xinhai yu et al. [15] reported energy efficient extraction of lipids from Chlorella vulgaris using IL combined with $\mathrm{CO}_{2}$ capture. The study showed $\sim 75 \%$ lipid ( $89 \%$ FAMEs) recovery but the proteins were denatured in the process. To be able to recover all components in their full functional state from microalgae biomass it is necessary to use mild techniques. Most of the articles discussed above are focussed on lipid extraction from microalgae and not on biorefining of biomass. Additionally, though ILs has been used in the studies the conditions such as temperature are high enough to degrade the protein.

The primary objective of the article is to fractionate the algal biomass into a hydrophilic fraction (proteins, carbohydrates) and a hydrophobic fraction (lipids) using mild pre-treatment with an aqueous solution of ionic liquid. Additionally, the ability of ILs to extract lipids from the cells under different temperature and concentration conditions was studied. The microalgae strain used in this study is $N$. oleoabundans which is a high lipid producing strain [16]. Both fresh and dried algae were studied to understand the influence of ionic liquid pre-treatment on extraction efficiency of individual components and the stability of proteins.

\section{Materials}

The ILs used in this study was $\geq 95 \%$ pure and used without further purification. All the ILs listed in Table 1 was purchased from lolitec. Chemicals and organic solvents used in the study, ethyl acetate, hexane, methanol sulphuric acid, phenol and fatty acid standards were bought from Sigma.

\section{Methods}

\section{Microalgae cultivation}

$N$. Oleoabundans was cultivated in the laboratory in fresh water medium as described by Breuer et al. [17] and the algae were stressed to have a higher lipid content. The microalgae were then harvested by centrifugation (4000 rpm for 10 minutes). The microalgae were freeze dried and used for extraction studies. For the study, using fresh cells the algae were grown at the AlgaeParc pilot facility, Wageningen, The Netherlands. The cell suspension was centrifuged at $4000 \mathrm{rpm}$ for 10 minutes and used for the study.

\section{Pre-treatment with lonic liquid and fractionation of Biomass}

As shown in Figure 6.1 two studies were performed, lipid extraction efficiency of IL from intact microalgae cells at different temperature and IL concentration (A) and IL pre-treatment of microalgae and subsequent fractionation into hydrophilic and hydrophobic component (B). 
$N$. oleoabundans cells $\sim 10 \mathrm{mg}$ of cells (freeze dried and/or fresh cells) were treated with $1.5 \mathrm{ml}$ of aqueous solution of IL under mild temperature conditions for 30 minutes. The studies were conducted with 7 different ILs. The ionic liquids used in the study are listed in Table 6.1. The influence of temperature $(35,45 \text {, and } 60)^{\circ} \mathrm{C}$ and concentrations of ILs $(40,80) \% \mathrm{w} / \mathrm{w}$ on extraction efficiency of lipids was investigated. The amount of lipids extracted in the IL phase was determined by measuring the residual amount of lipids remaining in the cells.

Additional studies were conducted using two ILs, BMIM DBP and TBP SO 4 . The cells were pre-treated with $1.5 \mathrm{ml}$ of $40 \%$ aqueous solution of IL at $45^{\circ} \mathrm{C}$ for 30 minutes. The cells, after pre-treatment, were separated from ionic liquids by centrifugation at $3000 \mathrm{rpm}$ for 10 minutes and then contacted with $3 \mathrm{ml}$ of solvent (ethyl acetate/hexane) for 2 hours. The hydrophobic components from microalgae (lipids and pigments) were extracted in the solvent phase. The biomass remaining after pre-treatment containing the hydrophilic components mainly proteins and carbohydrates is suspended in phosphate buffer and then this fraction was analysed for protein and carbohydrate content.

Table 6.1 lonic liquids used in the study

\begin{tabular}{|c|c|c|}
\hline Sr. No. & Ionic Liquid Names & Abbreviations \\
\hline 1 & Iolilyte $221 \mathrm{PG}$ & 10 \\
\hline 2 & $\begin{array}{l}\text { Tributylmethylphosphonium methyl sulfate } \\
\text { (Cyphos 108) }\end{array}$ & $\mathrm{TBPSO}_{4}$ \\
\hline 3 & $\begin{array}{l}\text { Triisobutylmethylphosphonium tosylate } \\
\text { (Cyphos 106) }\end{array}$ & TBP TOS \\
\hline 4 & $\begin{array}{l}\text { 1-Butyl-3-methylimidazolium } \\
\text { dibutylphosphate }\end{array}$ & BMIM DBP \\
\hline 5 & $\begin{array}{l}\text { 1-Ethyl-3-methylimidazolium } \\
\text { dibutylphosphate }\end{array}$ & EMIM DBP \\
\hline 6 & 1-Butyl-3-methylimidazolium acetate & BMIM Acetate \\
\hline 7 & 1-Butyl-3-methylimidazolium Dicynamide & BMIM DCA \\
\hline
\end{tabular}




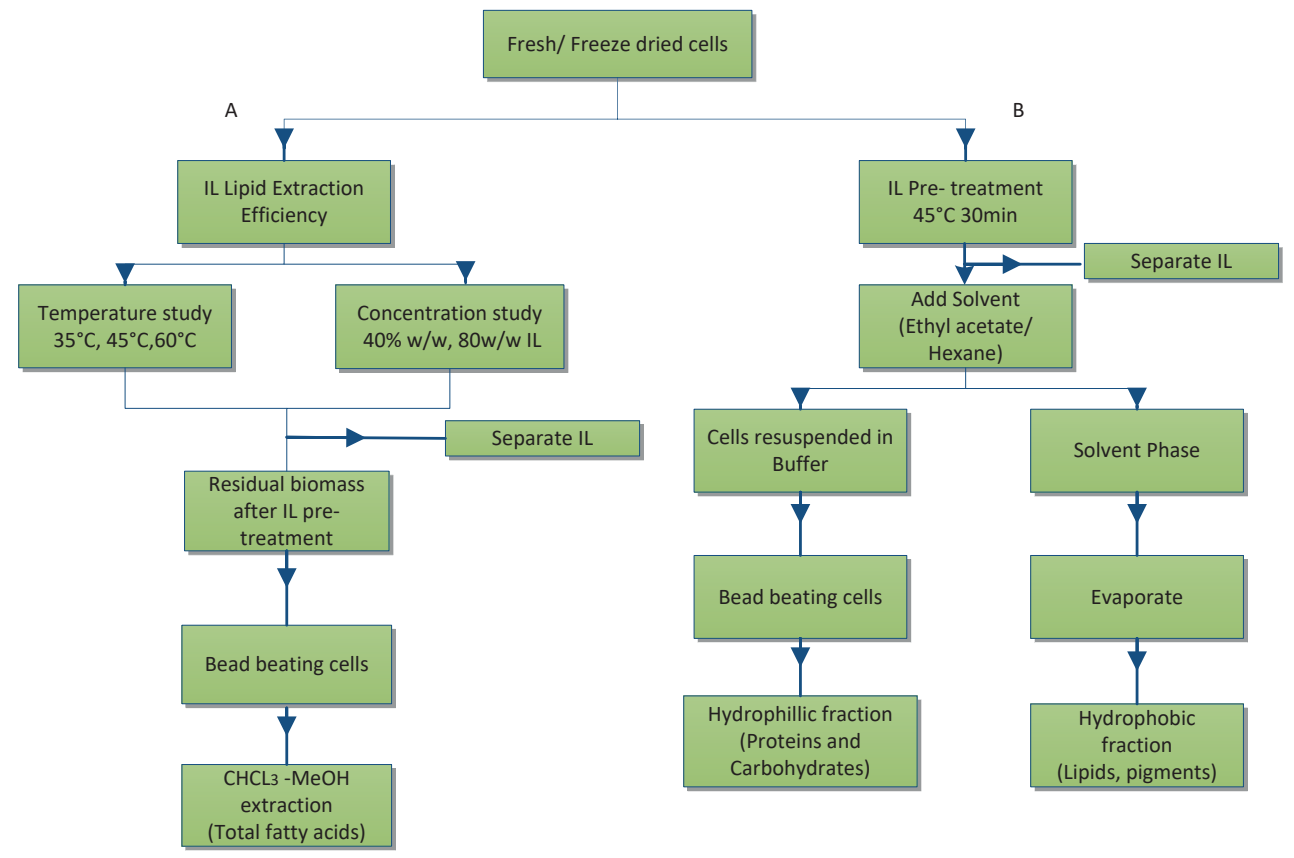

Figure 6.1 Experimental scheme, A) IL lipid extraction efficiency B) IL Pre-treatment and separation of hydrophobic and hydrophilic components

\section{Fatty acid determination}

The total fatty acids (FA) present in the microalgae is determined by treating the cells with $\mathrm{CHCl}_{3}$ $\mathrm{MeOH}$ as described by [18]. For temperature and concentration studies total amount of fatty acids extracted in the IL phase is determined by measuring residual amount of fatty acids remaining in the cells after treatment with IL and is expressed as follows:

Total FA extracted in IL per mg of biomass

$=$ Total FA in control sample - Total residual FA in the cells after pretreament

For calculating the total FA content of IL and solvent treated cells, the solvent phase (ethyl acetate/hexane) is evaporated under $\mathrm{N}_{2}$ stream and the residue was analysed for total FA content after transesterification. The samples were analysed in the GC (Agilent $7890 \mathrm{~A}$ ) and the run time was 30 minutes.

\section{Protein Analysis}

\section{Protein content}

Protein content was determined with a commercial assay kit (DC ${ }^{\mathrm{TM}}$ Protein assay, Bio-Rad, U.S.) using bovine serum albumin (Sigma-Aldrich A7030) as protein standard. The microplate assay protocol was used and the absorbance was measured at $750 \mathrm{~nm}$ using a microplate reader (Infinite M200, Switzerland)). The cells after pre-treatment with IL were suspended in $1 \mathrm{ml}$ of lysis buffer, 6o mM Tris and $2 \%$ SDS, pH 9 in lysing matrix D tubes (6913-500, MP Biomedicals Europe). The sample was bead 
beated for 3 cycles of 60 s at 6500 RPM with a pause of $120 \mathrm{~s}$ between each cycle (Precellys 24, Bertin Technologies). The cell suspension was than heated at $100^{\circ} \mathrm{C}$ for 30 minutes. The cells were separated by centrifugation and the supernatant was analysed for protein content using the DC ${ }^{\mathrm{TM}}$ Protein assay. The protein is expressed as the $\%$ of total protein in the cells:

$$
\% \text { of Total protein }=\left(\frac{\text { Total protein after pretreatment }}{\text { Total protein in cell }}\right) \times 100
$$

\section{Gel electrophoresis}

The stability of the proteins after pre-treatment with IL was confirmed by native gel electrophoresis. The cells after pre-treatment are suspended in $50 \mathrm{mM}$ Phosphate buffer and disrupted by bead beating. The supernatant was diluted 1:1 with native sample buffer. The diluted sample $\sim 25 \mu$ l was then applied on 4-20\% Criterion TGX, Tris glycine precast gel and run with $10 \mathrm{X}$ Tris glycine native buffer at $125 \mathrm{~V}$ for 75 minutes. The gel was stained with Pierce ${ }^{\mathrm{TM}}$ Silver Stain Kit. The material for electrophoresis was bought from Biorad and staining kit was purchased from Thermo Fisher Scientific.

\section{Carbohydrate analysis}

The total carbohydrate content was determined by acid hydrolysis of IL pre-treated cells, adapted from [19]. The IL- pre-treated cells were suspended in water such that the final cell concentration is $1 \mathrm{mg} / \mathrm{ml}$. To $50 \mu \mathrm{l}$ of this suspension $450 \mu \mathrm{l}$ water, $500 \mu \mathrm{l}$ of $5 \%$ phenol solution and $2.5 \mathrm{ml}$ of concentrated sulphuric acid was added. The mixture is incubated at room temperature for 10 minutes and then at $35^{\circ} \mathrm{C}$ in a water bath for 30 minutes. The carbohydrates react with acidic phenol to give yellow orange colour which is then measured at $483 \mathrm{~nm}$ using UV spectrophotometer (Beckman). For control process the cells were directly suspended in water without any pre-treatment. Starch samples were measured as positive controls. The calibration curve was prepared using glucose as the standard. The total carbohydrate content is expressed as:

$\%$ Total carbohydrate content $=\left(\frac{\text { Total carbohydrate content after pretreatment }}{\text { Total carbohydrate content in the cell }}\right) \times 100$

\section{Results and Discussion}

Extraction efficiency of different components (e.g. proteins, carbohydrates, lipids) after IL pretreatment is studied and the protein stability determined by electrophoresis. Aqueous solution of three ionic liquid classes including imidazolium, ammonium and phosphonium ILs were tested at different temperatures and concentration.

\section{IL lipid extraction efficiency}

Lipid extraction efficiency of aqueous IL solutions after IL pre-treatment at different temperatures (35, $45,60)^{\circ} \mathrm{C}$ and concentrations $(40,80) \% \mathrm{w} / \mathrm{w}$ were studied. In this study lipids represent the fatty acid methyl ester content that could be converted to biodiesel. Three classes of ILs (see table 6.1) were studied. The results show that at $80 \% \mathrm{w} / \mathrm{w}$ concentration of $\mathrm{IL}$, as the temperature increases, the 
amount of lipid extracted increases for all ILs (see Figure 6.2). Lipid extraction capacity was higher for BMIM ACE, BMIM DBP, EMIM DBP and TBP TOS, $~ 8-12 \% / \mathrm{mg}$ of biomass than for $1 \mathrm{O}, \mathrm{TBPSO}_{4}$ and BMIM DCA. Although at $60^{\circ} \mathrm{C}$, lipid extraction efficiency was higher, $45^{\circ} \mathrm{C}$ was selected for concentration studies to maintain mild conditions. Two ILs were selected, BMIM DBP which showed highest extraction efficiency among the ILs tested and $\mathrm{TBSO}_{4}$ which showed the least extraction efficiency but could have an impact on the cell wall. The effect of IL concentration on extraction efficiency was tested for BMIM DBP and $\mathrm{TBPSO}_{4}$ (see Figure 6.3). As the concentration of IL increases from $40 \% \mathrm{w} / \mathrm{w}$ to $80 \% \mathrm{w} / \mathrm{w}$ at $45^{\circ} \mathrm{C}$, the amount of lipid extracted increases from $2.61 \%$ to $9.89 \%$ per $\mathrm{mg}$ of biomass for BMIM DBP and from $1.28 \%$ to $3.27 \%$ per $\mathrm{mg}$ of biomass for TBP $\mathrm{SO}_{4}$. This increase in extraction capacity could be attributed to the hydrophobicity increase of the IL solution.

IL solutions under mild conditions were able to extract lipids from intact microalgae cells; the maximum amount extracted was $\sim 42 \%$ of the total fatty acid present in the cells. Based on the results in Figure 6.2 and 6.3, BMIM DBP could permeabilise the cells and extract lipids better than $\mathrm{TBP} \mathrm{SO}_{4}$ indicating that the cation and anion influences the extraction efficiency albeit to a different degree. The results confirm that the lipid solubility in aqueous solution of ILs is low. In other studies by different authors $[10,11,13,14]$ wherein the IL pre-treatment was done at temperatures close to $100^{\circ} \mathrm{C}$, lipids released were extracted with organic solvent and extraction efficiency was $>90 \%$ of the total fatty acid content. Thus, indicating that temperature is indeed an important factor influencing the extraction efficiency.

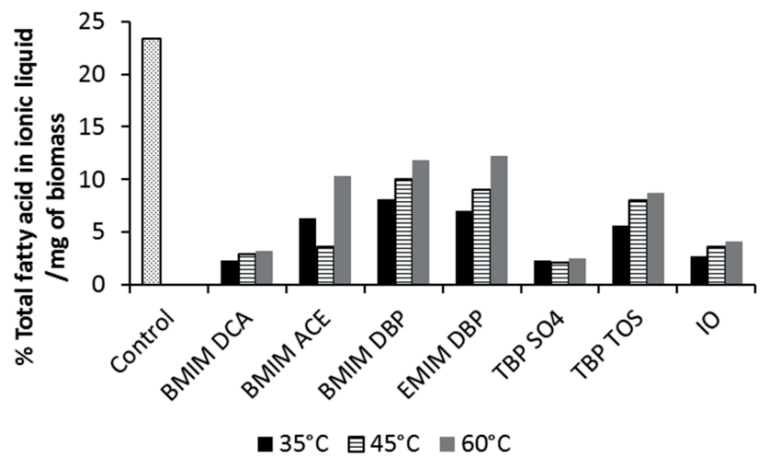

Figure 6.2 Effect of temperature on extraction of lipids using $80 \% \mathrm{w} / \mathrm{W}$ aqueous solution of IL 


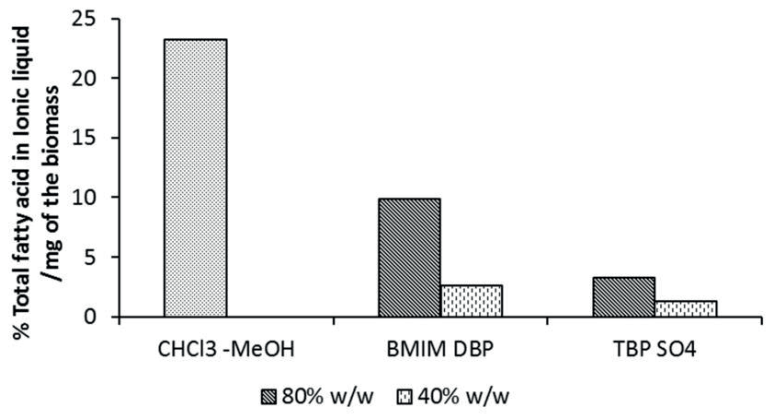

Figure 6.3 Effect of IL concentration on extraction of lipids at $45^{\circ} \mathrm{C}$

\section{IL pre-treatment and extraction with organic solvent}

The above studies showed that aqueous solutions could permeabilise the cells as well as extract the lipids without cell disruption. This observation is in accordance with our previously published studies [20] that aqueous IL solutions could permeabilise the intact microalgae cells under mild conditions and release the intracellular hydrophobic components pigments and lipids in this study.

Microalgae biomass also contains large amount of proteins and carbohydrates besides lipids. To recover these components in their native form after biomass pre-treatment with ILs, additional studies were performed. Pre-treatment studies were done on both wet and dried $N$. oleoabundans cells using $40 \% \mathrm{w} / \mathrm{w}$ BMIM DBP and TBP SO 4 . Despite low lipid extraction efficiency TBP $\mathrm{SO}_{4}$ was selected for further studies to understand the influence of the IL on cell wall permeabilization. Hydrophobic components were subsequently extracted with ethyl acetate and then the cells were mechanically disrupted to recover hydrophilic components. The amount of fatty acid extracted after pre-treatment was compared with Bligh and Dreyer method. The amount of lipid extracted from fresh biomass after pre-treatment was $11.39 \%$ and $17.66 \%$ for BMIM DBP and TBP $\mathrm{SO}_{4}$ compared to $25.96 \%$ using the Bligh and Dreyer method. For the freeze dried biomass, the amount of lipid extracted after pretreatment was $10.48 \%$ and $15.91 \%$ for BMIM DBP and TBP SO 4 compared to $18.20 \%$ using the Bligh and Dreyer method. The results (see Figure 6.4) show that lipid recovery was better with $\mathrm{TBP} \mathrm{SO}_{4}$ in comparison to BMIM DBP for both wet and dried cells. This shows that $\mathrm{TBP}_{4} \mathrm{SO}_{4}$ which has a low lipid extraction capacity, even at $80 \% \mathrm{w} / \mathrm{w}$ concentration, is able to permeabilise the cells and lipids can be subsequently extracted with ethyl acetate. The higher recovery with freeze dried cells could be attributed to effect of drying on the cell walls. The results also show that ethyl acetate alone is not able to permeabilise the cells and extract the lipids. Additionally, studies using hexane instead of ethyl acetate for extracting lipids after IL pre- treatment were performed (not shown). The results showed that no lipids were extracted in the hexane phase. This indicates a possible cooperative role of ethyl acetate together with IL in permeabilising the cell wall. 
The hydrophilic components, proteins and carbohydrates after lipid extraction are recovered by cell disruption. The percentage of total protein recovered after pre-treatment using BMIM DBP and TBP $\mathrm{SO}_{4}$ was $76.81 \%$ and $80.29 \%$ for fresh cells and for freeze dried cells $33.86 \%$ and $62.45 \%$ respectively (see Figure 6.5) were observed. The decrease in protein recovery for freeze dried cells could be due to direct contact of IL with proteins in the already compromised cell wall. In a separate study aqueous solution of BMIM DBP (results not shown) and $\mathrm{TBP} \mathrm{SO}_{4}$ [21] in contact with Rubisco (Ribulose-1,5biphosphate Carboxylase/Oxygenase) causes aggregation/precipitation of the protein molecule. These results thus indicates that TBP $\mathrm{SO}_{4}$ effectively permeabilises the cell wall such that proteins remain intact inside the cell and can be recovered in their functional state by further cell disruption. The proteins recovered after extraction of lipids were run on native gel and detected using silver stain (see Figure 6.7). Although microalgae contains other proteins, Rubisco is used as the known biomarker protein for microalgae. The native gels shows that Rubisco remains intact and is not dissociated into its subunits indicating that proteins recovered after IL pre-treatment retains it native form.

Additionally, the aqueous phase after cell disruption was analysed for carbohydrate content. The percentage of total carbohydrate recovered after pre-treatment usng BMIM DBP and TBP $\mathrm{SO}_{4}$ was $49.06 \%$ and $77.10 \%$ for fresh cells and $74.62 \%$ and $64.81 \%$ respectively for freeze dried cells (see Figure 6.6).

The results thus show that the microalgae components lipids, proteins and carbohydrates can be selectively fractionated after IL pre-treatment and whereby the proteins retain their full functional composition.

Table 6.2 Summary of biomass components separated under different IL pre-treatreatment

\begin{tabular}{ccccccc}
\hline & Control & $\begin{array}{c}\text { 40\% BMIM } \\
\text { DBP }\end{array}$ & $\begin{array}{c}40 \% \text { TBP } \\
\text { SO4 }\end{array}$ & Control & $\begin{array}{c}\text { 40\% } \\
\text { BMIM } \\
\text { DBP }\end{array}$ & $\begin{array}{c}40 \% \text { TBP } \\
\text { SO4 }\end{array}$ \\
\hline $\begin{array}{c}\text { Total Fatty Acid/mg } \\
\text { of biomass } \\
\text { Proteins/mg } \\
\text { of biomass }\end{array}$ & 25.96 & 11.39 & 17.66 & 18.20 & 10.48 & 15.91 \\
$\begin{array}{c}\text { Carbohydrates /mg } \\
\text { of biomass }\end{array}$ & 16.17 & 12.41 & 12.98 & 21.39 & 7.24 & 13.36 \\
\hline
\end{tabular}




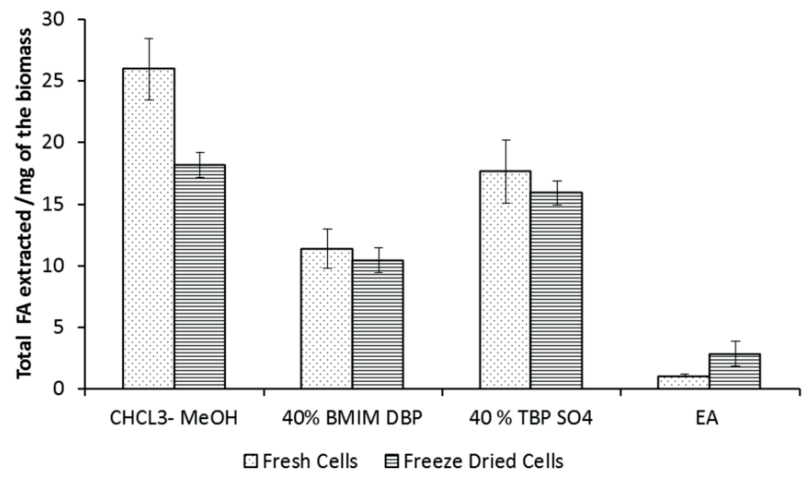

Figure 6.4 Total lipids extracted with ethyl acetate after IL pre-treatment at $45^{\circ} \mathrm{C}$

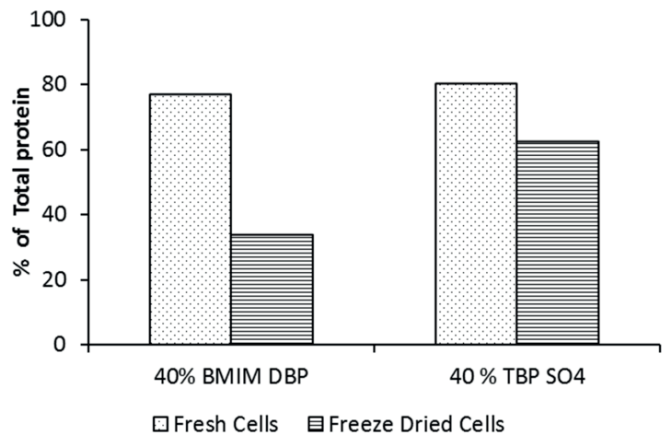

Figure 6.5 Total Proteins in the biomass after IL pre-treatment at $45^{\circ} \mathrm{C}$

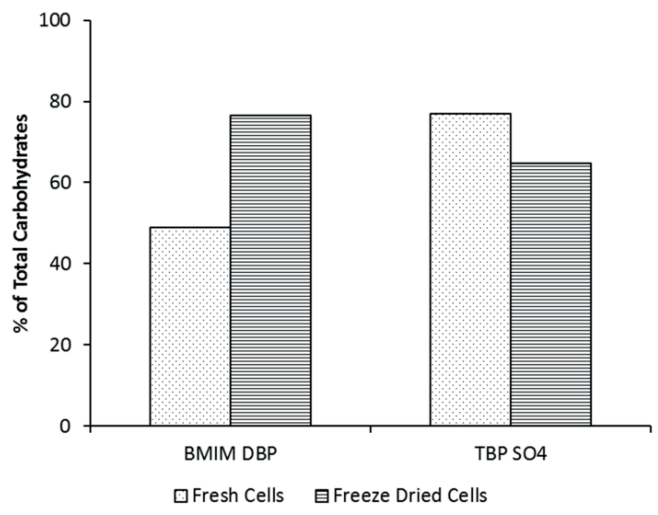

Figure 6.6 Total carbohydrates in biomass after IL pre-treatment at $45^{\circ} \mathrm{C}$ 


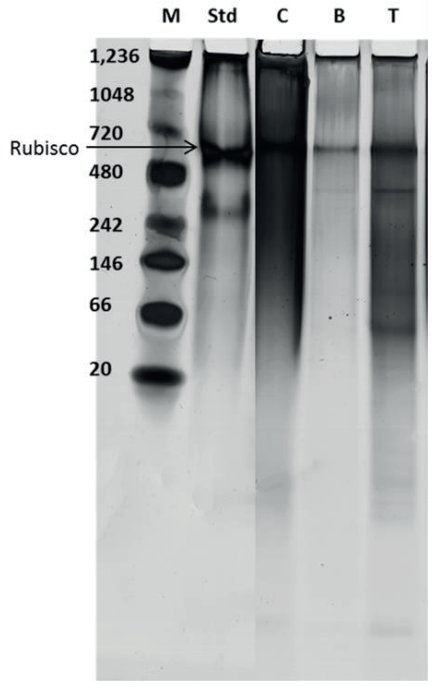

Figure 6.7 Protein stability determined by native gel electrophoresis; $M$ - marker, Std-standard Rubisco, Ccontrol supernatant after bead beating the cells, $B$ and T-After treatment with BMIM DBP and TBP SO ${ }_{4}$ respectively cells suspended in water and bead beated

\section{Perspective on IL based microalgal biorefinery}

Although microalgae have potential for biodiesel production, the high cost of producing oil is the key bottleneck in its commercialization. Therefore, adoption of an integrated biorefinery approach wherein different products (biofuel, nutraceutical, speciality chemicals) are produced at large scale could improve the economics of oil production. As discussed earlier, current processes are directed to towards single product recovery and use of solvents and high temperatures results in denaturation of proteins.

So far studies on the use of ILs in microalgae are focussed on lipid extraction by either hydrolysis of whole cells in IL at high temperature or by use of co-solvents. There are two main approaches to use ILs in microalgal biorefinery mainly:

1. Hydrolysis

2. Pre-treatment

Hydrolysis of microalgae in IL results in separation of oil which could be separated but studies should be done on recovering the proteins and carbohydrates dissolved in IL. Although theoretically dissolved components could be separated using techniques such as chromatography, there is no empirical data to prove it. Hydrolysis of biomass offers the advantage of lower waste generation and reduced number of processing steps The proteins recovered should also be tested for it functionality as it could be affected by the ILs.

On the other hand pre-treatment studies as described in this article show the novelty of separating lipids without mechanical disruption and subsequent separation of hydrophilic components (proteins, 
carbohydrates) in their native form after cell disruption. The process can be optimised further to improve the yields. There are various parameters which influence the efficacy such as biomass loading, time of contact with IL and organic solvent, amount of solvent added and type of IL and should be investigated in detail.

While ILs indeed has a potential role to play in microalgal biorefinery, it can only be realised if they are biocompatible, biodegradable and economical. The ILs must be tested for their reusability and recyclability so as to make the process economically viable. To be able to judge a process superior than other would require a systematic approach and set of criteria on basis of which the process is evaluated. Most of these studies are at their infancy and should be evaluated in terms of energy consumption, efficacy and cost. It is also necessary to have set controls with which it can be compared to.

\section{Conclusion}

In this article, pre-treatment of $N$. oleoabundans using ILs and subsequent fractionation into hydrophilic and hydrophobic components was studied for both fresh and freeze dried biomass. Additionally, the lipid extraction efficiency of aqueous IL solution under different temperature and concentration conditions were studied. We have demonstrated that aqueous solution of imidazolium and phosphonium based ILs was able to extract lipids from intact microalgae, albeit to a different degree. We have also shown that pre-treatment of microalgae with BMIM DBP and $\mathrm{TBP}_{4} \mathrm{SO}_{4}$ at low concentration $(40 \% \mathrm{w} / \mathrm{w})$ results in permeabilisation of cells. The biomass can then be fractionated into hydrophilic and hydrophobic components whereby the proteins were recovered without losing their nativity. The recovery of total fatty acids was $\sim 68 \%$ and that of proteins and carbohydrates was $\sim 80 \%$ and $77 \%$ respectively of the total amount present in the cells, after pre- treatment of fresh biomass with TBP $\mathrm{SO}_{4}$. Most of the current processes that use energy consuming mechanical cell disruption (e.g. bead milling, high pressure homogenisation) [22] and solvents such as methanol/chloroform and hexane [3] are able to recover only lipids and render the proteins unsuitable for use due to denaturation. This article is a step forward in establishing the role of ILs in microalgae biorefinery by developing a novel selective fractionation concept for both hydrophobic compounds (e.g. lipids) and hydrophilic compounds (e.g. proteins, carbohydrates). However, more studies are needed to optimise the process in terms of yields and recycling of ILs. The observations made in this study shows significant potentials in terms of biorefining the algal biomass.

*Note: Fresh and freeze dried cells from different batches. For proteins and carbohydrates average of 2 values are presented and also for temperature and concentration studies values presented is an average of 2. 


\section{References}

1. Wijffels, R.H. and M.J. Barbosa, An outlook on microalgal biofuels. Science, 2010. 329(5993): p. 796-9.

2. Vanthoor-Koopmans, M., et al., Biorefinery of microalgae for food and fuel. Bioresource Technology, 2012. 135: p. 142-149.

3. Cuellar-Bermudez, S.P., et al., Extraction and purification of high-value metabolites from microalgae: essential lipids, astaxanthin and phycobiliproteins. Microbial Biotechnology, 2015. 8(2): p. 190-209.

4. Soxhlet, F., Dingler's Polytechnisches J., 1879. 232: p. 461-465.

5. Bligh, E.G. and W.J. Dyer, A rapid method of total lipid extraction and purification. Canadian Journal of Biochemistry and Physiology, 1959. 37(8): p. 911-917.

6. Herrero, M., A. Cifuentes, and E. Ibañez, Sub-and supercritical fluid extraction of functional ingredients from different natural sources: Plants, food-by-products, algae and microalgae: $A$ review. Food Chemistry, 2006. 98(1): p. 136-148.

7. Ursu, A.-V., et al., Extraction, fractionation and functional properties of proteins from the microalgae Chlorella vulgaris. Bioresource Technology, 2014. 157: p. 134-139.

8. Freemantle, M., Designer Solvents. Chemical \& Engineering News Archive, 1998. 76(13): p. 3237.

9. Young, G., et al., Lipid extraction from biomass using co-solvent mixtures of ionic liquids and polar covalent molecules. Separation and Purification Technology, 2010. 72(1): p. 118-121.

10. Kim, Y.-H., et al., lonic liquid-mediated extraction of lipids from algal biomass. Bioresource Technology, 2012. 109(0): p. 312-315.

11. Choi, S.-A., et al., Effects of ionic liquid mixtures on lipid extraction from Chlorella vulgaris. Renewable Energy, 2014. 65(o): p. 169-174.

12. Fujita, K., et al., Direct dissolution of wet and saliferous marine microalgae by polar ionic liquids without heating. Enzyme and Microbial Technology, 2013. 52(3): p. 199-202.

13. Teixeira, R.E., Energy-efficient extraction of fuel and chemical feedstocks from algae. Green Chemistry, 2012.14(2): p. 419-427.

14. Olkiewicz, M., et al., A novel recovery process for lipids from microalgae for biodiesel production using a hydrated phosphonium ionic liquid. Green Chemistry, 2015. 17(5): p. 2813-2824.

15. $\mathrm{Yu}, \mathrm{X}$., et al., Energy-efficient extraction of fuel from Chlorella vulgaris by ionic liquid combined with $\mathrm{CO}_{2}$ capture. Applied Energy, 2015. 160(o): p. 648-655.

16. Gouveia, L., et al., Neochloris oleabundans UTEX \#1185: a suitable renewable lipid source for biofuel production. J Ind Microbiol Biotechnol, 2009. 36(6): p. 821-826.

17. Brever, G., et al., The impact of nitrogen starvation on the dynamics of triacylglycerol accumulation in nine microalgae strains. Bioresource Technology, 2012. 124: p. 217-226.

18. Brever, G., et al., Analysis of Fatty Acid Content and Composition in Microalgae. Journal of Visualized Experiments, 2013(80): p. e50628.

19. Dubois, M., et al., A colorimetric method for the determination of sugars. Nature, 1951. 168(4265): p. 167.

20. Desai, R.K., et al., Novel astaxanthin extraction from Haematococcus pluvialis using cell permeabilising ionic liquids. Green Chemistry, 2016.

21. Desai, R.K., et al., Extraction and stability of selected proteins in ionic liquid based aqueous two phase systems. Green Chemistry, 2014. 16(5): p. 2670-2679.

22. Günerken, E., et al., Cell disruption for microalgae biorefineries. Biotechnology Advances, 2015. 33(2): p. 243-26o. 
Chapter 7

General Discussion 
Abstract

In the preceding chapters we have shown the feasibility of using IL and IL based systems for extraction of fragile biomolecules from microalgal biomass. We developed two different fractionation techniques; 1) Using lonic liquids and solvents to extract pigments/lipids from intact cells and then further disrupting the cells to obtain carbohydrates and proteins in their native form 2) Using IL based emulsion stabilised by core shell particles to separate hydrophobic from hydrophilic components after cell disruption and keeping the proteins in its native form. There are some challenges in using IL based system such as, recovery from ionic liquid, biodegradation of IL and an outlook on future separations using IL based systems are discussed in this chapter. 


\section{Introduction}

The need to develop more sustainable and environmentally safe processes drives the development of newer separation and extraction technologies. In addition there is a constant drive to develop energy efficient and cost effective processes. Although the separation technology is product and raw material specific, for most biochemical processes it is possible to develop separation technology principles which could then be tailored to specific needs. ILs has gained considerable attention in the past decade. The role of IL as medium for catalysis $[1,2]$, in extraction and separation $[3,4]$, and dissolution of biomaterials [5] has been well demonstrated, the efficiency of IL based systems in extraction of fragile biomolecules such as proteins is scarcely studied. The research in this thesis thus focuses on novel IL based systems for extraction of biomolecules (proteins, pigments, lipids and carbohydrates) from microalgae.

Biomass feedstock such as microalgae, apart from being a potential source for biofuels also contains other value added components such as proteins and carbohydrates. The recovery of these components is mostly based on solid-liquid extraction processes. These processes such as one employing volatile organic solvents aim at recovering only one type of biomolecule i.e. hydrophobic lipids. The spent biomass which is a rich source of hydrophilic components, mainly proteins and carbohydrates after removal of lipids is rendered unsuitable for feed and food application. Furthermore, the proteins are denatured by use of organic solvents. This necessitates the need to develop mild separation techniques for complete utilization of biomass. Interest in separation processes based on ILs has gained interest in past couple of years due to higher extraction yields of bioactives from biomass under moderate conditions of temperature and pressure [6]. Thus, the aim of this thesis was to study the feasibility of using novel IL based systems for separation of multiple (fragile) biomolecules and pre-treatment of microalgal biomass. In this chapter a summary of the outcomes of the feasibility studies and bottlenecks obtained in the study are discussed. Additionally an outlook on the future separation studies is presented.

\section{Protein Stability}

One of the prime requirements to use IL based systems for separation of proteins from microalgae or other feedstocks is to determine its stability in ionic liquids. In chapter 3, we studied the stability of three proteins (Rubisco, IgG, and BSA) of varying nature in two ILs (lolityte 221 PG and Cyphos 108). It was observed that the proteins form aggregates at higher concentration of ILs, however, the extent to which the aggregates are formed varied depending on the type of protein. We also observed an unexplained behaviour of BSA in Cyphos 108, wherein as the concentration of Cyphos 108 increased to $20 \%$ the BSA peak intensity (see chapter 3, Figure 3.9) decreased and when the concentration was increased to $50 \%$ an increase in the BSA peak intensity was observed together with the formation of aggregates (chapter 3). Thus, indicating that the molecular interactions between BSA and Cyphos 108 
promote this behaviour. The number of studies on protein stability in ILs is limited to model proteins, such as BSA, lysozyme etc. Due to the diverse nature of proteins and ILs it is indeed difficult to state general guidelines for protein stability in ILs. However, based on our studies and together with the available literature [7] it could indeed be stated that high concentrations of ILs affect the structural integrity of the proteins such as promoting protein unfolding or induce the formation of aggregates. Additionally, the protein molecular weight too determines the IL threshold concentration. As seen in chapter 3, BSA which is a small sized molecular weight protein $(\sim 66 \mathrm{kDa})$ is stable up to $50 \%$ concentration of Iolilyte 221 PG whereas Rubisco, a high molecular weight protein ( $540 \mathrm{kDa})$, forms aggregates at $25 \%$ concentration of lolilyte $221 \mathrm{PG}$.

Studies on proteins of commercial interest are limited. As a step forward in this direction we looked into the stability of IgG and Rubisco in imidazolium based ILs. The stability of IgG and Rubisco was tested in different concentrations ( $10 \% \mathrm{v} / \mathrm{v}$ to $40 \% \mathrm{v} / \mathrm{v}$ ) of 1-ethyl 3 -methyl imidazolium dibutyl phosphate (EMIM DBP). A trend similar to the ILs studied in chapter 3 was observed, higher concentration causes aggregation of IgG and Rubisco. In Figure $7.1 \mathrm{a}-\mathrm{b}$, the stability of IgG in EMIM DBP is shown using high performance size exclusion chromatography (SEC-HPLC). SEC-HPLC studies showed that IgG was stable at $40 \%$ IL concentration. Qualitative studies revealed better stability of IgG when compared to Rubisco in imidazolium ILs. As also mentioned in chapter 3, the difference in stability of protein in ILs could be due to difference in size, structure, folding and connections of the subunits of the two molecules, Rubisco $\sim 540 \mathrm{kDa}$ and IgG $150 \mathrm{kDa}$. Structurally IgG has 2 large and 2 small subunits which are covalently linked unlike Rubisco which has non-covalently linked 8 large and 8 small subunits. We also tested the recovery of IgG from EMIM DBP by using desalting columns and the fractions collected showed an IgG band on native gel. Ionic liquids being salt could be separated from proteins using desalting columns. The proteins being large molecules elutes first and then the IL. However the study is more qualitative and a quantitative study must be done to determine the precise recovery of the protein from IL. While these are preliminary studies, future work should be focussed on recovery of proteins from ILs and investigate the protein-IL interactions explaining the molecular behaviour between ILs and proteins. Recovery of components dissolved in ILs is an important aspect and demands more research on this topic. 
a)

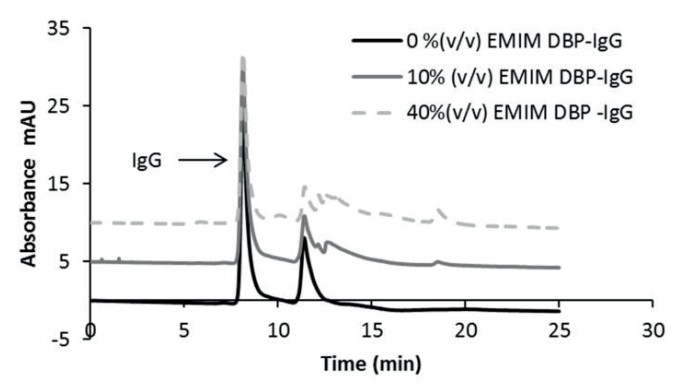

b)

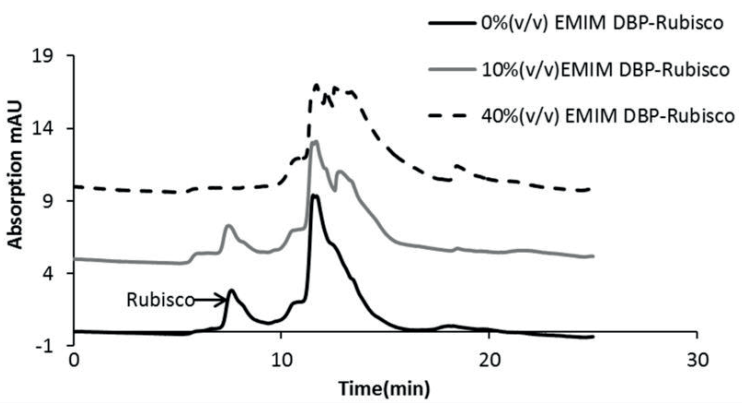

Figure 7.1 Effect of increasing concentration of ionic liquid-EMIM DBP on a) IgG and b) Rubisco

\section{IL based system}

In this thesis we studied two novel IL based systems for separation of biomolecules:

1. IL based Aqueous Biphasic System (ABS)

2. IL based emulsion stabilised by microgel particles

As discussed in chapter 2 and 3, IL based aqueous biphasic system are novel systems and have advantage over traditional aqueous biphasic system in terms of better extraction efficiency and selectivity. In chapter 3, we studied the extraction of Rubisco using IL based ABS. We observed higher partition coefficient for Rubisco, a major microalgal protein, in the IL rich phase in comparison to the conventional PEG based ABS. Despite high partitioning, the higher concentration of IL in IL rich phase led to protein instability. As mentioned earlier, protein stability in IL plays an important role in separation processes using IL based system. Rubisco stability studies revealed that when the concentration of IL used, loliyte $221 \mathrm{PG}$, was $\sim 10 \% \mathrm{v} / \mathrm{v}$ then it retains it nativity. Designing $A B S$ such that the concentration of IL in the IL rich phase is $\sim 10 \% \mathrm{v} / \mathrm{v}$, would help to stabilise the protein. Higher concentration of IL leads to formation of aggregates. This directs towards more systematic studies on phase diagrams which would help in designing ABS system with desired concentrations of phase components. 
While IL based ABS are widely studied for extraction of biomolecules such as alkaloids, antioxidants [8] using model systems, their potential for extracting biomolecules like antibiotics from complex matrices such as fermentation broth is also established [9]. Additionally, these systems offer the possibility to tailor the polarities of the phases in order to improve efficiency and selectivity [10]. This ability of IL based $A B S$ holds huge prospect in extracting fragile biomolecules from microalgae biomass which contains molecules of different polarity. No work has been done on separating microalgae proteins using IL based ABS except, the studies described in this thesis. Although the feasibility studies show aggregation of Rubisco at concentration studied, additional work is required before this technique is rendered suitable for microalgal protein separation. More extensive studies using different ILs and careful design of IL based ABS should be performed using microalgal biomass.

We also investigated another novel system based on ILs, which is an emulsion stabilised by microgel particles for its feasibility to separate fragile biomolecules of varied polarities simultaneously from microalgae (chapter 4). The emulsion is IL in water type, wherein a hydrophobic IL, cyphos 109, forms the discontinuous phase and water forms the continuous phase. With mixing microalgae biomass (cracked cells), the proteins remain in the aqueous phase and pigment, astaxanthin, is extracted in the hydrophobic core. The interesting part is that the proteins retains it nativity. The microgel particles used to stabilise the emulsion are porous hence allows the transfer of small molecules and prevents direct contact of proteins with the IL, thus assists in retaining nativity of the protein. In chapter 4 , we presented a proof of concept for a novel continuous separation. The microgel particles are thermoresponsive, a property of emulsion which was unexplored in this work. As the temperature is raised above $32^{\circ} \mathrm{C}$ the particles collapse and the emulsion breaks. This property of the emulsion should be explored in the separation process in the near future. The technique is still at its infancy and should be tested with different ILs and smaller IL droplets so as to increase mass transfer. Additionally, although the emulsion facilitates simultaneous separation of components from biomass, the process still needs to be optimised in terms of efficiency and reusability of IL and microgel particles. Future research should focus not only on optimization of process parameters but also on finding newer applications for this emulsion, which provides a complete toolbox for separation and extraction of value added components from different biomass streams.

\section{Pre-treatment studies on microalgal biomass using IL}

In addition to IL based systems, we also investigated the influence of IL solutions on microalgal cells and recovery of components thereof. Microalgae are known to have a tough cell wall and require mechanical disruption to be able to release the intracellular components. In chapter 5 , we showed that a $40 \%$ aqueous solution of EMIM DBP, an imidazolium based IL, was able to permeabilise intact cells of H. pluvialis under mild condition and astaxanthin could subsequently be extracted with ethyl acetate. Microscopic study confirmed that the cells were not ruptured. Based on these observations we 
postulated a possible mechanism wherein we stated permeabilization of the microalgal cells by ILs. However, it's unclear as to what solubilises in the IL to make the cell wall porous. A similar observation was also made when $N$. oleoabundans cells were treated with IL (chapter 6 ). In addition to imidazolium IL, a phosphonium based IL, Cyphos 108, permeabilised the cell wall of $N$. oleoabundans. However, this IL did not permeabilise the cell wall of $H$. Pluvialis. This indicates the difference in cell wall composition of different algae. The ability of IL to permeabilise both fresh and freeze dried cells of $N$. oleoabundans rules out the possible role freeze drying of cells on the cell wall permeability, although it would indeed aid in weakening the cell wall. We hypothesize that IL pre-treatment together with solvent ethylacetate partially dissolves some component of the cell wall thereby leaching the lipids/pigments from the intact cells.

In chapter 6, we went a step ahead and showed the feasibility of biomass fractionation. After cell wall permeabilization with IL and de-lipidation with ethyl acetate, the cells were mechanically disrupted to recover the proteins and carbohydrates. The proteins so recovered were in their native form. These results portraits the potential of ILs in fractionation and separation of microalgal biomass components in a biorefinery concept. While the early results are promising, we need more in depth knowledge and understanding of the effect of IL on cell walls. The most logical approach would be to study the cell wall of microalgae and its composition. Together with this we need advanced analytics to analyse components dissolved in IL. These studies would help in selecting and designing a suitable IL for different microalgae.

\section{Key outcomes of the thesis}

Table 7.1 A summary of the main findings of the thesis

\section{Main Finding}

-Rubisco is stable at low concentration ( 10\%) of Ionic liquids

- Extraction of pigments/lipids from intact microalgal cells using ionic liquids and solvents and further fractionation into native proteins and carbohydrates by cell disruption

-Separation of hydrophobic from hydrophilic components using IL based emulsion stabilised by microgel particles.

\section{Bottleneck}

-Analysis of dissolved component in ILS

- Cost of IL

- Biodegradability of ILs

-Recovery of biomolecules from IL

\section{Ionic liquids in Separation process and Challenges}

ILs has gained popularity as unique solvents in different areas of separation techniques. Owing to tunable properties which can be selected by choosing appropriate cationic or anionic constituents, they 
can be applied in chromatographic methods as mobile phase or stationary phase modifiers and electrochromatographic methods such as capillary electrophoresis or in sample preparations processes as new extraction solvents [11]. Most of the IL based separation techniques are focused towards analytical separation and sample preparation [11]. ILs has been used successfully for the separation and extraction of a wide range of analytes (organic ions, inorganic ions, metal ions and organic compounds) with different properties. On the other hand, more targeted IL-based materials are needed for the extraction and separation of bioactive targets compounds from complex matrices such as plants and different biomass at preparative scale.

Despite the potential shown by ILs in pre-treatment and separation there are bottlenecks which needs to be overcome before successful use of ILs in large scale preparative applications. The cost of using ILs as extractants or for pre-treatment should be considered. The economic use of ILs could be achieved by recycling and reusing the ILs. ILs is considered green primarily due to their non-volatile nature. However, not all ILs can be considered green, as some of them are toxic and are non-biodegradable.

\section{Conclusion and Outlook}

In conclusion, this thesis describes two novel IL based systems for extraction of fragile molecules from complex matrices and also shows direction towards continuous processing. It also demonstrates the permeabilization of microalgal cell wall using ILs and subsequent fractionation of biomolecules therein. To develop more sustainable scalable processes, future research should focus on using biodegradable ILs such as cholinium based IL. While high extraction efficiency of biomolecules in ILs is achieved, recovery of biomolecules from ILs must be studied as ILs are non-volatile. The IL based emulsion studied in this thesis has potential and efforts should be made to find newer applications. IL based ABS should be assessed for extracting multiple biomolecules from different biomass streams (e.g. microalgal biomass).

Currently, IL based separation system despite being milder and high in yields have to compete with existing technologies, thus requiring the process to be cost effective. Nevertheless, they hold a good chance in microalgal biorefinery, wherein there is need to develop an efficient process to ensure complete fractionation of the biomass. The role of ILs in fractionation of microalgal biomass is shown in this thesis. With research ongoing within several research groups on reusing/recycling ILs and development of more biodegradable ILs, brings the processes based on these liquids closer to an ideal sustainable process which eventually will be the need as the world moves towards a biobased economy. 


\section{References}

1. Wasserscheid, P. and W. Keim, lonic Liquids-New "Solutions" for Transition Metal Catalysis. Angewandte Chemie International Edition, 2000. 39(21): p. 3772-3789.

2. Sheldon, R.A., et al., Biocatalysis in ionic liquids. Green Chemistry, 2002. 4(2): p. 147-151.

3. Huddleston, J.G., et al., Room temperature ionic liquids as novel media for 'clean' liquid-liquid extraction. Chemical Communications, 1998(16): p. 1765-1766.

4. Gutowski, K.E., et al., Controlling the aqueous miscibility of ionic liquids: aqueous biphasic systems of water-miscible ionic liquids and water-structuring salts for recycle, metathesis, and separations. J Am Chem Soc, 2003. 125(22): p. 6632-3.

5. Swatloski, R.P., et al., Dissolution of Cellose with lonic Liquids. J Am Chem Soc, 2002. 124(18): p. 4974-4975.

6. Passos, H., M.G. Freire, and J.A.P. Coutinho, Ionic liquid solutions as extractive solvents for valueadded compounds from biomass. Green Chemistry, 2014. 16(12): p. 4786-4815.

7. Heller, W.T., et al., Characterization of the Influence of the Ionic Liquid 1-Butyl-3methylimidazolium Chloride on the Structure and Thermal Stability of Green Fluorescent Protein. The Journal of Physical Chemistry B, 2010. 114(43): p. 13866-13871.

8. Louros, C.L., et al., Extraction of biomolecules using phosphonium-based ionic liquids $+K(3) P O(4)$ aqueous biphasic systems. Int J Mol Sci, 2010. 11(4): p. 1777-91.

9. Pereira, J.F.B., et al., Extraction of tetracycline from fermentation broth using aqueous two-phase systems composed of polyethylene glycol and cholinium-based salts. Process Biochemistry, 2013. 48(4): p. 716-722.

10. Pereira, J.F.B., et al., Combining ionic liquids and polyethylene glycols to boost the hydrophobichydrophilic range of aqueous biphasic systems. Physical Chemistry Chemical Physics, 2013. 15(45): p. 19580-19583.

11. Han, D. and K.H. Row, Recent Applications of Ionic Liquids in Separation Technology. Molecules, 2010. 15(4): p. 2405. 
Summary 
Liquid-liquid extraction (LLE) techniques are widely used in separation primarily due to ease of scale up. Conventional (LLE) systems based on organic solvents are not suitable for extraction of fragile molecules such as proteins as it would result in denaturation. On the other hand Aqueous Biphasic System (ABS) though suitable for extraction of proteins they are restricted by limited polarity range. Ionic liquids have gained interest in extraction over the past years due to its non-volatility and tunable properties. In this thesis we explored the feasibility of using two ionic liquid based systems for extraction: 1) Ionic liquid based aqueous two phase system for extraction microalgae protein and 2) ionic liquid based emulsion for separation of hydrophilic and hydrophobic components from complex biomass such as microalgae. Additionally the influence of IL pre-treatment on microalgae cell wall and subsequent fractionation of its component was also investigated.

In part 1 of the thesis we studied extraction of biomolecules using known and novel IL based system. In Chapter 2, a review on protein extraction using ionic liquid based aqueous two phase system has been discussed. The stability of proteins in ionic liquids and factors influencing the extraction of proteins using ABS are presented. A systematic approach towards use of ionic liquid based system for extraction of proteins together with the major bottlenecks in using such systems is discussed.

The stability of proteins in ionic liquids is crucial to use ionic liquid based extraction system for their extraction. Therefore, in Chapter 3 the stability of commercially important proteins such as Rubisco and IgG, and model protein such as bovine serum Albumin (BSA) was studied in various aqueous solutions of ionic liquids at different concentrations. We observed that protein properties such as size, number of subunits influence its stability in ionic liquid, however the general trend was that the proteins were found to be stable at low concentration of ionic liquids, $\sim 10 \% \mathrm{w} / \mathrm{w}$. The extraction efficiency of Rubisco in PEG based and ionic liquid based aqueous two phase systems were evaluated. The partition coefficient for Rubisco in ionic liquid rich phase was $3-4$ fold higher than in PEG based two phase system.

In Chapter 4, another ionic liquid based system, an ionic liquid in water emulsion stabilised by microgel particles was studied for feasibility of separation of components in microalgal biomass. The system was evaluated for its efficiency to selectively separate hydrophilic components such as proteins from hydrophobic components such as pigments present in lysed microalgal biomass. The system could selectively separate the components and moreover the proteins so obtained retained its nativity. A proof of concept for continuous operation is also presented.

In part 2 of the thesis we explored the possibility of using ionic liquids for pre-treatment of microalgal biomass. Microalgae are known to have a tough cell wall and usually require energy intensive mechanical cell disruption to recover the intracellular components. In Chapter 5 the influence of aqueous solution of different ionic liquids on cell wall of $H$. pluvialis was studied. Aqueous solution of 
the ionic liquid, 1-ethyl, 3-methyl imidazolium dibutyl phosphate was found to permeabilise the cell wall of Haematococcus pluvialis under mild condition of temperature below $50^{\circ} \mathrm{C}$. The pigment, astaxanthin could then be recovered using ethyl acetate. We hypothesized that ionic liquid was capable of dissolving certain components such as mannan polymer thereby disrupting the polymer structure and forming tiny holes in the cell wall, thus paving the way for solvent to penetrate and extract astaxanthin. Using microscopy we showed that the cells remain intact after ionic liquid and solvent treatment and thus shows that ionic liquid permeabilises the microalgae cell wall.

While we showed that tough cell wall of $H$. pluvialis could be permeabilised with ionic liquid under mild condition, we extended the study to other microalgae, Neochloris oleoabundans in Chapter 6 . Different ionic liquids were tested for their ability to permeabilise and subsequently extract all hydrophobic components (e.g. lipids) from the cell without affecting the functionality of fragile molecules such as proteins. The results showed that microalgae could be permeabilised with the ionic liquid, Tributylmethylphosphonium methyl sulfate in addition to 1-ethyl, 3-methyl imidazolium dibutyl phosphate used for $\mathrm{H}$. Pluvialis, indicating possible difference in the cell wall composition of two microalgae strains. The lipids are extracted using ethyl acetate and the cells were further disrupted by mechanical cell disruption to separate the proteins and carbohydrates. The protein analysis showed that they were native. While these were all feasibility studies, the process can optimised to improve efficiency.

Finally in Chapter 7, we summarise and highlight the main finding in this thesis together with the implication of overall results of the thesis for future research is discussed. The results in this thesis highlight the potential of Ionic liquids and ionic liquids based extraction system for extraction of biomolecules from complex biomass such as microalgae. 


\section{Acknowledgement}

Finally the most read part of the thesis, acknowledgement. PhD is not only about science but as the name suggest, it's a Philosophy. There are times during your period of PhD when you are at the extremes of emotions. It's then the people around you, who support and be a part of this journey. I want to take this opportunity to thank all those who have been a part of my PhD journey and make it memorable.

I would like to thank you both Michel and René, my promotor, my supervisor for giving me this opportunity. Michel you have always being optimistic and enthusiastic about my work and encouraging when I was disappointed and last but not the least, for being so prompt in replying to email. I remember you always mentioned "go step by step". I want to express my gratitude to René, my promoter, for all your support and for making me a part of BPE family. Mathieu, my daily supervisor, thank you for being so supportive, understanding and for giving me the freedom to manoeuvre. Working with ionic liquids was new for all of us but your support and encouragement made it all possible, Bedankt for alles.

Any research is never complete without a good analytical system. I want to thank all the technicians, Wendy, Sebastiaan, Fred, Snezana, and Bregje for being my analytical support. Miranda and Marina thank you for helping me out with all the administrative work. A special thanks to my students, Niousha and Maria. I enjoyed having you around and thank you for your contribution towards this thesis.

I want to thank my office mates Jue, Jorein Angelica, Sebastiaan, Anne, Lenneka, Abdulla Aziz, Catalina, Lenny, Guido and Camilo. I enjoyed all the interesting discussions that we had.

I want to thank all my foodie buddies Mitsue, Ilse, Jorijn, Gerard, Agi, Joao, Xiao, Ruchir, Marta and Luci for all the fun international dinners that we had. You all made my time at BPE really interesting and thank you for all help and support. I really appreciate it. I want to thank you Douwe for bringing more science with Journal clubs and I enjoyed our discussions that made coffee breaks livelier. I want to thank everyone at BPE, my fellow colleagues Anna, Carsten, Ward, Marjon, Youri, Tim, Richard, Mark, lago, Jereon, Stephanie, Kira, Edwin, Pauline, Malgorzata, Edgar and the staff members Arjen, Marcel, Packo, Dirk, Marian, Ruud, Hans, Giuseppe and Maria. You all contributed in one way or other during the four years. I wish you all good luck and success.

I want to thank my STW project team for the all the interesting discussions.

Thank you Nirmal, for all the support, motivation and being there for me when needed the most. Ayan, my little boy thank you for keeping my happiness index high. I want thank my family, my support system, for everything. Baa and Dada, thank you for everything that you did and I owe my accomplishments to you. 


\section{About The Author}

Rupali K. Desai was born on $10^{\text {th }}$ July, 1981 in Mumbai, India. After completing her Junior college in Mumbai in 1999, she started her Bachelors in Pharmacy at Bharati Vidyapeeth College of Pharmacy, Mumbai University. In 2003, she started working as a trainee in a Pharmaceutical Company, Cipla Ltd. and at the same time started preparing for entrance exams

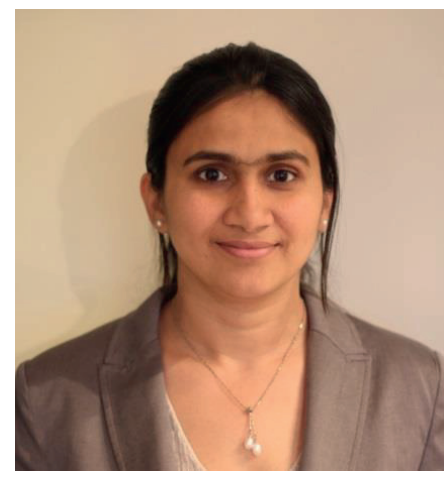
for further studies. In 2004, she started her Masters in Bioprocess Technology from the of Institute of Chemical technology, Mumbai. After completion of Masters, she was working as a Process development Scientist in Biocon, Bangalore, India. In 2010, she moved to the Netherlands. She was working for DSM in Delft before she joined Bioprocess Engineering group of Wageningen University on an STW project under the supervision of Prof. Dr M.H.M Eppink and Prof. Dr Rene Wijffels and Dr Mathieu Streefland. Since July 2016, she works as a Scientist, downstream processing, at uniQure, Amsterdam, The Netherlands. 


\section{List of Publications}

Desai RK, Streefland M, Wijffels RH, Eppink MHM (2016) Extraction of Proteins with ABS. In: Freire MG (ed) Ionic-Liquid-Based Aqueous Biphasic Systems: Fundamentals and Applications. Springer Berlin Heidelberg, pp 123-134. doi:10.1007/978-3-662-52875-4_6 (Chapter 2)

Desai RK, Streefland M, Wijffels RH, Eppink MHM (2014) Extraction and stability of selected proteins in ionic liquid based aqueous two phase systems. Green Chemistry 16 (5):2670-2679. doi:10.1039/c3gc42631a (Chapter 3)

Desai RK, Streefland M, Wijffels RH, Eppink MHM (2016) Mild separation concept for functional biomolecules using IL based emulsions, Submitted (Chapter 4)

Desai RK, Streefland M, Wijffels RH, Eppink MHM (2016) Novel astaxanthin extraction from Haematococcus pluvialis using cell permeabilising ionic liquids. Green Chemistry 18 (5):12611267. doi:10.1039/c5gc01301a (Chapter 5)

Desai RK, Streefland M, Wijffels RH, Eppink MHM (2016) Novel selective fractionation technology for fragile biomolecules from Neochloris oleoabundans using ionic liquids, To be submitted (Chapter 6) 


\section{Overview of completed training activities}

\section{Discipline specific}

Umetrics DoE

Biorefinery course *

Advanced Downstream processing course

Industrial food proteins

Biorefinery minisymposium $\neq$

COIL- 5 *

Biorefinery for food and Fuel (BFF) *

STW congress *

$N B C^{*}$

Continuous processing for biotherapeutic proteins

\section{General}

Endnote

Scientific writing

Project and time management

Techniques for writing and presenting a Scientific paper

Ethics and philosophy in life sciences

Vlag week

\section{Optionals}

Preparation of research proposal

Weekly group meetings (AIO day, BPE meetings and Colloquia)

STW meetings

Biorefinery group meetings

*Poster presentation

‡Oral Presentation

$\begin{array}{ll}\text { Birmingham } & 2012 \\ \text { Wageningen } & 2012 \\ \text { Wageningen } & 2012 \\ \text { Wageningen } & 2013 \\ \text { Wageningen } & 2013 \\ \text { Faro } & 2013 \\ \text { Wageningen } & 2013 \\ \text { Utrecht } & 2012 \\ \text { Ede } & 2014 \\ \text { Oss } & 2015\end{array}$

Wageningen 2012

Wageningen 2013

Wageningen 2013

Wageningen 2013

Wageningen 2013

Baarlo

2012

Wageningen 2011

Wageningen 2011-2015

Netherlands 2011-2015

Wageningen 2012-2015 
This research is supported by the Dutch Technology Foundation STW, which is part of the Netherlands Organisation for Scientific Research (NWO), and which is partly funded by the Ministry of Economic Affairs (Project No. 11410). 